Universidad Nacional de La Plata

Facultad de Cs. Astronómicas y Geofísicas

\title{
ESTUDIO DE PROPIEDADES FOTOMÉTRICAS DE GALAXIAS EN EL CÚMULO DE ANTLIA
}

AUTOR: LIC. JUAN PABLO CALDERÓN

Directora: DRA. LILIA P. BASSINO

CO-Director: DR. SERGIO A. CELLONE

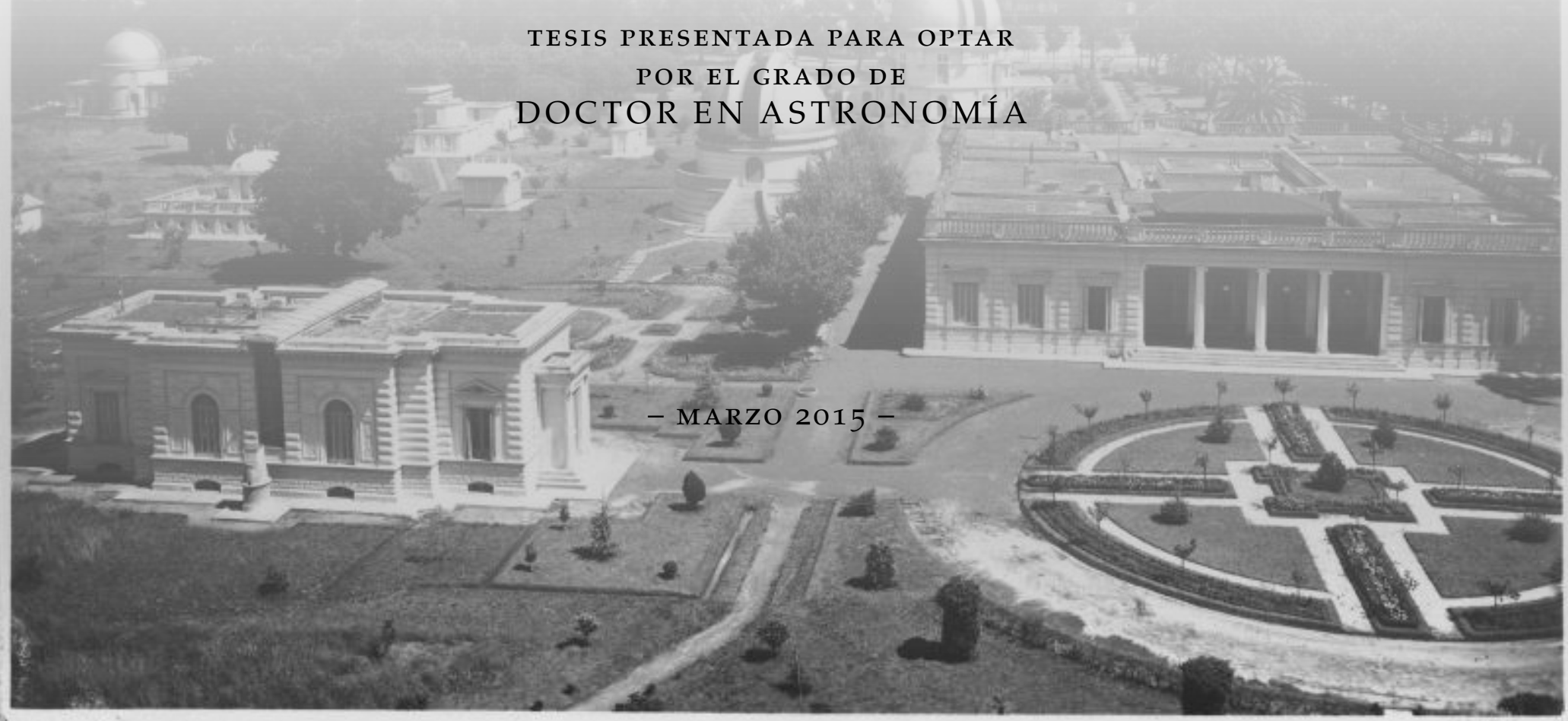




\section{Lic. Juan Pablo Calderón:}

Estudio de propiedades fotométricas de galaxias en el Cúmulo de Antlia, (c) marzo 2015

Imagen de tapa: Vista aérea del predio del Observatorio Astronómico de la Universidad Nacional de La Plata, hoy parte de la Facultad de Ciencias Astrómicas y Geofísicas.

Fuente: Archivo del Observatorio.

Año: 1914. 
Esta Tesis de Doctorado se presenta como parte de los requisitos para obtener el grado académico de Doctor en Astronomía de la Universidad Nacional de La Plata. La misma contiene los resultados de mis estudios de investigación desarrollados bajo la dirección de la Dra. Lilia P. Bassino y co-dirección del Dr. Sergio A. Cellone, en la Facultad de Ciencias Astronómicas y Geofísicas de la UNLP, y el Instituto de Astrofísica de La Plata, dependendiente del Consejo Nacional de Investigaciones Científicas y Técnicas (CONICET) y de la Universidad Nacional de La Plata. 

En esta Tesis Doctoral se presenta un estudio en gran escala de propiedades fotométricas de la población de galaxias del Cúmulo de Antlia. En el mismo, se incluyen galaxias de tipo temprano, desde elípticas gigantes hasta enanas elípticas y esferoidales, incluyendo zonas periféricas, aledañas a la parte central del cúmulo, no analizadas hasta la fecha. Este trabajo involucra aproximadamente 180 galaxias, entre las cuales se encuentran las ya catalogadas previamente sobre placas fotográficas por Ferguson y Sandage (1990) sumadas a 77 nuevas galaxias descubiertas.

El material observacional que se utilizó en este trabajo consiste en imágenes CCD de 4 campos del cúmulo de Antlia, incluyendo entre ellos la zona central. Las imágenes han sido obtenidas con el telescopio Víctor Blanco de 4-m del Observatorio Interamericano de Cerro Tololo (CTIO-Chile), con la cámara MOSAIC II de 8 CCDs y los filtros $\mathrm{R}$ de Kron-Cousins y $\mathrm{C}$ del sistema de Washington. Cada imagen tipo mosaico cubre un área proyectada sobre el plano del cielo de 36 ! × 36!', con lo que la cobertura total del cúmulo es aproximadamente de 1.5 grados cuadrados.

Se ha realizado fotometría superficial para cada objeto en forma individual. Se obtuvieron los perfiles de brillo superficial mediante la tarea ELLIPSE del paquete IRAF y se realizaron ajustes a tales perfiles, utilizando un modelo de Sérsic, mediante la tarea NFIT1D. Los perfiles teóricos se integraron numéricamente hasta infinito para calcular magnitudes totales. De este modo, para cada galaxia se obtuvieron magnitudes y colores integrados, brillos superficiales, radios efectivos, índices de Sérsic, y demás parámetros estructurales. Posteriormente, se analizaron las correlaciones entre tales parámetros galácticos que caracterizan los diferentes tipos y/o morfologías presentes en el entorno de un cúmulo de galaxias.

Se estudió la relación color-magnitud de las galaxias de tipo temprano, que se encuentra en buen acuerdo con relaciones análogas para otros cúmulos, y muestra un suave quiebre en la parte brillante, que se explica mediante resultados de modelos. Se construyeron relaciones de escala estructurales y fotométricas entre las magnitudes totales integradas, los brillos superficiales central, efectivo y efectivo promedio $\left(\mu_{0}, \mu_{e},\left\langle\mu_{e}\right\rangle\right)$, el radio efectivo $\left(r_{e}\right)$, etc., las que además se han comparado con otros cúmulos de galaxias. Se encuentra un buen acuerdo global, principalmente en la zona de bajo brillo superficial. 
Finalmente, se analizaron tales relaciones de escala a fin de determinar si están presentes distintas secuencias para distinto tipo de galaxias tempranas, mostrando separaciones o dicotomías, o si es posible representar distintos tipos de galaxias tempranas con correlaciones únicas. En función de estas opciones, e incluyendo los datos de otros grupos y cúmulos, resulta factible interpretar el origen y/o evolución de las galaxias de tipo temprano, brillantes y enanas, a partir de procesos diferentes, dado que los ajustes realizados mediante dos secuencias diferentes para cada subpoblación parecen ser los más apropiados. 


\section{ÍNDICE GENERAL}

Índice de figuras $\quad$ ix

Índice de Tablas $\quad x$

i INTRODUCCIÓN I

I INTRODUCCIÓN 3

1.1 Galaxias elípticas ................. 5

1.2 Modelos de formación y evolución de galaxias . . . . . 9

1.2.1 Galaxias enanas . . . . . . . . . . . . . 13

1.3 Motivación de la Tesis . . . . . . . . . . . . . . I 14

2 El Cúmulo de antlia 17

2.1 El cúmulo de Antlia . . . . . . . . . . . . . . . . . 17

2.2 El catálogo de Ferguson \& Sandage (FS9o) . . . . . . . 19

2.3 Otros estudios previos . . . . . . . . . . . . . 21

2.4 Objetivos específicos de la Tesis . . . . . . . . . 23

ii PERFILES DE BRILlO SUPERFICIAL 27

3 MATERIAL OBSERVACIONAL 29

4 PERFILES DE BRILlo 35

4.1 Cálculo de los perfiles de brillo . . . . . . . . . . . . 35

4.2 Procedimiento adoptado . . . . . . . . . . 38

4.2.1 Ajuste numérico del perfil . . . . . . . . . . . 4 4 I

4.3 El efecto del seeing sobre los parámetros modelados . . . 43

4.4 Relación señal-ruido . . . . . . . . . . . . . . 45

5 Selección de la muestra de galaxias 47

5.1 Muestra original: catálogo FS9o . . . . . . . . . . 47

5.2 Muestra final . . . . . . . . . . . . . 48

iii RELACIONES DE ESCALA 53

6 RELACIONES DE ESCALA 55

6.1 Resultados . . . . . . . . . . . . . . 55

6.1.1 La relación color-magnitud . . . . . . . . . . 55

6.1.2 Relaciones de escala de parámetros estructurales 57

6.1.3 La relación de Kormendy . . . . . . . . . . . . 60

6.1.4 Cálculo de la completitud de la muestra . . . . . . 62

6.2 Discusión . . . . . . . . . . . . . . . 62

6.2.1 Las relaciones fotométricas . . . . . . . . . 63

6.2.2 Las relaciones estructurales . . . . . . . . . . . 65

6.2.3 Comparación con otros cúmulos de galaxias . . . 67

iv CONCLUSIONES

7 CONCLUSIONES 
V APÉNDICE

A Catálogos del cúmulo de antlia 79

A.1 Catálogos . . . . . . . . . . . . . . . . 79

B PERFILES DE bRILlo SUPERFICIAL 89

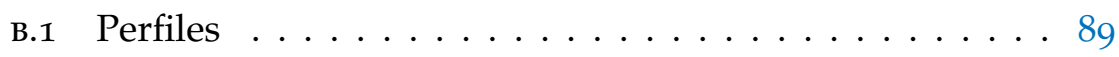

$\begin{array}{ll}\text { BIBLIOGRAFÍA } & 91\end{array}$ 
Figura 1.1 Esquema de clasificación morfológica dada por Hubble (1936). . . . . . . . . . . . . . . 3

Figura 1.2 Esquema de clasificación morfológica dada por van den Bergh (1976) . . . . . . . . . . . 5

Figura 1.3 Perfiles de brillo tipo core y tipo power-law. . . . 6

Figura 1.4 Esquema de la formación de galaxias de Bower et al. (1999) . . . . . . . . . . . . . . 10

Figura 2.1 Distribución espacial de los objetos estudiados en el catálogo FS9o. Reproducción de la Figura 9 de Ferguson \& Sandage (1990). . . . . . . . 18

Figura 2.2 Mapa de contornos de emisión en rayos- $X$ de ASCA (Pedersen et al., 1997). . . . . . . . . . 19

Figura 2.3 Relación color-magnitud para la zona central del cúmulo de Antlia (Smith Castelli et al., 2012) 22

Figura 2.4 Distribución espacial proyectada de la muestra de galaxias estudiada por Smith Castelli et al. (2012). . . . . . . . . . . . . 23

Figura 2.5 Relaciones estructurales para galaxias de tipo temprano de diferentes cúmulos. Datos tomados de Bender et al. (1992). . . . . . . . . . . . . 25

Figura 2.6 Relación magnitud total en el filtro $V$ con el índice de Sérsic (Kormendy et al., 2009). . . . . . 26

Figura 3.1 Composición de los cuatro campos del cúmulo de galaxias de Antlia que se utilizaron para la identificación y posterior fotometría de las galaxias que componen la muestra analizada. . . 30

Figura 4.1 Ejemplos de isofotas tipo disky y boxy. . . . . . 37 Figura 4.2 Figura 5.1 Análisis del efecto del seeing. . . . . . . . . . . 44 Ejemplos de galaxias excluidas de la muestra. Cada imagen cubre un campo de $23 \times 23 \mathrm{kpc}^{2}$ a la distancia de Antlia, y las galaxias están ubicadas en el centro de cada una de ellas. . . . 49

Figura 5.2 Diagrama color-magnitud de galaxias de tipo temprano y nuevas galaxias descubiertas en el cúmulo de Antlia. . . . . . . . . . . . . 51

Figura 6.1 Apartamiento respecto al comportamiento lineal en la zona brillante de la relación colormagnitud . . . . . . . . . . . . . . 56

Figura 6.2 Relaciones de escala para la muestra final del cúmulo de Antlia. . . . . . . . . . . . . . 58 
Figura 6.2 Relaciones de escala para la muestra final del cúmulo de Antlia (cont.). . . . . . . . . . . . . 59

Figura 6.3 Relación de Kormendy para la muestra final del cúmulo de Antlia incluyendo datos de otros grupos y cúmulos. . . . . . . . . . . . . . 61

Figura 6.4 Análisis de completitud de la muestra. . . . . . 63

Figura 6.5 Relaciones de escala para la muestra final del cúmulo de Antlia . . . . . . . . . . . . . . . . . 69

Figura 6.5 Relaciones de escala para la muestra final del cúmulo de Antlia (cont.) . . . . . . . . . 70

ÍNDICE DE TABLAS

Tabla 2.1 Fracciones de galaxias según el tipo morfológico estimadas por Ferguson \& Sandage (1991) para Antlia, y comparadas con los cúmulos de Fornax y Virgo. . . . . . . . . . . . . . . 20

Tabla 3.1 Detalle de las imágenes MOSAIC II utilizadas para el desarrollo de esta Tesis. La ubicación relativa de las mismas se puede ver en Figu-

Tabla 3.2 ra Coeficientes y errores de la ecuación de calibración (Ecuación 3.1). . . . . . . . . . . . . 33

Tabla 5.1 Nuevas galaxias enanas, miembros de Antlia, confirmados mediante espectros de VIMOS. . . 51

Tabla A.1 Parámetros obtenidos de las galaxias estudiadas en esta Tesis. . . . . . . . . . . . . . . . 80 
Parte I

INTRODUCCIÓN 



\section{INTRODUCCIÓN}

Las galaxias son la unidad fundamental de la Astronomía Extragaláctica. Aunque fueron denominadas originalmente como nebulae debido a la forma difusa que presentaban en telescopios primitivos; los avances en instrumentación, las técnicas modernas de observación y el procesamiento de imágenes permitieron (y permiten) observar un amplio rango de formas cuya interconexión sigue siendo un misterio para la astrofísica. El estudio de la morfología de las galaxias continúa siendo un área de investigación y desarrollo que no ha perdido validez a lo largo de los años.

En particular, la clasificación morfológica visual de galaxias es aún más precisa que las clasificaciones automáticas, aunque en un futuro esta afirmación podría dejar de ser completamente cierta. Algunas de las razones que sostienen el valor de la clasificación visual fueron claramente expuestas por Buta (2013). Principalmente, la clasificación morfológica es un punto de partida natural para entender cómo funcionan las galaxias e impone condiciones que deben ser tenidas en cuenta por los modelos teóricos de origen y evolución.

La clasificación morfología de las galaxias se dividió en dos grandes grupos: elípticas (Es) y espirales ( $\mathrm{Ss}$ ), y las galaxias que no poseen simetría apreciable se denominas galaxias irregulares (Irrs). Siguiendo esta separación, el diagrama más popular que las describe es el dado por Hubble (1936) que se muestra en la Figura • I.1.

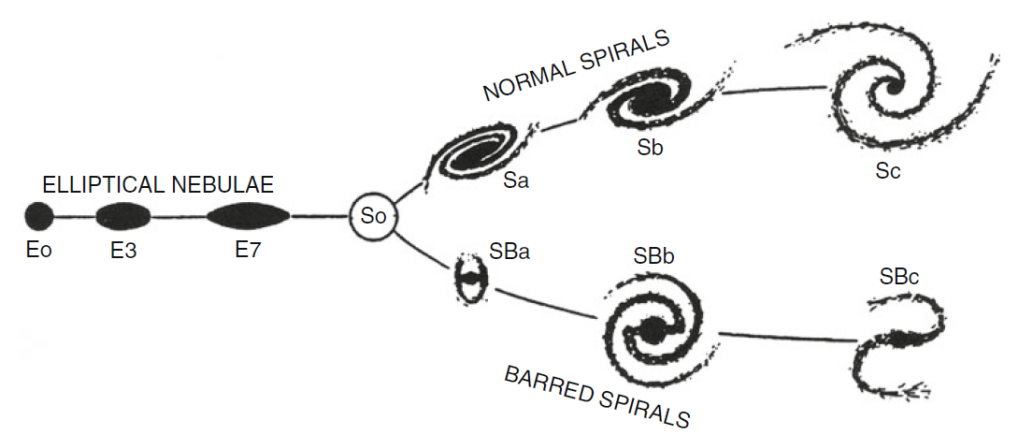

Figura 1.1: Esquema de clasificación morfológica dada por Hubble (1936). Existen otras clasificaciones para diferentes longitudes de onda y que incluyen diferentes características físicas. Se ha presentado una revisión de este esquema en Kormendy \& Bender (2012)

Las galaxias Es quedan bien descriptas por una distribución de brillo uniforme, generalmente no poseen ninguna estructura destacada, 
y el ajuste de isofotas elípticas suele ser una buena opción para la descripción del perfil de brillo. La secuencia de galaxias Es es indicada según el grado de excentricidad, con $n=10[1-(b / a)]$, donde $a$ y $b$ son los semiejes mayor y menor, respectivamente (medidos sobre la imagen proyectada). De esta forma, las galaxias EO aparecen circulares mientras que las galaxias E6 - E7 se encuentran entre las galaxias más alargadas observadas. Mientras que esto es sólo una proyección sobre el plano del cielo, la forma "real" de las galaxias Es bien podría ser esferoidal o triaxial.

Las galaxias Ss tienen características espirales evidentes como "brazos" con diferentes grados de enrollamiento. Se pueden descomponer en un abultamiento central, o bulbo, y un disco delgado que contiene los brazos espirales. Además, puede estar presente una "barra" que cruza el bulbo. Dependiendo de la presencia de la barra, las galaxias $\mathrm{S} s$ se clasifican como barradas (SB) o normales (S). Las galaxias Ss se subclasifican en función del enrollamiento y definición de los brazos espirales. Las galaxias $\mathrm{Sa}$ tienen sus brazos bien apretados y un bulbo bien definido mientras que las galaxias $S c$ tienen los brazos más abiertos.

Es posible clasificar un tipo intermedio entre las galaxias Es y Ss, las galaxias lenticulares (SO). Estas galaxias tienen un bulbo central de brillo suave rodeado por una gran estructura intrínsecamente plana. Como una $S$, una galaxia lenticular puede ser barrada (SBO) o normal (SO).

Por último, las galaxias irregulares se subdividen en IrrI e IrrII. Las galaxias IrrII presentan una distribución de luz completamente irregular, mientras que las IrrI se asemejan a una $S$ deformada.

En la secuencia de Hubble (Figura - 1.1), las galaxias que están del lado izquierdo de las So son llamadas también de tipo temprano, mientras que las restantes se conocen como de tipo tardío. Esta forma de referirse a ambos grupos de galaxias se utiliza en la actualidad, aunque incorrectamente se lo interpreta en un contexto evolutivo, se refieren a la ubicación en la secuencia, sin pretender ninguna hipótesis evolutiva (Baldry, 2008).

Una alternativa al esquema de Hubble fue desarrollada por van den Bergh (1976), quien consideró que la relación de brillo B/T entre el bulbo y el brillo total resulta ser más significativa, para definir la posición de un objeto en la clasificación, que cualquier otra característica morfológica observada en imagen directa. La modificación consistió en disponer en forma de una secuencia paralela a las espirales (ordinarias y barreadas) $\mathrm{Sa}-\mathrm{Sb}-\mathrm{Sc}$, los tipos $\mathrm{SOa}-\mathrm{SOb}-\mathrm{S} 0 \mathrm{c}$. Más recientemente, Kormendy \& Bender (2012) realizaron modificaciones a este esquema que se puede ver en la Figura $>$ 1.2. La principal fue agregar las galaxias enanas (o esferoidales según Kormendy, Sph) e irregulares al final de las secuencias de las $S 0$ y $S$, respectivamente. 
Esta modificación está motivada por permitir una explicación más clara de los procesos de evolución de los distintos tipos de galaxias.

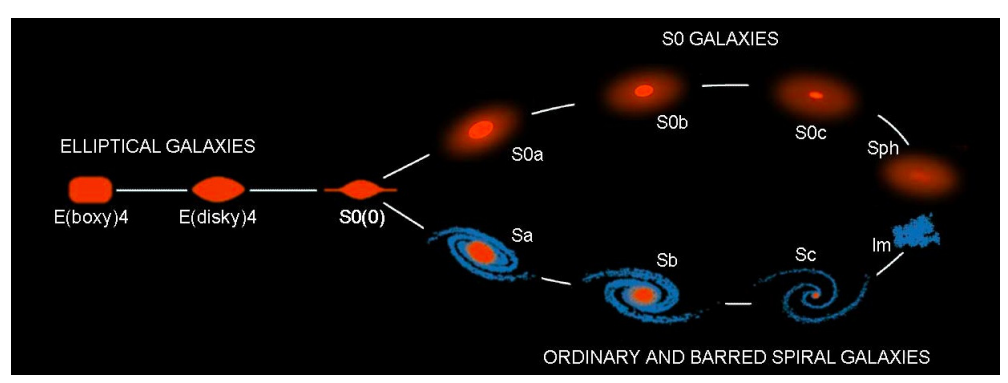

Figura 1.2: Revisión del esquema de van den Bergh (1976) publicada por Kormendy \& Bender (2012).

En esta Tesis se describen los resultados obtenidos para la población de galaxias de tipo temprano, tanto normales como enanas, del cúmulo de Antlia. Por tal motivo, se descartan del análisis los objetos que presentan forma irregular o espiral en nuestras imágenes. Estos objetos serán estudiados en una instancia posterior, cuando se haga un estudio global del cúmulo.

\subsection{GALAXIAS ELÍPTICAS}

Una galaxia elíptica se puede aproximar con un elipsoide de revolución triaxial cuyo perfil de brillo resulta ser suave y sin características particulares. Presentan bajo contenido de gas y polvo y exhiben principalmente una población estelar vieja y roja (Renzini, 2006; Clemens et al., 2006, 2009). Las galaxias de tipo temprano son más frecuentes en ambientes densos como los cúmulos, este resultado es conocido como la relación morfología-densidad (Dressler, 1980).

El brillo superficial de una galaxia elíptica cae suavemente con el radio, generalmente se describe mediante el modelo de Sérsic (1968):

$$
I(r)=I_{0} e^{-\left(r / r_{0}\right)^{1 / n}}
$$

donde $I(r)$ es el brillo superficial a una distancia $r$ del centro, $I_{0}$ es este valor en el centro, $r_{0}$ es una longitud de escala, y $n$ es el parámetro de forma o índice de Sérsic. Esta expresión generaliza la ley $\mathrm{r}^{1 / 4}$ ( $n=4$, de Vaucouleurs 1948) que se utiliza para las galaxias elípticas luminosas, sin embargo para elípticas más brillantes en cúmulos, esta ley es sólo válida para la región interna. Por otro lado, la región exterior de las elípticas enanas o normales suele quedar por debajo de la ley $r^{1 / 4}$. El índice $n$, introducido por Sérsic, funciona como un parámetro de forma que mide la curvatura del perfil de luz de la galaxia y está fuertemente correlacionado con la masa y tamaño para las galaxias elípticas menos luminosas (Prugniel \& Simien, 1997). El 
índice $n=1$ corresponde al perfil exponencial, que es un valor típico para las galaxias enanas. La importancia del índice de Sérsic como una medida de la concentración de la luz de la galaxia, se ha incrementado en los últimos años debido a su fuerte correlación con otras propiedades físicas de las galaxias elípticas. En particular, existe una correlación bien definida entre el índice $n$ y la masa del agujero negro central de la galaxia, en el sentido que los agujeros negros más masivos parecen encontrarse en las galaxias más concentradas (Graham et al., 2003a; Erwin et al., 2004; Graham \& Driver, 2007).

Actualmente, con observaciones desde tierra resulta muy dificultoso estudiar el perfil de brillo de una galaxia en la región más interna. Observaciones del Telescopio Espacial Hubble han posibilitado el estudio de la forma real que presentan los núcleos de las galaxias sin estar afectados por la atmósfera. Los perfiles de brillo para las galaxias más brillantes presentan un radio de quiebre (o break radius) en donde el perfil cambia de comportamiento, se observa que dentro de este radio la caída del perfil puede ser más o menos pronunciada que para el resto del perfil. Las galaxias con perfiles de brillo planos en el centro son llamados galaxias tipo core, mientras que las que presentan centros empinados, de tipo power-law. En Trujillo et al. (2004b) se introdujo una modificación al modelo de Sérsic que lleva el nombre core-Sérsic que unifica las expresiones para los perfiles con estas características centrales. En la Figura $>1.3$ se puede ver un modelo core-Sérsic ajustado a NGC 3348.

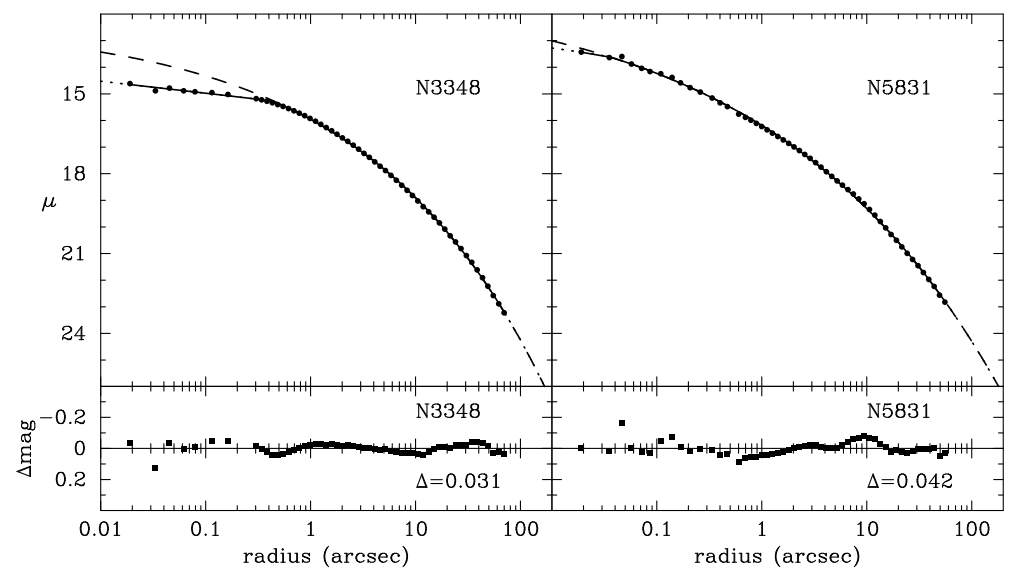

Figura 1.3: Del lado izquierdo se grafica un modelo core-Sérsic (línea continua) ajustado al perfil de brillo superficial en la banda R (puntos) de NGC 3348. La zona plana dentro del radio de quiebre corresponde a una falta de masa estelar de $\sim 3 \times 10^{8} \mathrm{M}_{\odot}(\mathrm{Graham}, 2004)$. Del lado derecho, el perfil de NGC 5831 que es descripto por un modelo de Sérsic clásico. Notar que en este caso el centro plano del perfil es casi despreciable. Figura tomada de Graham et al. (2003b). 
Mediante simulaciones se ha mostrado que la forma del centro del perfil de brillo está relacionada con la historia de formación de la galaxia y las propiedades de sus progenitores. Por ejemplo, Milosavljević \& Merritt (2001) muestran que la fusión de dos sistemas tipo powerlaw con agujeros negros centrales masivos producen una galaxia con perfil tipo core. Las teorías predicen que la falta de masa central $M_{\text {def }}$ es proporcional a $0.5 \mathrm{NM}_{\mathrm{bh}}$, donde $\mathrm{M}_{\mathrm{bh}}$ es la masa final del agujero negro central y $\mathrm{N}$ es el número de fusiones mayores secas (major dry mergers), esto es, fusiones a gran escala en ausencia de gas. En particular, Graham (2004) utilizó el modelo de core-Sérsic para cuantificar la falta de luminosidad relacionada con la extrapolación interna del perfil de Sérsic externo, y sugirió que para las galaxias elípticas más luminosas, la cantidad de fusiones secas se encuentra entre 10 2, en acuerdo con los modelos ACDM (Cold Dark Matter, Haehnelt \& Kauffmann, 2002; Volonteri \& Madau, 2003).

A pesar de la forma elíptica de este tipo de galaxias, un gran número de ellas presentan características morfológicas particulares (por ejemplo Malin \& Carter, 1983; Schweizer \& Seitzer, 1988; Seitzer \& Schweizer, 1990; Barnes \& Hernquist, 1992a). Estas estructuras se pueden observar en forma de regiones de "luz" extra que afectan (o distorsionan) el ajuste de las isofotas del perfil de brillo. Estas distorsiones pueden tomar diferentes formas: cáscaras, colas, plumas, etc. (Malin \& Carter, 1983; Schweizer \& Seitzer, 1988; Reid et al., 1994).

Otro tipo de estructuras observadas en galaxias elípticas son las isofotas tipo "disco" y tipo "caja". Las isofotas tipo disco son el resultado de luz extra que se extiende a lo largo de los ejes principales de la elipse (semiejes mayor y menor), mientras que las isofotas tipo caja son debidas a la luz extra que se extiende a ángulos cercanos a $45^{\circ}$ de los anteriores. En estudios detallados sobre la forma de las isofotas en galaxias elípticas masivas, Bender et al. (1989) y Nieto \& Bender (1989) encontraron que ésta no está correlacionada con los parámetros fotométricos como el radio efectivo o la elipticidad. Sin embargo, galaxias rodeadas por halos de rayos-X generalmente poseen isofotas irregulares o de tipo caja. Bender et al. (1989) también encontraron que estas galaxias parecen tener cocientes masaluminosidad $\left(\sim 11.5 \pm 0.9 \mathrm{M}_{\odot} / \mathrm{L}_{\odot}\right)$ mayores que las galaxias tipo disco $\left(\sim 6.4 \pm 0.6 \mathrm{M}_{\odot} / \mathrm{L}_{\odot}\right)$. Dependiendo de la luminosidad de las galaxias, las de baja luminosidad tienden a tener isofotas tipo disco, mientras que las más luminosas suelen presentar las de tipo caja. Estas correlaciones observadas marcan el origen de la diferenciación entre isofotas tipo caja y disco, y la dependencia con la historia de formación de la galaxia (Bekki \& Shioya, 1997).

Las bandas de polvo centrales son una característica común en una fracción significativa de galaxias elípticas (por ejemplo Sadler \& Gerhard, 1985; Ebneter et al., 1988). Muchas galaxias con esta caracte- 
rística son conocidas por ser también emisores en radio, como por ejemplo Centaurus A (NGC 5128) y Fornax A (NGC 1316). El origen del polvo en galaxias de tipo temprano es aún motivo de debate. Algunos estudios sugieren una fuente interna como la eyección de gas y polvo de estrellas gigantes rojas evolucionadas. Sin embargo, Forbes (1991) no encuentra una correlación apreciable entre la emisión de polvo en el lejano IR en galaxias elípticas y su luminosidad en el óptico. Este resultado indicaría que el polvo es producido por procesos de origen externo, por ejemplo, podría ser colectado durante la acreción de una galaxia rica en gas. Estos resultados fueron confirmados por Goudfrooij \& de Jong (1995) y Trinchieri \& Goudfrooij (2002).

A pesar de lo distintos que pueden ser los mecanismos de formación de las galaxias de tipo temprano para diferentes luminosidades, parecen seguir ciertas relaciones entre sus parámetros estructurales. Estas relaciones cumplen un rol central en el estudio de la formación y evolución de galaxias dado que conectan propiedades fotométricas y químicas con propiedades dinámicas, entre las que se pueden nombrar: la relación Faber-Jackson $\mathrm{L}_{\text {tot }}-\sigma_{0}$ (Faber \& Jackson, 1976), la relación color $-\sigma_{0}$ (Bower et al., 1992), la relación $\mathrm{Mg}_{2}-\sigma_{0}$ (Terlevich et al., 1981; Dressler et al., 1987; Guzman et al., 1992; Bender et al., 1993), la relación $M_{\mathrm{BH}}-\sigma_{0}$ (Ferrarese \& Merritt, 2000; Gebhardt et al., 2000; Gültekin et al., 2009), donde $\sigma_{0}$ es la dispersión central de velocidades, $\mathrm{Mg}_{2}$ es uno de los índices de Lick y $\mathrm{M}_{\mathrm{BH}}$ es la masa del agujero negro central. Es necesario destacar el llamado Plano Fundamental (PF, Djorgovski \& Davis, 1987; Dressler et al., 1987), una de las relaciones más utilizadas que conecta el radio efectivo $\left(r_{e}\right)$, el brillo superficial central efectivo promedio $\left(\left\langle\mathrm{I}_{e f}\right\rangle\right)$ y la dispersión central de velocidades $\left(\sigma_{0}\right)$. Debido a que la dispersión de velocidades y el brillo superficial son observables independientes de la distancia, y no así el radio efectivo, se suele escribir al $\mathrm{PF}$ en la siguiente forma

$$
r_{e} \propto \sigma_{0}^{a}\left\langle I_{e f}\right\rangle^{b}
$$

para obtener los parámetros a y b se puede suponer que las galaxias elípticas son sistemas que se encuentran en equilibrio virial (Faber, 1987; Djorgovski \& Davis, 1987; Bender et al., 1992) con lo que se llega a los valores teóricos $\mathrm{a}=2 \mathrm{y} \mathrm{b}=-1$ (Djorgovski \& Davis, 1987). Los parámetros $\mathrm{a}$ y $\mathrm{b}$ ajustados de las observaciones suelen ser menores que los anteriores, esto es llamado la "inclinación" del Plano Fundamental (Prugniel \& Simien, 1996; Ciotti et al., 1996; Busarello et al., 1997; Scodeggio et al., 1998; Trujillo et al., 2004a; Reda et al., 2005; Robertson et al., 2006; Graves et al., 2009; Secco \& Bindoni, 2009; Allanson et al., 2009; Grillo \& Gobat, 2010; Humphrey \& Buote, 2010). Las mediciones de los parámetros del PF observado difieren sensiblemente de los valores anteriores, por ejemplo: Gibbons et al. (2001) $a=1.37 \pm 0.04$ y $b=-0.82 \pm 0.01$, Bernardi et al. (2003) $a=1.49 \pm 0.05$ 
y $b=-0.75 \pm 0.01$ (D'Onofrio et al., 2006, y referencias allí citadas). Jorgensen et al. (1996) encontraron que la dispersión del PF no puede ser debida exclusivamente a errores observacionales.

\subsection{MODELOS DE FORMACIÓN Y EVOLUCIÓN DE GALAXIAS}

Las homogeneidades observadas en las propiedades de las galaxias elípticas como sus perfiles de brillo superficial, colores y dispersión de velocidades motivan el estudio de las relaciones entre sus parámetros estructurales a diferentes redshift (Stanford et al., 1998; Saglia et al., 2000) y sugieren un mecanismo de formación y evolución para este tipo de galaxias. Además, la existencia de galaxias masivas a redshift intermedio (Cimatti et al., 2004), ubica la formación de las galaxias elípticas en el Universo temprano. Actualmente la formación de las galaxias de tipo temprano es fuertemente debatida, siendo fundamentales los modelos cosmológicos ^CDM (Bell et al., 2003; Gallazzi et al., 2008).

La Figura $>1.4$ muestra un esquema resumido de los modelos que se detallarán en esta sección. A pesar que existen comprobaciones observacionales de los mismos, aún no se ha logrado una comprensión completa de la formación de las galaxias de tipo temprano como función de la morfología, redshift y condiciones ambientales. Probablemente, la mejor descripción de la formación y evolución de las galaxias provenga de una combinación adecuada de ambos modelos.

El escenario de formación conocido como el modelo de "colapso monolítico disipativo" postula que las galaxias elípticas fueron formadas a altos redshift en un corto período de tiempo durante un colapso rápido de material gaseoso que formaba un única nube (Eggen et al., 1962; Larson, 1974; Arimoto \& Yoshii, 1987; Chiosi \& Carraro, 2002; Bressan et al., 1994; Kawata \& Gibson, 2003; Matteucci, 2003). Sus estrellas se formaron en un corto e intenso estallido de formación que duró como mínimo $1 \mathrm{~Gy}$, seguido por viento galáctico, cuya intensidad depende del pozo de potencial, que despejó el gas de las galaxias y evitó la formación estelar posterior. Las galaxias masivas pueden mantener la componente de gas más tiempo, en el cual realizan procesos de síntesis y producen metales pesados que se observan como altas metalicidades, dando lugar al comportamiento conocido como la relación masa-metalicidad. El producto final de este modelo es una galaxia elíptica compuesta principalmente por estrellas y una insignificante fracción de gas. La subsecuente evolución de la componente estelar es considerada un problema de dinámica estelar o colapso no disipativo (van Albada, 1982; Trenti et al., 2005). Los modelos de colapsos no disipativos pueden reproducir algunas de las propiedades observables de galaxias elípticas, como los perfiles de brillo, así como también ciertas relaciones dinámicas características de este 


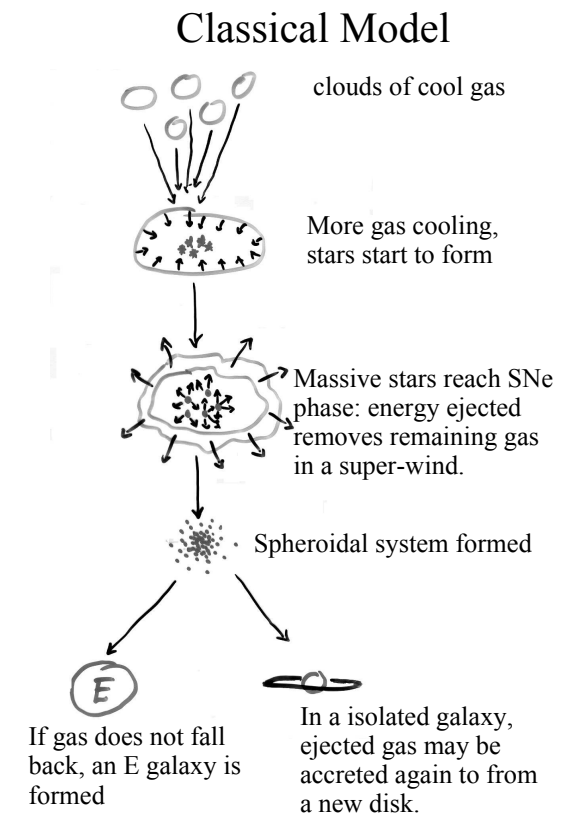

Hierarchical Model

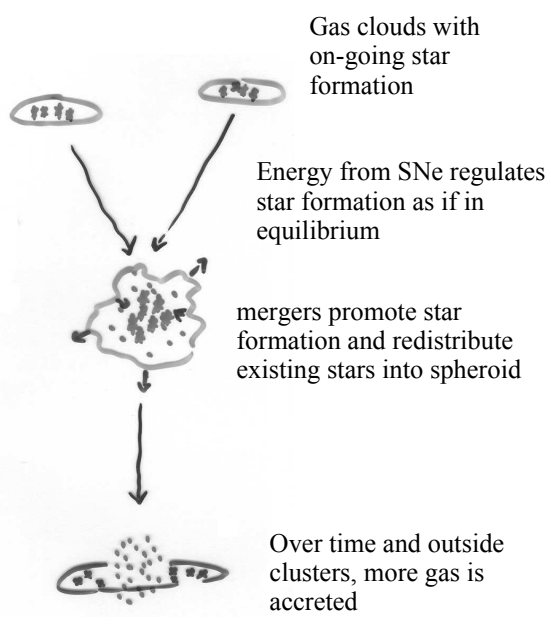

NB. there is no inbuilt link between morphology and star formation history

Figura 1.4: Esquema de la formación de galaxias de Bower et al. (1999). En el modelo monolítico (o clásico) la componente esferoidal se formó en un evento repentino de formación estelar a alto redshift y luego continuó una evolución pasiva (E) o una acreción continua de gas sobre el disco para galaxias en los ambientes menos densos. En el modelo jerárquico (o de mezcla), las galaxias pueden cambiar de morfología dependiendo de la cantidad y fuerza de las fusiones e interacciones.

tipo morfológico y la relación color-magnitud o el plano fundamental (Kodama et al., 1998; van Dokkum \& Stanford, 2003). Además, las simulaciones de $\mathrm{N}$-cuerpos más recientes de alta resolución en halos de materia oscura preexistentes (Nipoti et al., 2006) son capaces de reproducir galaxias elípticas con perfiles de brillo superficial parecidos a los observados, como el perfil de Sérsic (Sérsic, 1968) en un rango del índice $n$.

Sin embargo, de acuerdo con el escenario de colapso, los parámetros fotométricos y morfológicos de una galaxia son independientes del ambiente local de la galaxia, lo que no justifica la relación morfología-densidad. Además, este escenario no explica la evidencia observada de población estelar de edad intermedia en galaxias de tipo temprano (Terlevich \& Forbes, 2002; McDermid et al., 2006), o la estructura morfológica fina como capas o plumas y colas (Malin \& Carter, 1983) que fue encontrada en un número significativo de galaxias.

El otro modelo sugerido es el de "fusión jerárquica" o modelo de fusión (Toomre, 1977; White \& Rees, 1978; Steinmetz \& Navarro, 2002). Este escenario provee una explicación para las características observacionales y se sustenta, por ejemplo, en observaciones de galaxias interactuantes en diferentes estadios del proceso de fusión (Schwei- 
zer, 1980; Schweizer \& Seitzer, 1988; Barnes \& Hernquist, 1992b). El escenario de fusión para la formación y evolución de galaxias a diferentes redshift es una extensión natural de la teoría de agrupamiento jerárquico, como los modelos cosmológicos de CDM. El Universo comienza con una distribución de fluctuaciones de densidad pequeñas que es posteriormente amplificada por una inestabilidad gravitatoria interactuando con la materia oscura fría, hasta que se vuelven no lineales. Los grumos resultantes colapsan para formar halos de materia oscura fría casi virializada. En el escenario de fusión, se forman primero los halos más pequeños y se vuelven progresivamente más masivos mediantes fusiones entre sí (Peebles, 1982; Blumenthal et al., 1984). Una fracción del contenido bariónico del halo comienza a enfriarse por emisión de radiación hacia el centro del halo (Rees \& Ostriker, 1977; Silk, 1977; White \& Rees, 1978). El colapso disipativo continúa hasta que el gas frío se establece en discos sostenidos rotacionalmente (Fall \& Efstathiou, 1980; Mo et al., 1998). Los procesos de fusión y acreción continúan formando grandes estructuras a diferentes escalas, tales como galaxias masivas, grupos de galaxias, cúmulos y supercúmulos. Sin embargo, la formación de galaxias elípticas en cúmulos mediante fusión fue más probable en las primeras etapas de la formación del mismo, en donde la velocidad relativa entre las galaxias fue suficientemente baja como para permitir fusiones.

Si una galaxia consume el contenido de gas en procesos de formación estelar, seguidos por vientos estelares que eyectan el gas remanente hacia el medio intergaláctico, posteriormente una gran fusión no disipativa entre dos galaxias (o fusión seca) producirá una galaxia elíptica masiva con población estelar uniformemente vieja. Además, las simulaciones numéricas de fusiones no disipativas pueden reproducir las relaciones de escala observadas en galaxias elípticas (Capelato et al., 1995; Dantas et al., 2003; González-García \& van Albada, 2003; Boylan-Kolchin et al., 2005). Por ejemplo, el modelo de Naab et al. (2006) reproduce la cinemática de una galaxia y la forma de sus isofotas como función de la masa.

Por otra parte, otras simulaciones remarcan la importancia de la componente gaseosa durante las fusiones para obtener la dispersión y la pendiente de las relaciones de escala (Ciotti \& van Albada, 2001; Evstigneeva et al., 2004; Boylan-Kolchin et al., 2006). Además, las simulaciones numéricas de Robertson et al. (2006), encuentran que la disipación del gas contribuye significativamente a la inclinación del Plano Fundamental observado. Sin embargo, encuentra que el impacto de la disipación en las propiedades de los remanentes es dependiente de la masa. Durante el primer pasaje pericéntrico del progenitor masivo, el gas se calienta y se dirige al halo dando lugar a una fusión sin disipación. Por otro lado, galaxias de baja masa experimentan conversiones rápidas de gas en estrellas, lo que incrementa 
el impacto de la disipación del gas en las propiedades centrales del remanente.

Desde los primeros trabajos de Larson \& Tinsley (1978) y Lavery \& Henry (1988), se conoce que las fusiones gaseosas pueden inducir eventos de formación estelar secundaria como así también otras subestructuras cinemáticas y morfológicas (Mihos \& Hernquist, 1996; Barnes, 2004). Por lo tanto, se espera que las galaxias más masivas tengan una población estelar central más joven y rica en metales, que se formó durante las fusiones a lo largo de escalas de tiempo más grandes que para las galaxias más pequeñas. Sin embargo, estas predicciones están en contradicción con las relaciones de escala observadas entre la magnitud absoluta (o la dispersión central de velocidades) y tanto la edad como la metalicidad de las poblaciones estelares centrales (Bender \& Saglia, 1999; Mehlert et al., 2003; Collobert et al., 2006). Las relaciones masa-edad y masa-metalicidad observadas indican que las galaxias elípticas más masivas son más viejas y más ricas en metales que las menos masivas. Este fenómeno parece ser más fuerte para desplazamientos al rojo altos que en el Universo actual, y es conocido como "la reducción del tamaño" (down-sizing) (Cowie et al., 1996; Madau et al., 1996; Shaver et al., 1996).

Esta evidencia observacional ha sido el motivo para que se desarrollen mecanismos para suprimir los procesos de formación de estrellas en los modelos de galaxias más masivas. De Lucia et al. (2004) sugieren que la dependencia de la tasa de formación de estrellas con la velocidad circular de la galaxia, es capaz de acelerar más la formación de estrellas en galaxias masivas que en las menos masivas. Otra consecuencia es que un agujero negro masivo central y la retroalimentación AGN en galaxias masivas, también puede conducir a la relación masa-edad observada (Springel et al., 2005; Croton et al., 2006).

Una de las diferencias más importantes entre los modelos es la morfología. En el modelo de colapso, la morfología se establece en el comienzo de la historia de la galaxia, mientras que en el modelo jerárquico las galaxias pueden cambiar de morfología dependiendo de la cantidad y fuerza de las fusiones e interacciones. La segregación entre los dos escenarios puede ser interpretada como una forma de la discusión entre naturaleza-ambiente (del inglés nature-nurture). Es decir, ¿hasta que punto las propiedades de las galaxias son determinadas por las condiciones iniciales (nature)?, y ihasta que punto son motivadas por efectos ambientales (nurture)? 


\subsubsection{Galaxias enanas}

Las galaxias elípticas enanas ( $\mathrm{dEs}$ ) son la población de objetos más frecuentes en los cúmulos de galaxias, poseen tamaños que van desde $1 \mathrm{kpc}$ a $10 \mathrm{kpc}$, presentan magnitudes absolutas en la banda B entre $-14 \mathrm{mag}$ y $-18 \mathrm{mag}$, y el rango de masas que cubren es $10^{7} \mathrm{M}_{\odot} \mathrm{a}$ $10^{9} \mathrm{M}_{\odot}$.

Las $\mathrm{dEs}$ se han convertido en un objetivo muy útil para poder comprobar los diferentes mecanismos de formación y evolución de las galaxias, ya que, además de ser la población dominante del Universo (Ferguson \& Binggeli, 1994), su baja masa y su pozo de potencial poco profundo ayudan a entender el papel de la masa y el entorno en la evolución galáctica. Son sistemas fácilmente perturbables por el entorno, por lo tanto, si la densidad del medio en el que se encuentran juega algún papel en su formación y evolución, serán los objetos más afectados. Además, las observaciones de galaxias enanas enfocadas específicamente en la búsqueda de sistemas estelares con luminosidad en los límites de detección, son esenciales para resolver el missing satellite problem (Klypin et al., 1999). Esto se refiere, en términos generales, a la sobreabundancia de halos de CDM predichos por los modelos cosmológicos en comparación con las galaxias satélite observadas en el Grupo Local.

En estudios de sistemas de bajo brillo superficial se han encontrado similitudes entre las propiedades estructurales de galaxias que presentan formación estelar y dEs en el Universo cercano. Por ejemplo, ambas poblaciones de objetos tienen perfiles de brillo exponenciales (Lin \& Faber, 1983; Binggeli et al., 1984; Ferrarese et al., 2006). Este hecho sugiere que las dEs son el resultado de la pérdida de gas y posterior truncamiento de la formación estelar en galaxias de baja luminosidad ricas en gas. Varios escenarios se han propuesto para explicar esta transformación entre galaxias de tipo tardío y tipo temprano.

El escenario más simple consiste en considerar que la extinción del gas, y por lo tanto el enrojecimiento de las galaxias, ocurre a través de procesos internos. Las explosiones de supernova que se producen en una galaxia como consecuencia de la evolución estelar, son el mecanismo más eficiente para barrer el gas interestelar (ver por ejemplo Yoshii \& Arimoto 1987). Otro procedimiento posible es a través de consecutivos episodios de formación estelar que agotan el gas de la galaxia (Davies \& Phillipps, 1988). Estos mecanismos son independientes del entorno en el que se encuentran las galaxias.

El entorno donde habitan las galaxias puede alterar también la apariencia de las mismas (Boselli \& Gavazzi, 2006). Se conoce como starvation a un fenómeno típico del entorno: en una región densa la caída del material necesario para alimentar la formación de estrellas se de- 
tiene, de forma que una vez que el gas frío se consume, la galaxia se hace más débil (Larson, 1980). Existen dos mecanismos puramente ambientales que son importantes cuando se trata de objetos menos masivos: galaxy harassment, o acoso entre galaxias, y ram-pressure stripping, pérdida de gas como consecuencia de la presión de choque generada al entrar la galaxia en un medio intergaláctico denso. Por ejemplo, en el modelo jerárquico las galaxias progenitoras de las dEs se ven afectadas por múltiples interacciones con galaxias vecinas y como consecuencia sufren una transformación completa convirtiéndose en galaxias de tipo temprano (Moore et al., 1998). Este proceso requiere que las galaxias estén ubicadas en regiones densamente pobladas, como sucede en el centro de los cúmulos de galaxias (Mastropietro et al., 2005).

Los modelos presentados por Smith et al. (2010) han demostrado que galaxias menos masivas con formación estelar reciente (presencia de disco) que están cayendo en un cúmulo no sufrirían harassment apreciable. Los únicos casos que podrán dar lugar a una galaxia elíptica enana son aquellos que adquieran una órbita con un apocentro pequeño (menores a $250 \mathrm{kpc}$ ). Sin embargo, estas órbitas son muy improbables para galaxias que estén cayendo debido al profundo pozo de potencial del cúmulo (Smith et al., 2010). Por otro lado, en el escenario de ram-pressure stripping, el gas de las galaxias enanas que entran en el cúmulo es eliminado, deteniendo de forma abrupta la formación estelar en escalas de tiempo muy cortas (150 millones de años), pero este proceso no afecta al momento angular de la galaxia (Boselli et al., 2008).

En resumen, el estudio de las galaxias enanas de tipo temprano es importante para entender la formación y evolución de las galaxias en general. Al ser la población dominante en cúmulos, nos ofrecen una visión privilegiada sobre los efectos del entorno, y cómo el estar rodeado de muchas otras galaxias afecta a su evolución.

\subsection{MOTIVACión DE LA TESis}

Este trabajo pretende proporcionar nuevos conocimientos sobre las galaxias enanas y gigantes de tipo temprano situadas en el cúmulo de Antlia, así como comparaciones con otros cúmulos de galaxias que presentan diferentes estados dinámicos. Esta Tesis constituye el relevamiento fotométrico más completo de galaxias del cúmulo de Antlia realizado hasta la fecha, actualizando en base a datos de imágenes de CCDs, el único catálogo (fotográfico) previo existente (Ferguson \& Sandage, 1990).

Estas poblaciones de galaxias de tipo temprano (enanas y gigantes) han sido elegidas por las siguientes razones: 
- El estudio de las galaxias elípticas masivas permite analizar los modelos monolíticos y jerárquicos de formación de galaxias, ya que, mientras la fusión jerárquica de sistemas predice que las regiones de mayor densidad son las que colapsan primero y se fusionan rápidamente (Thomas et al., 2005; Renzini, 2006), el colapso monolítico no depende de la densidad del medio. Por lo tanto, el estudio de las poblaciones estelares de galaxias masivas situadas en diferentes entornos nos da información acerca de la escala de tiempo de su formación y de su dependencia con la densidad de la zona donde habitan.

- Las galaxias enanas son candidatos apropiados para estudiar los efectos del entorno sobre la evolución galáctica debido a que su pozo de potencial es poco profundo, lo que las convierte en objetos fácilmente perturbables para cualquier tipo de estudio de interacción.

- La comparación entre las elípticas masivas y enanas contribuye a comprobar el escenario de fusiones jerárquicas. Si las galaxias enanas fueron los constituyentes originales de las galaxias más masivas, entonces se esperaría que ambas poblaciones tuviesen propiedades similares, siendo entonces las galaxias enanas la contrapartida a baja luminosidad de las gigantes. 



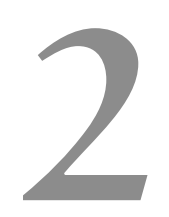

EL CÚMULO DE ANTLIA

\subsection{EL CÚMULO DE ANTLIA}

Unas de las primeras referencias sobre este cúmulo en la bibliografía es de la década del 70, en que se contaba con solo 13 miembros confirmados por velocidad radial y otros 3 objetos de pertenencia dudosa. En palabras de A. Sandage:

"... beatiful small group dominated by the two equally bright E galaxies NGC 3258 and NGC 3268. This is a mixed group with a few spiral galaxies among the $\mathrm{E}$ and $\mathrm{SO}^{\prime}$ 's. There is some reddening $(\mathrm{E}(\mathrm{B}-\mathrm{V}) \sim 0.1)$ in this low latitude field as evidenced by redder than normal B - V colors for NGC 3258 and NGC 3268. NGC 3250 is probably not a member; it is quite distant from the center of the group. B-M class III."

- Sandage (1975)

La clasificación B-M class III corresponde a la dada por Bautz \& Morgan (1970) cuya característica principal es la de no estar dominado por una sola galaxia brillante. Como veremos más adelante, en la zona central del cúmulo de Antlia se encuentran las dos galaxias elípticas más masivas del cúmulo: NGC 3268 y NGC 3258. Adoptaremos para el cúmulo de Antlia una distancia de $\sim 35 \mathrm{Mpc}$, que equivale a un módulo de distancia de $m-M=32.73$ mag (Dirsch et al., 2003).

Posteriormente, Hopp \& Materne (1985) realizaron un estudio de 5 agrupaciones en la dirección del supercúmulo de Hydra-Centauro; pese a la poca cantidad de objetos confirmados, ya se hacía referencia a la estructura elongada que presenta el cúmulo. Recién en Ferguson \& Sandage (1990) podemos encontrar el primer relevamiento fotográfico a gran escala, con 375 objetos. En la Figura $>2.1$ se puede ver una reproducción de la Figura 9 de Ferguson \& Sandage (1990). A pesar de la poca cobertura en superficie con 21 miembros confirmados por velocidad radial, determinaron una velocidad heliocéntrica de $2786 \mathrm{~km} \mathrm{~s}^{-1}$ con una dispersión central de velocidades de $561 \mathrm{~km} \mathrm{~s}^{-1}$, una masa virial de entre 29.2 y $31.7 \times 10^{13} \mathrm{M}_{\odot}$ (hasta un radio medio de $R=0.77 \mathrm{Mpc}$ ) y una relación masa-luminosidad, $M / L$, de entre 494 y 539. Desde los primeros trabajos, se midió en Antlia una densidad central de objetos mayor que en otros cúmulos más estudiados, dominada ampliamente por galaxias enanas elípticas. 


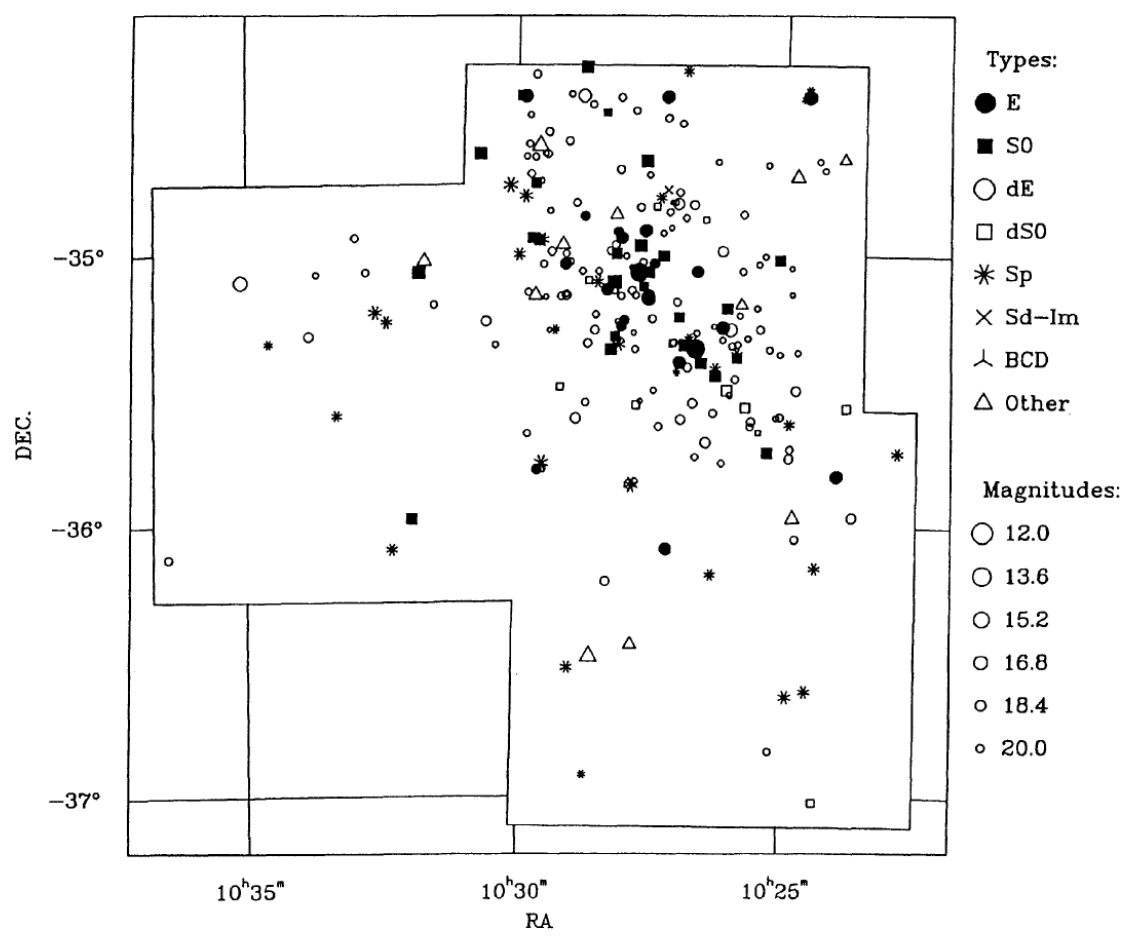

Figura 2.1: Distribución espacial de los objetos estudiados en el catálogo FS9o. Reproducción de la Figura 9 de Ferguson \& Sandage (1990).

Más recientemente, Pedersen et al. (1997), utilizando observaciones en rayos-X centradas en NGC 3258, obtenidas con la misión ASCA ${ }^{1}$ (Advanced Satellite for Cosmology and Astrophysics), lograron mapear la emisión de gas caliente en torno a dicha galaxia, la que se extiende en la dirección de la compañera NGC 3268, que conformaría un grupo menor. Suponiendo que el gas intracúmulo es isotermo y se encuentra en equilibrio hidrostático (Fabricant et al., 1980), Pedersen et al. (1997) obtuvieron para el grupo de NGC 3258 una temperatura de $\mathrm{kT} \sim 1.7 \mathrm{keV}, \mathrm{M}_{\text {gas }} \sim 0.7 \times 10^{12} \mathrm{M}_{\odot} \mathrm{y} \mathrm{M}_{\text {grav }} \sim 23 \times 10^{12} \mathrm{M}_{\odot}$, a un radio de $240 \mathrm{kpc}$ del centro del grupo. En la Figura $\bullet 2.2$ se pueden apreciar los contornos de la emisión en rayos-X del grupo de NGC 3258 y una elongación en la dirección de NGC 3268.

Nakazawa et al. (2000) realizaron el primer estudio en rayos- $X$ de NGC 3268 utilizando observaciones de ASCA y datos de archivo de ROSAT $^{2}$ (Röntgen Satellite). Se puede observar en el mapa de su Figura la emisión extendida que parece conectar las dos galaxias elípticas más brillantes del cúmulo, mientras que el gas conforma un halo a una temperatura de $\mathrm{kT} \sim 2 \mathrm{keV}$. A pesar de la usual presencia de un exceso de brillo en las zonas centrales de otros cúmulos de galaxias (generalmente dominados por una galaxia tipo $\mathrm{cD}$ ) debido la forma del potencial gravitatorio, Antlia no tendría un exceso en

1 http://heasarc.gsfc.nasa.gov/docs/asca/

2 http://heasarc.gsfc.nasa.gov/docs/rosat/rosgof.html 


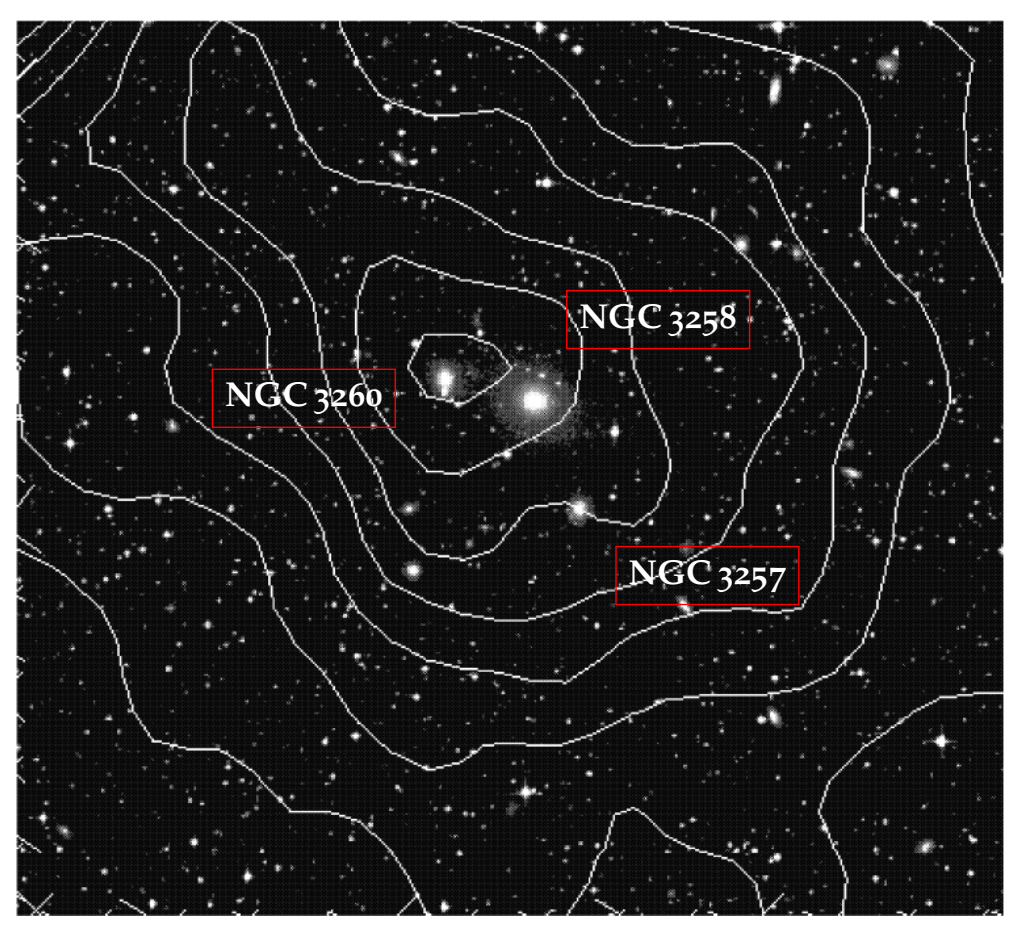

Figura 2.2: El campo es tomado del DSS (Digitalized Sky Survey), está centrado en NGC 3258 y cubre un área de $30^{\prime} \times 30^{\prime}$. El Norte hacia arriba y Este hacia la izquierda. Se observa superpuesto un mapa de contornos de emisión en rayos- $X$ de ASCA, donde se puede apreciar la elongación de la emisión en la dirección de NGC 3268 (hacia el NE). Reproducción de la Figura 1 de Pedersen et al. (1997).

rayos-X en la zona central. Esto lo convierte en el cúmulo más cercano, al grupo local, sin este tipo de característica (Nakazawa et al., 2000). Un posterior estudio espectroscópico en rayos-X de NGC 3258 fue realizado por Finoguenov et al. (2001, 2002), el cual forma parte de una muestra de galaxias brillantes. En los mismos, se estudió la relación masa-temperatura de cúmulos de galaxias así como también abundancias de elementos pesados en el contexto de los modelos de pre-calentamiento cósmico.

\subsection{EL CATÁlogo DE FERGUSON \& SANDAGE (FS9O)}

Como mencionamos anteriormente, Ferguson \& Sandage (1990) fue el primer trabajo, que aunque no se centró únicamente en el cúmulo de Antlia, constituyó el más extenso sobre la población de galaxias en este cúmulo. Mediante la inspección visual de placas fotográficas, identificaron 375 galaxias con un diámetro isofotal límite de 15.", dentro de un área de aproximadamente $8 \mathrm{Mpc}^{2}$. En el catálogo presentado en FS9o, entre los datos de cada objeto se incluye un nivel 
de membresía o grado de pertenencia evaluado (en los casos sin redshift observado) según criterios morfológicos, por ejemplo, el brillo superficial, la existencia de grumos o estructura interna y por la clase de luminosidad en el caso de galaxias de tipo tardío (Binggeli et al., 1985):
1: miembro definitivo (definite member)
- 2: miembro probable (likely member)
- 3: miembro posible (possible member)

Esto fue necesario al momento de la confección del catálogo dado que sólo el $6 \%$ de los objetos contaba con velocidades radiales medidas.

Ferguson \& Sandage (1990) confirmaron la estructura elongada del cúmulo y notaron las dos concentraciones en su distribución. Calcularon un tiempo de cruce mucho menor que el tiempo de Hubble, confirmando que Antlia es un sistema ligado. Estos autores también mostraron que la densidad central de galaxias de Antlia es un factor 1.4 y 1.7 veces mayor que en los cúmulos de Fornax y Virgo, respectivamente. El módulo de distancia adoptado fue de $(m-M)=34.1 \mathrm{mag}$, que se traduce en una distancia $d=66.1 \mathrm{Mpc}$ (Tammann \& Sandage, 1985, en donde se consideró $\mathrm{H}_{0}=50 \mathrm{~km} \mathrm{~s}^{-1} \mathrm{Mpc}^{-1}$ ), esto es casi el doble que la considerada en la presente Tesis. Ferguson \& Sandage (1991) estimaron las fracciones de tipos morfológicos para el cúmulo de Antlia y realizaron comparaciones con los cúmulos de Fornax y Virgo. Para galaxias más brillantes que $M_{B}=-14.5 \mathrm{mag}$ (si se tiene en cuenta el módulo de distancia utilizado en esta Tesis, la magnitud se transforma a $M_{B}=-13.1 \mathrm{mag}$; en Virgo: $M_{B}=-12.9$ mag utilizando $(\mathrm{m}-\mathrm{M})=30.1 \mathrm{mag}$; en Fornax: $\mathrm{M}_{\mathrm{B}}=-12.9$ mag utilizando (m$\mathrm{M})=32.2 \mathrm{mag}$ ), y separando las galaxias elípticas enanas en nucleadas $(d E, N)$ y no-nucleadas $(d E)$, se pueden ver sus resultados en la tabla siguiente:

\begin{tabular}{lccc}
\hline & \multicolumn{3}{c}{$\mathrm{M}_{\mathrm{B}}<-14.5 \mathrm{mag}$} \\
\cline { 2 - 4 } Clasificación & Antlia & Fornax & Virgo \\
\cline { 2 - 4 } E, SO & $17.2 \%$ & $22.5 \%$ & $13.6 \%$ \\
$\mathrm{dE}$ & $38.9 \%$ & $12.5 \%$ & $16.1 \%$ \\
$\mathrm{dE}, \mathrm{N}$ & $14.9 \%$ & $27.3 \%$ & $26.9 \%$ \\
Sa, Scd,Sd, Im & $21.9 \%$ & $25.3 \%$ & $32.1 \%$ \\
\hline
\end{tabular}

Tabla 2.1: Fracciones de galaxias según el tipo morfológico estimadas por Ferguson \& Sandage (1991) para Antlia, y comparadas con los cúmulos de Fornax y Virgo.

Durante el desarrollo de esta Tesis, se utilizó el catálogo de Ferguson \& Sandage (1990) como base para la identificación inicial de 
las galaxias de la muestra, y posteriormente se identificaron nuevos objetos aún no catalogados en la bibliografía.

\subsection{OTROS ESTUDIOS PREVIOS}

Existen pocas referencias en la literatura sobre estudios del cúmulo de Antlia basados en datos de CCDs. Debemos mencionar a Smith Castelli et al. (2008a), quienes realizaron el primer estudio de objetos extendidos en la zona central de cúmulo. Utilizaron observaciones de la cámara MOSAIC II de CTIO, al igual que en esta Tesis, y obtuvieron magnitudes y colores isofotales en el sistema de Washington. Dicho trabajo contó con 93 galaxias, entre las que se encuentran las dos gEs: NGC 3258 y NGC 3268, y varias candidatas a cEs. La siguiente publicación se enfocó en el estudio de candidatas a galaxias cE (Smith Castelli et al., 2008b), dos de las cuales fueron confirmadas como miembros en Smith Castelli et al. (2012): FS90 110 y FS90 192. En este último trabajo se presentó además un análisis más profundo, en el que se extendió el estudio a galaxias más débiles $\left(M_{T 1} \gtrsim-10 \mathrm{mag}\right)$ en la zona central de Antlia. Entre ellas se encuentran 21 galaxias de bajo brillo superficial nuevas (no catalogadas previamente), de las cuales 5 son confirmadas como miembros del cúmulo y 16 son candidatas.

El análisis fotométrico realizado en la serie de trabajos de Smith Castelli et al., permitió mostrar que la relación color-magnitud T1 vs. $(\mathrm{C}-\mathrm{T} 1)$ de galaxias de tipo temprano (ver Figura -2.3 ) ubicadas en la zona central del cúmulo de Antlia, se extiende a lo largo de 12 magnitudes, desde las más brillantes hasta las dShps en el extremo más débil. Además, no encontraron un cambio significativo de la pendiente en el ajuste lineal realizado, ni tampoco se observó un incremento considerable de la dispersión en el color si se consideran solo los miembros confirmados. Las nuevas galaxias catalogadas pertenecen al rango de magnitudes $18<\mathrm{T}_{1}<22$ mag y presentan radios efectivos menores que los de las dEs más brillantes, habiéndose obtenido para estas últimas valores de $r_{e} \sim 1 \mathrm{kpc}$. Esta última diferencia puede atribuirse al límite considerado para la fotometría isofotal, que provoca la pérdida de una fracción del brillo de las galaxias más débiles. Respecto a la existencia de dicotomías o quiebres en las relaciones fotométricas (Kormendy et al., 2009), no encuentran ningún indicio con el que se puedan discriminar las poblaciones de galaxias elípticas brillantes de las de bajo brillo superficial. Pero esto último no es completamente concluyente, dado que las galaxias de brillo intermedio que se encuentran en el cúmulo son mayoritariamente lenticulares.

La población de dEs estudiada con magnitudes entre $13<\mathrm{T}_{1}<$ $18 \mathrm{mag}$ presenta radios efectivos promedio cercanos a $\left\langle\mathrm{r}_{\mathrm{e}}\right\rangle \sim 0.9 \mathrm{kpc}$ lo que se encuentra en acuerdo con otros cúmulos (Smith Castelli et al., 2008a, y referencias allí citadas). Mientras que para galaxias 


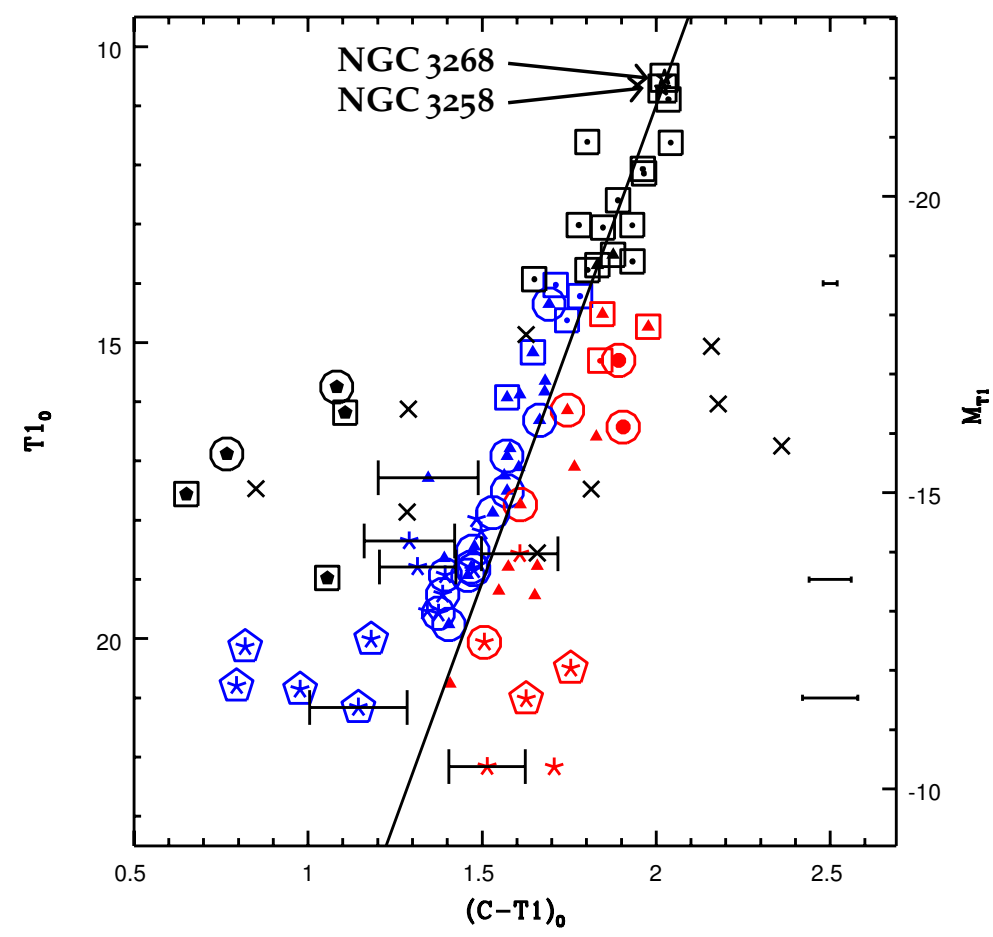

Figura 2.3: Relación color-magnitud para la zona central del cúmulo de Antlia de Smith Castelli et al. (2012). En el extremo brillante de la relación $\left(M_{\mathrm{T} 1} \sim-22 \mathrm{mag}\right)$ se encuentran las dos $\mathrm{gEs}$ del cúmulo representadas por estrellas grandes. El resto de las referencias: circulos llenos, cEs; triángulos llenos, elípticas; puntos SOSs; pentágonos llenos, dIs y BCDs; asteriscos, candidatas a dEs; cuadrados y círculos vacíos, galaxias confirmadas por espectroscopía GEMINI y MAGALLANES, respectivamente.

más débiles que $T_{1}=18 \mathrm{mag}$. el valor promedio del radio efectivo es $\left\langle r_{e}\right\rangle \sim 0.6 \mathrm{kpc}$, lo que coincide con las galaxias más débiles estudiadas en el Grupo Local y los grupos NGC 5044 y M 81. Por otro lado, no encontraron correlación entre los colores de las galaxias y su ubicación dentro del cúmulo o sus tamaños proyectados, lo que puede estar sesgado por la escasa cobertura del material observacional. Por último, la distribución espacial proyectada (Figura $>2.4$ ) sostiene la existencia de dos grupos en la zona central del cúmulo, cada uno alrededor de cada galaxia gE. El que está centrado en NGC 3258 muestra características de grupo, mientras que el centrado en NGC 3268 podría ser un cúmulo pequeño.

Cabe mencionar, además, que se han realizado estudios sobre la población de objetos puntuales, esto es cúmulos globulares y enanas ultra-compactas (UCDs), en Antlia. En ambos casos se analizan los sistemas de cúmulos globulares (Dirsch et al., 2003; Bassino et al., 2008) 


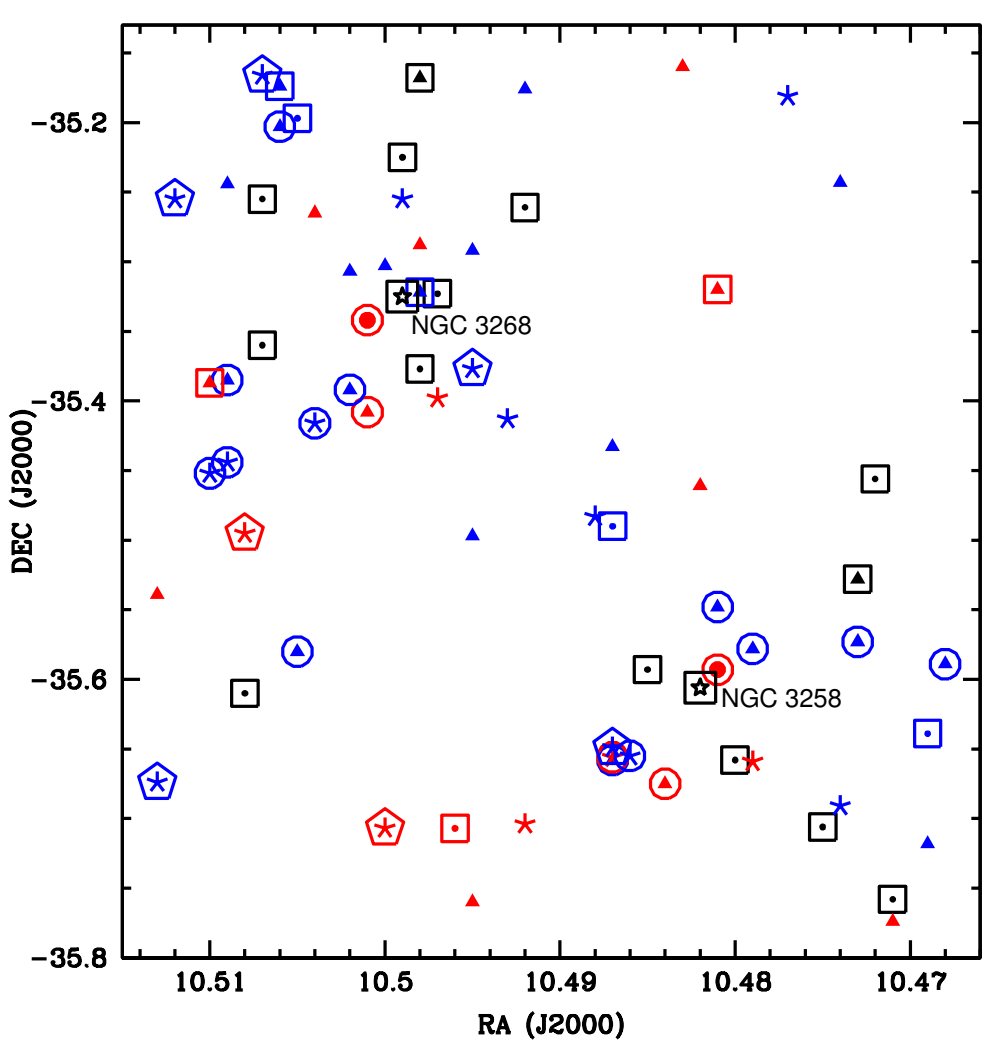

Figura 2.4: Distribución espacial proyectada de la muestra estudiada por Smith Castelli et al. (2012) (zona central del cúmulo). Las referencias son las mismas que para la figura anterior. El Norte se encuentra ubicado hacia arriba y el Este hacia la izquierda.

y las UCDs (Caso et al., 2013, 2014) que rodean a las dos galaxias gE ubicadas en la zona central del cúmulo de galaxias.

\subsection{OBJETIVOS ESPECÍfICOS DE LA TESIS}

El interés de la astrofísica en las galaxias elípticas no es sólo motivado por su morfología. Uno de los problemas actuales, con cuya respuesta definitiva aún no se cuenta, es:

¿Las galaxias elípticas enanas y gigantes son realmente del mismo tipo morfológico?, ¿comparten los mismos mecanismos de formación?, ¿tienen un origen común?

El análisis de las relaciones de escala entre parámetros tanto fotométricos como estructurales que siguen los distintos tipos de galaxias, conforma una herramienta de gran potencial para discriminar en grupos según sus características físicas e inferir en qué marco se los puede encuadrar, según los modelos actuales de origen y evolución de las galaxias. Estas relaciones de escala son también utilizados 
para separar las galaxias según sus componentes, por ejemplo bulbo, disco y halo.

Desde principios de los años 40, mediantes observaciones fotográficas de galaxias del Grupo Local (Baade, 1944), se inició una controversia con respecto a si la familia de galaxias de tipo temprano representa una única secuencia en algunas relaciones de escala o, por lo contrario, carecen de una relación intrínseca común debido a procesos físicos propios y diferentes. A pesar de la variedad que presentan sus caracteristicas dinámicas internas, su estructura y contenido estelar, las galaxias de tipo temprano también muestran un alto grado de homogeneidad. Sus parámetros fundamentales están fuertemente correlacionados con una muy pequeña dispersión intrínseca. Además de seguir una única relación color-magnitud, existen otras relaciones de escala que conectan propiedades observadas de las galaxias de tipo temprano. La más importante es el Plano Fundamental (Djorgovski \& Davis, 1987) y sus proyecciones sobre otros planos: relación brillo superficial efectivo-radio efectivo, conocida como relación de Kormendy (Kormendy, 1977), y relación luminosidad-dispersión central de velocidades o relación de Faber-Jackson (Faber \& Jackson, 1976). Estas relaciones fueron estudiadas para objetos brillantes, aunque en la actualidad se ha ido completando la zona correspondiente a brillos superficiales débiles.

Los primeros estudios centrados en el análisis de las poblaciones de galaxias dEs y Es en cúmulos se realizaron en los años 9o. Binggeli \& Cameron (1991) mostraron que las dEs podían ser bien descriptas por perfiles exponenciales, mientras que las Es presentaban un perfil de brillo mejor representado por un modelo de de Vaucouleurs. Por un lado, algunas relaciones entre los parámetros estructurales, como la relación de Kormendy, han sido interpretadas como mostrando dicotomías entre las Es y las dEs, lo que sugiere orígenes diferentes para cada grupo. Particularmente, la relación entre el brillo superficial efectivo promedio y la magnitud total muestra una segregación bastante clara, donde se pueden identificar una correlación que involucra desde enanas $\mathrm{dE}$ y dSph hasta $\mathrm{E}$ normales en el extremo opuesto, y otra correlación orientada prácticamente en forma perpendicular, que va desde las gEs hasta las cEs en el extremo opuesto. Los objetos de la zona de intersección de ambas correlaciones $\left(M_{B} \sim-18\right.$ mag) presentan particularidades en los perfiles de brillo (i.e. perfiles de múltiples componentes) lo cual puede llevar a incertezas en la clasificación. En la Figura -2.5 se pueden ver las relaciones entre la magnitud total en la banda B y dos parámetros estructurales efectivos, calculados a partir del perfil de brillo: el brillo superficial efectivo promedio $\left(\left\langle\mu_{e}\right\rangle\right)$ en la Figura $\bullet 2.5$ a el radio efectivo $\left(r_{e}\right)$ en la Figura $>2.5 b$.

Por otro lado, en la actualidad se utiliza un modelo más general para los perfiles de brillo que comprende al exponencial y de de Vau- 


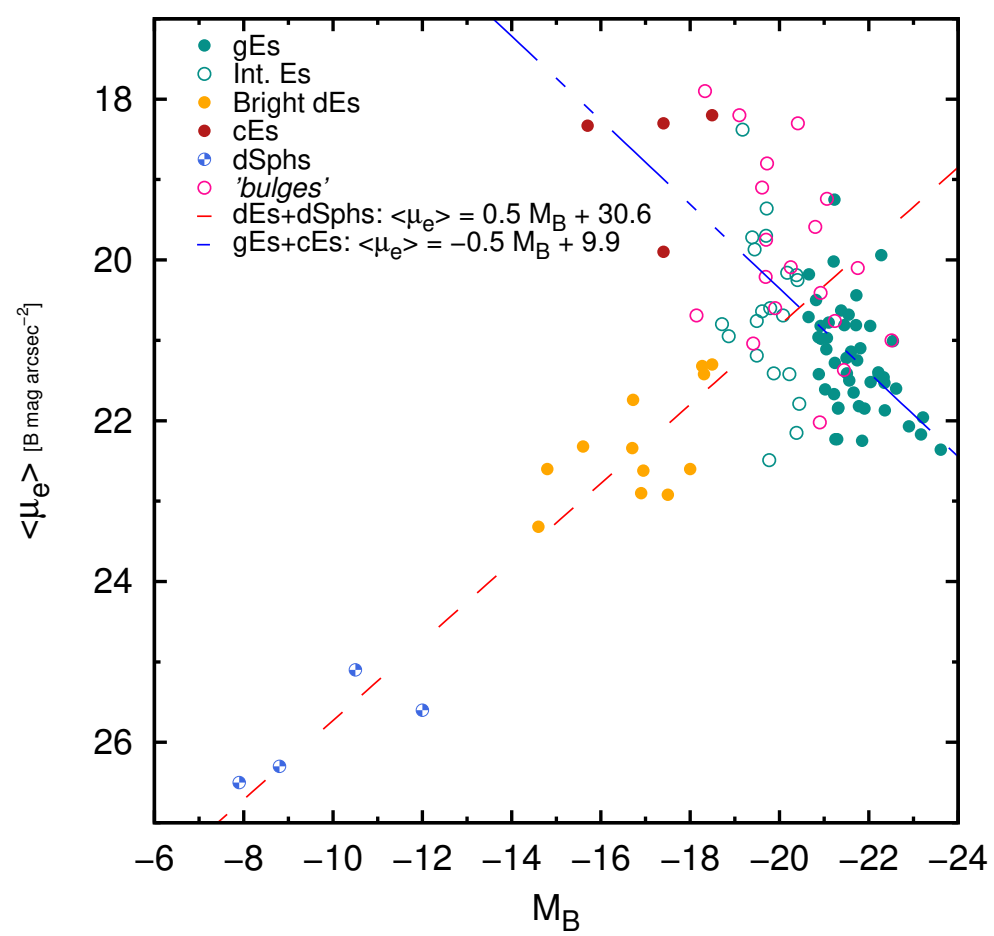

(a) Relación entre el brillo superficial efectivo promedio y la magnitud absoluta en el filtro B.

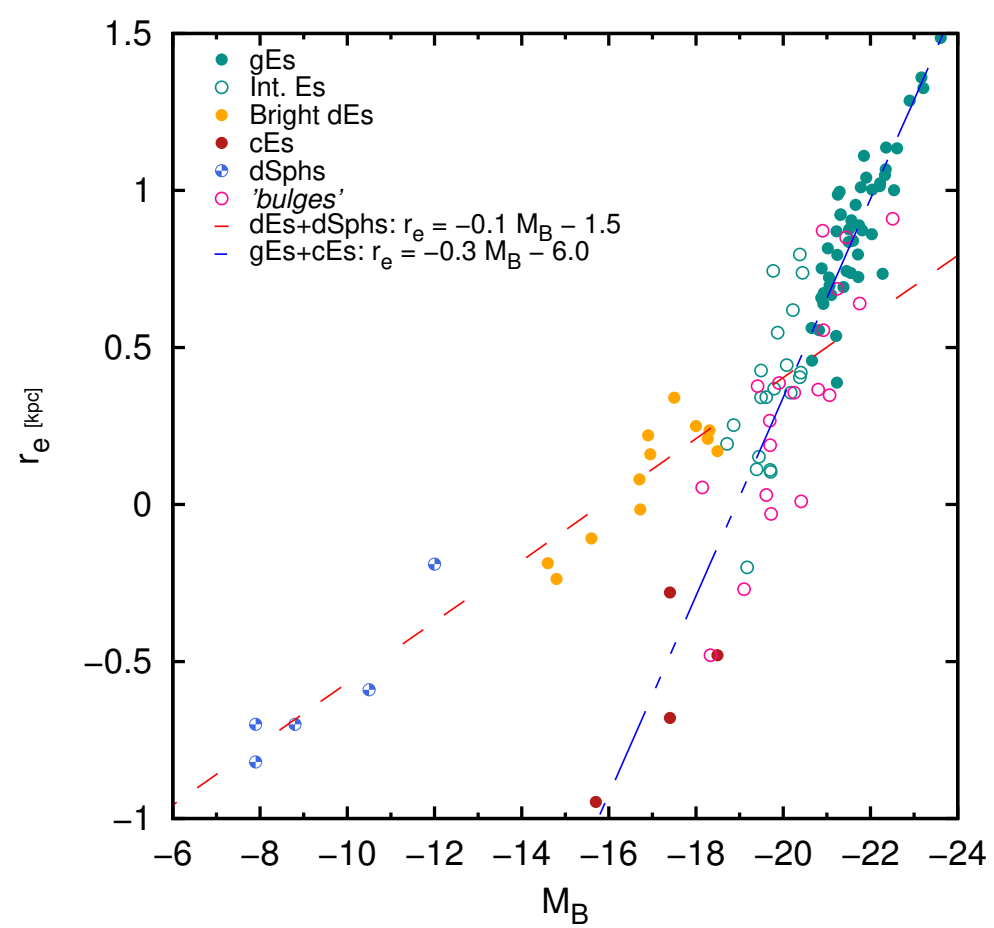

(b) Relación entre el radio efectivo y la magnitud absoluta en el filtro B.

Figura 2.5: Relaciones estructurales para galaxias de tipo temprano de diferentes cúmulos. Datos tomados de Bender et al. (1992). 
couleurs, el modelo de Sérsic (Sérsic, 1968), el cual puede describir tanto los perfiles de brillo de galaxias enanas (para índices de Sérsic $\mathrm{n}$ chicos), como gigantes (para $\mathrm{n}$ grandes). Varios autores argumentan que las relaciones de escala siguen naturalmente los parámetros que resultan del ajuste del modelo de Sérsic. Tanto las Es como las dEs (sin incluir las cEs) siguen una única relación entre la luminosidad y la forma del perfil de brillo, siendo esta última cuantificada por el citado índice de Sérsic $n$, lo que sugiere que tanto las Es brillantes como las dEs mas débiles son esencialmente el mismo tipo de objeto (Jerjen \& Binggeli, 1997; Binggeli \& Jerjen, 1998; Gavazzi et al., 2005). Vemos este efecto en la compilación realizada por Kormendy et al. (2009) que se muestra en la Figura 2.6, con datos de diferentes cúmulos. Debe notarse que las llamadas dSphs en este gráfico corresponden a las que aquí consideramos dEs. Volveremos sobre esta controversia en la sección de Resultados.

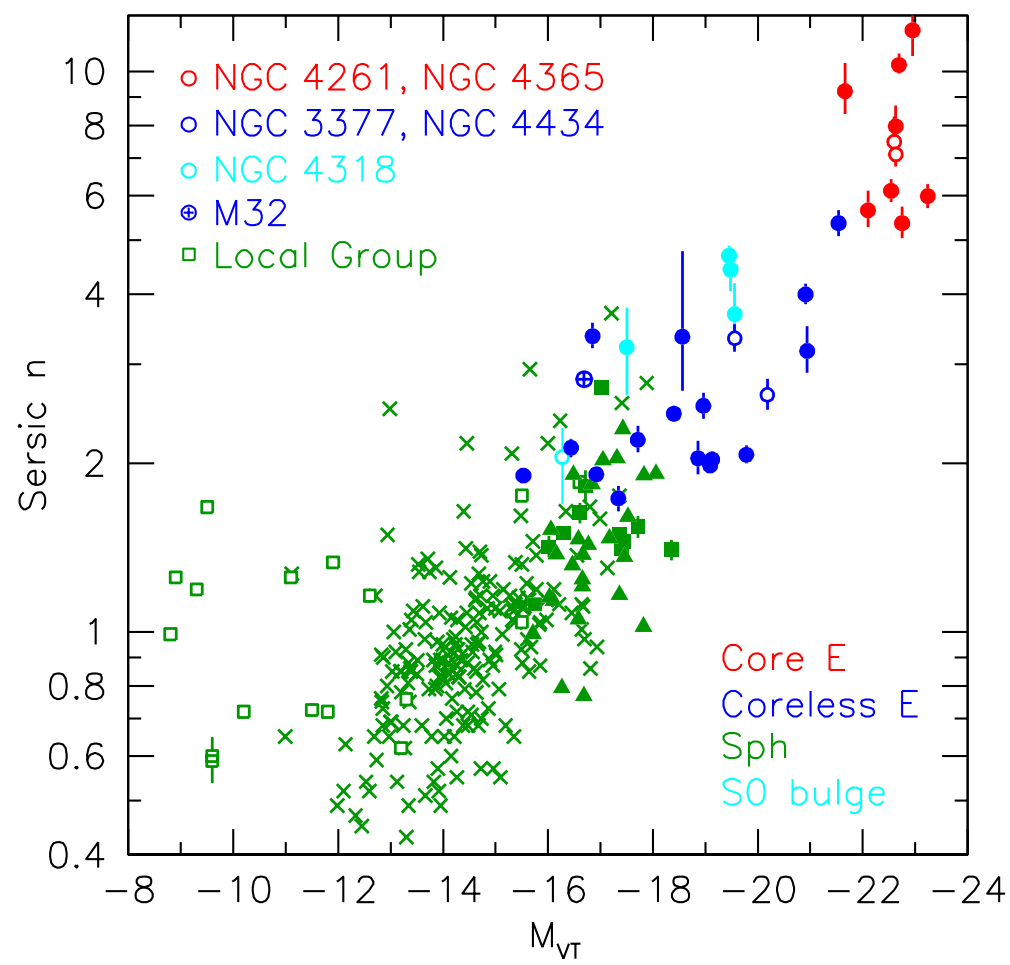

Figura 2.6: Relación magnitud total en el filtro $\mathrm{V}$ con el índice de Sérsic. Los puntos rojos, azules, verdes y turquesas representan Es tipo core, Es, Sphs y bulbos de galaxias SO del cúmulo de Virgo (Kormendy et al., 2009). Los triángulos verdes son dEs de Ferrarese et al. (2006). Los cuadrados vacios son dEs del Grupo Local (Caldwell 1999; Jerjen et al. 2000). 
Parte II

PERFILES DE BRILLO SUPERFICIAL 

El estudio fotométrico que se presenta en esta Tesis, se basó en imágenes CCD obtenidas de la cámara MOSAIC II del telescopio Blanco del Observatorio Interamericano de Cerro Tololo (CTIO, Chile), utilizando los filtros $\mathrm{R}$ de Kron-Cousins y $\mathrm{C}$ del sistema fotométrico de Washington (Canterna, 1976). Cada imagen cubre $36 \times 36 \mathrm{arcmin}^{2}$ que corresponde, aproximadamente, a $370 \times 370 \mathrm{kpc}^{2}$, a la distancia adoptada para el cúmulo de Antlia (Dirsch et al., 2003). La cámara MOSAIC II posee una resolución de 0.27 " / pix y esta constituida por 8 CCDs, por lo que fue necesario tomar una serie de imágenes levemente desplazadas entre sí ("dithering"), a fin de obtener una imagen final sin las separaciones ("gaps") debidas a los distintos CCDs. El campo central (campo 0 según nuestra denominación) fue observado en abril de 2002, mientras que en marzo de 2004 se observaron tres campos aledaños al anterior ubicados al N, NE y E (campos 1, 2 y 3, de aquí en más). En la Figura 3.1 se puede ver una composición, en el filtro $R$, de los campos estudiados, en donde también se muestra la ubicación de las galaxias gEs. Dado que los campos fueron observados en distintos turnos, y a fin de obtener una fotometría homogénea, se los seleccionó de modo que tuvieran áreas de superposición entre sí.

Cada uno de los campos mostrados en la Figura - 3.1 es, en realidad, producto de una combinación como promedio de una serie de imágenes, que se detallan en la Tabla 3.1. En dicha tabla también se muestran las coordenadas centrales de cada campo, así como el número de imágenes combinadas para cada campo y los tiempos de exposición individuales. Las dos últimas columnas dan las masas de aire y FWHM (Full Width Half Maximum) de las respectivas imágenes finales.

La reducción de las imágenes fue realizada con anterioridad al desarrollo de esta Tesis (para más detalles, Calderón, 2010). Para la misma se aplicó el procedimiento estándar utilizando el paquete de tareas mscred de IRAF ${ }^{1}$. Parte de las tareas de dicho paquete permiten realizar las correcciones por bias, flats, etc., mientras que otras tareas más específicas se utilizan para reducir cada imagen tipo mosaico a una única imagen. Se corrigió, asimismo, por efectos debidos a diferencias existentes entre las características de los 8 CCDs (ganancia, ruido de lectura, etc.).

1 IRAF (Image Reduction and Analysis Facility) es distribuido por National Optical Astronomy Observatories (NOAO) 


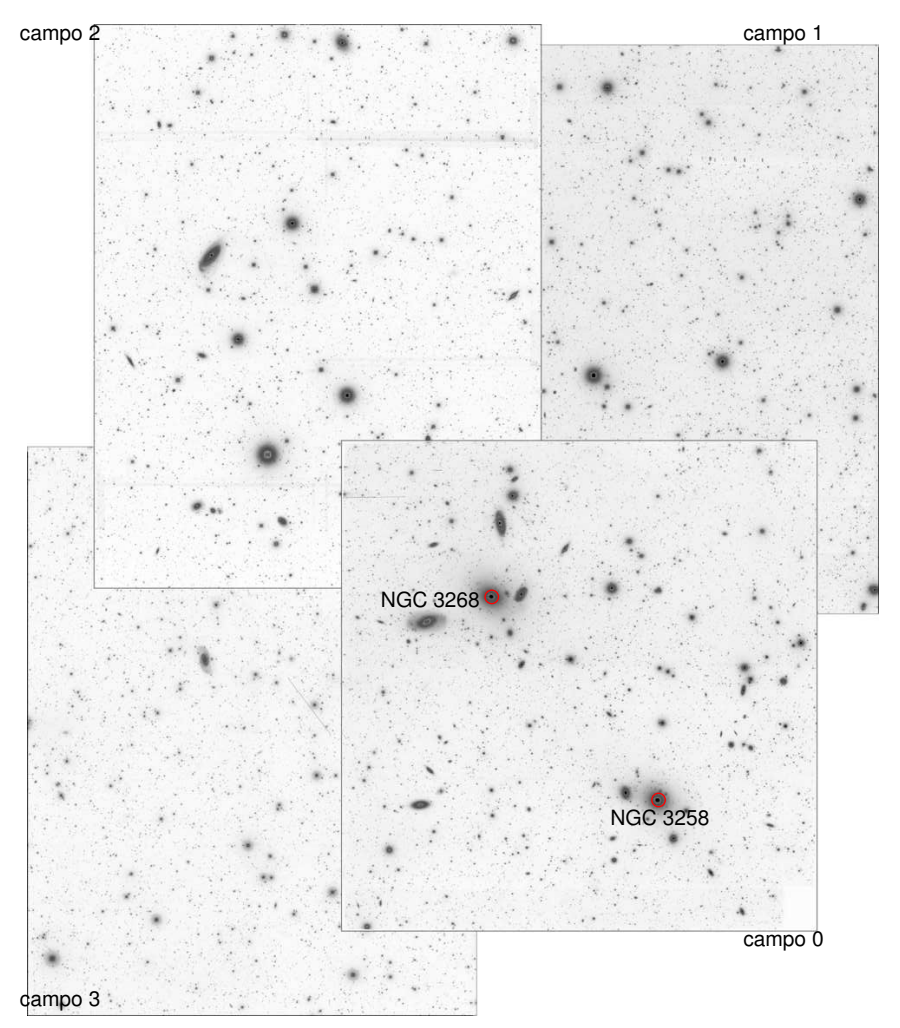

Figura 3.1: Composición de los cuatro campos del cúmulo de galaxias de Antlia que se utilizaron para la identificación y posterior fotometría de las galaxias que componen la muestra analizada.

Las calibraciones al sistema de magnitudes estándar se obtuvieron, para el campo 0, de Dirsch et al. (2003), mientras que para los restantes campos se utilizó Calderón (2010). Cabe aclarar que, además de pasar al sistema estándar, se transforma el filtro $R$ de Kron-Cousins al $T_{1}$ de Washington para trabajar con ambos filtros en este último sistema. Se eligió observar con el filtro R porque Geisler (1996) ha mostrado que este último es más eficiente que el $\mathrm{T}_{1}$, y sólo existe una diferencia de punto de cero $\mathrm{R}-\mathrm{T} 1=0.02 \mathrm{mag}$ (Dirsch et al., 2003) entre ambas magnitudes. Por completitud, se detallan las ecuaciones de calibración utilizadas, que se pueden encontrar en los trabajos citados anteriormente:

$$
\begin{aligned}
T_{1} & =\left(m_{R}+0.02\right)+a_{1}+a_{2} X_{R}+a_{3}\left(C-T_{1}\right) \\
C & =m_{C}+b_{1}+b_{2} X_{C}+b_{3}\left(C-T_{1}\right)
\end{aligned}
$$

donde los coeficientes y sus errores se encuentran detallados en la Tabla 3.2, $m_{R}, m_{C}$ son las magnitudes instrumentales, $X_{R}, X_{C}$ las masas de aire en cada filtro, y $\mathrm{T}_{1}$ y $\mathrm{C}$ las magnitudes en el sistema estándar. 
Todas las magnitudes y colores presentados en este trabajo fueron corregidas por absorción y enrojecimiento. El exceso de color $\mathrm{E}(\mathrm{B}-\mathrm{V})$ fue obtenido de Schlafly \& Finkbeiner (2011) y usamos las relaciones $\mathrm{E}\left(\mathrm{C}-\mathrm{T}_{1}\right)=1.97 \mathrm{E}(\mathrm{B}-\mathrm{V})$ (Harris \& Canterna, 1977) y $A_{R} / A_{V}=0.75$ (Rieke \& Lebofsky, 1985) para calcular la absorción y el enrojecimiento en el sistema de Washington.

Como ya se ha mencionado, a consecuencia de utilizar imágenes de dos turnos diferentes y del gran tamaño de las mismas, es esperable que existan diferencias entre las magnitudes de los puntos de cero, para cada filtro, entre los cuatro campos. Para estimar tales diferencias ("offsets") se utilizaron fuentes puntuales que están ubicadas en las áreas de superposición entre los distintos campos, tanto en los filtros $C$ como $T_{1}$. Se calcularon las diferencias promedio en los puntos de cero de los campos 1, 2, y 3 con respecto al 0 . Finalmente, se aplicaron tales diferencias en puntos de cero y de ese modo todas las magnitudes $\mathrm{C}_{\text {y }} \mathrm{T}_{1}$ quedaron referidas al campo central, que es el que se toma como referencia. Dichos "offsets" resultaron mayores para el filtro $\mathrm{T}_{1}(\approx 0.1 \mathrm{mag})$, y entre 0.01 y $0.04 \mathrm{mag}$ para el filtro $\mathrm{C}$.

Además de las imágenes MOSAIC II, se cuenta con espectros de resolución media, obtenidos con GEMINI-GMOS (programas GS-2011AQ-35 and GS-2013A-Q-37) y con VIMOS-VLT (programa 79.B-0480), ambos instrumentos en modo multi-objeto. En todos los casos, las máscaras fueron preparadas para obtener espectros de galaxias, UCDs y cúmulos globulares en forma conjunta, además de eventuales objetos de fondo. Para esta Tesis, sólo se utilizaron las velocidades radiales de las galaxias para confirmar su membresía al cúmulo. La descripción de las observaciones, reducción, y medición de velocidades radiales están dadas en Caso et al. (2014) para los espectros de GMOS, que es un trabajo que presenta el estudio de cúmulos globulares brillantes y UCDs de NGC 3268, mientras que para los espectros VIMOS están dadas en Caso et al. (en preparación) que es un estudio cinemático global del cúmulo de Antlia. 


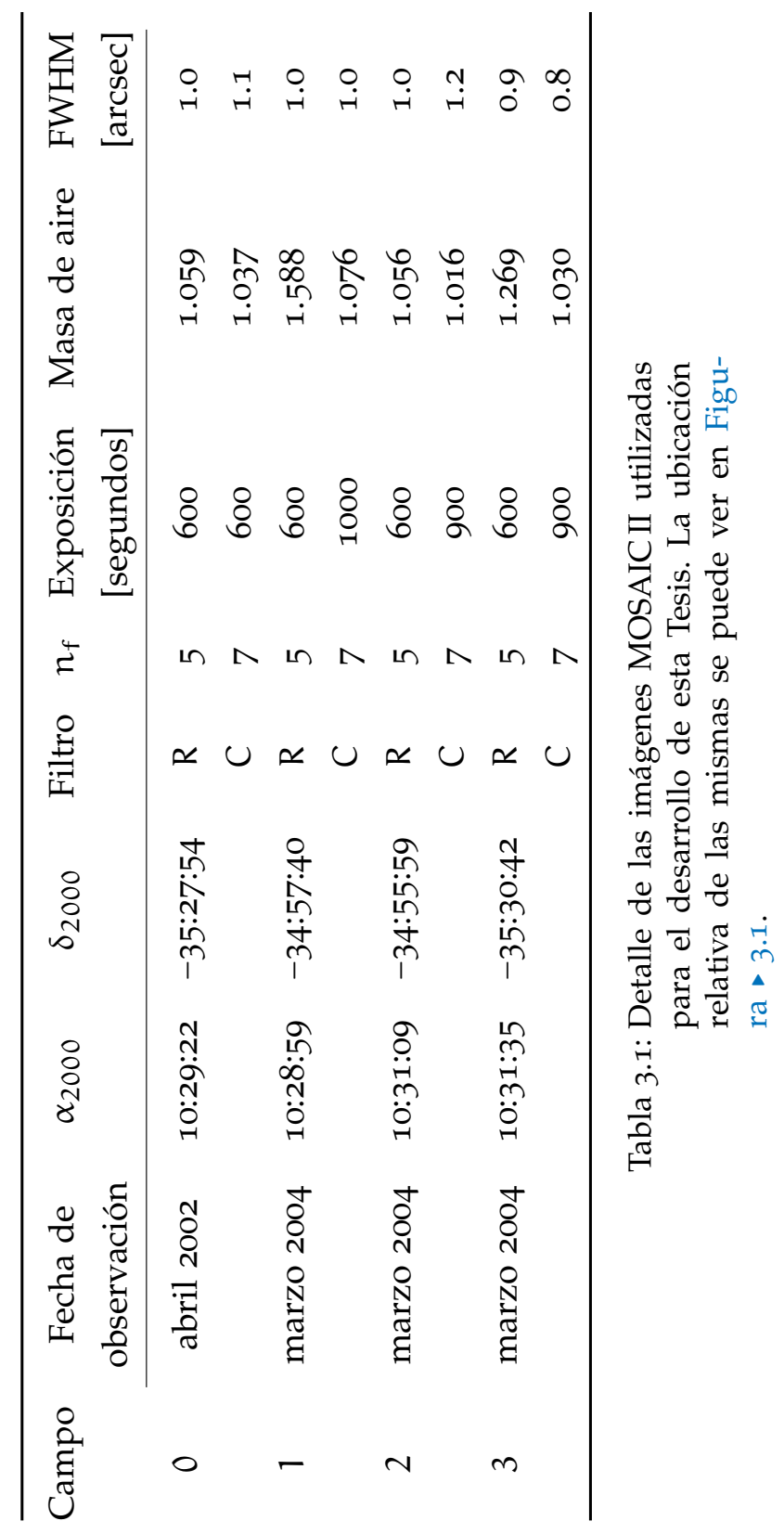




\begin{tabular}{clcccccc}
\hline & & $\mathrm{a}_{1}$ & $\mathrm{a}_{2}$ & $\mathrm{a}_{3}$ & $\mathrm{~b}_{1}$ & $\mathrm{~b}_{2}$ & $\mathrm{~b}_{3}$ \\
\cline { 3 - 8 } campo 0 & Coef. & 0.71 & -0.07 & 0.033 & -0.104 & -0.02 & 0.121 \\
& Error & 0.01 & 0.01 & 0.003 & 0.02 & 0.01 & 0.005 \\
campos 1, 2 y 3 3 & Coef. & 0.608 & -0.140 & 0.0184 & -0.059 & -0.418 & 0.111 \\
& Error & 0.003 & 0.001 & 0.002 & 0.004 & 0.006 & 0.005 \\
\hline
\end{tabular}

Tabla 3.2: Coeficientes y errores de la ecuación de calibración (Ecuación 3.1). 

En la siguiente sección se describe el cálculo de los perfiles de brillo de galaxias de la muestra utilizada.

Las galaxias elípticas tienen perfiles de brillo superficial que decrecen suavemente con el radio. Como en todo aspecto en la Naturaleza, este comportamiento (aunque muy usual) puede tener excepciones. Estos perfiles permiten describir la estructura (visible) de las galaxias y conforman una herramienta observacional para testear predicciones sobre modelos de formación de galaxias. Además, el análisis de la fotometría obtenida a partir de los perfiles de brillo permite revelar la distribución de masa estelar si se tiene una determinación apropiada del cociente $M / L$, donde las estrellas son la principal componente bariónica. Más aún, si se cuenta con fotometría en diferentes bandas, se pueden explorar las propiedades subyacentes de población estelar, tales como evolución química y formación estelar.

\subsection{CÁlculo De los PERFiles de BRILlo}

Las isofotas de galaxias Es pueden ser razonablemente descriptas por elipses matemáticas, y éstas ser utilizadas para obtener un perfil de brillo radial, i. e. la intensidad media en función del radio. Además, es posible obtener de los perfiles radiales los parámetros geométricos que definen la elipse, como por ejemplo elipticidad ( $\epsilon$ ), ángulo de posición (PA), etc., que resultan fundamentales al momento de realizar un análisis cuantitativo del perfil de brillo superficial.

La imagen obtenida por un detector CCD es la proyección sobre el plano del cielo de un objeto tridimensional. Como se mencionó anteriormente (Capítulo $\S 1$ ), las principales componentes de una galaxia, en forma general, son un bulbo esferoidal y un disco. En la proyección sobre el plano del cielo, cualquiera de las componentes da lugar a isofotas elípticas, incluso si son tomadas juntas. Los parámetros geométricos que definen estas elipses proyectadas son importantes en la comprensión de la distribución de la luminosidad de una galaxia. En esta sección se describe el procedimiento de ajuste de isofotas mediante elipses matemáticas.

Cualquier elipse puede se completamente descripta por cinco parámetros: semiejes mayor y menor ( $\mathrm{a} y \mathrm{~b}$ ), ángulo de posición del semieje mayor, elipticidad y coordenadas del centro $\left(x_{c}\right.$ e $\left.y_{c}\right)$. El principio básico consiste en ajustar una serie de isofotas, para diferentes 
semiejes mayores, en donde la elipse matemática (dado un semieje mayor a) constará de una elipticidad dada por $\epsilon=1-b / a$, un PA para la inclinación del semieje mayor $\left(0^{\circ}<\mathrm{PA}<180^{\circ}\right)$, y las coordenadas del centro de la elipse.

El ajuste de las elipses matemáticas fue realizado mediante la tarea ELLIPSE de IRAF que realiza un procedimiento iterativo descripto por Jedrzejewski (1987). El primer paso consiste en definir los parámetros geométricos de una elipse inicial, para un semieje mayor intermedio. La intensidad (I) varía a lo largo de la elipse inicial de forma periódica y puede ser aproximada por la siguiente ecuación:

$$
I=I_{0}+\sum_{n=1}^{\infty} A_{n} \operatorname{sen}(n E)+B_{n} \cos (n E),
$$

donde $I_{0}$ es la intensidad media a lo largo de la elipse, $A_{n}$ y $B_{n}$ con $n=1,2, \ldots$ son las amplitudes de los armónicos de la serie de Fourier y E es la anomalía excéntrica. En la práctica, no pueden calcularse con precisión momentos superiores a $n=4$. Si las isofotas fuesen elipses perfectas, los coeficientes con $n \leq 2$ serían los únicos no nulos. Para una galaxias real, las isofotas no son elipses perfectas. El proceso de ajuste comienza suponiendo que los dos primeros órdenes son no nulos,

$$
I=I_{0}+A_{1} \operatorname{sen}(E)+B_{1} \cos (E)+A_{2} \operatorname{sen}(2 E)+B_{2} \cos (2 E) .
$$

Cada uno de los cuatro coeficientes $\left(A_{1}, A_{2}, B_{1}\right.$ y $\left.B_{2}\right)$ está relacionado con uno de los parámetros geométricos de la elipse y describe cuánto se desvía de la elipse inicial y de la isofota ajustada. A continuación se aplican correcciones a la elipse inicial modificando levemente los parámetros iniciales y el procedimiento continúa iterativamente hasta que se cumple uno de los siguientes criterios:

- La amplitud de algunos de los coeficientes está por debajo de un cierto valor de tolerancia.

- Se llega al máximo de iteraciones establecidas por el usuario.

Cuando se cumple alguno de los criterios, se obtienen los parámetros geométricos de la mejor elipse ajustada, i. e. las coordenadas del centro, $\epsilon$, PA y la intensidad media $\mathrm{I}_{0}$.

Una vez que se obtienen los mejores parámetros que determinan la elipse, se continúa ajustando el tercer y cuarto armónico mediante un ajuste por mínimos cuadrados de

$$
I=I_{0}+A_{3} \operatorname{sen}(3 E)+B_{3} \cos (3 E)+A_{4} \operatorname{sen}(4 E)+B_{4} \cos (4 E) .
$$

En la ecuación anterior, los coeficientes $\left(A_{3}, A_{4}, B_{3}\right.$ y $\left.B_{4}\right)$ determinan la desviación de la isofota de la elipse perfecta (para la cual de- 
berían ser nulos). En particular, el coeficiente $\mathrm{B}_{4}$ indica la presencia de una estructura disky $\left(\mathrm{B}_{4}>0\right)$ o boxy $\left(\mathrm{B}_{4}<0\right)$. En la Figura $>$ 4.I se muestra el efecto sobre las isofotas de los coeficientes no nulos de cuarto orden del desarrollo de Fourier (Figura $>4.1 \mathrm{a}$ ), junto con la galaxia elíptica NGC 4660 que presenta una componente tipo disky en su perfil de brillo (Figura 4.Ib), mientras que NGC 5322 presenta isofotas tipo boxy (Figura -4 .Ic). Tener en cuenta que la denominación utilizada por Bender et al. (1988) en las figuras intercambia los coeficientes del desarrollo de Fourier B por A, respecto a esta Tesis.
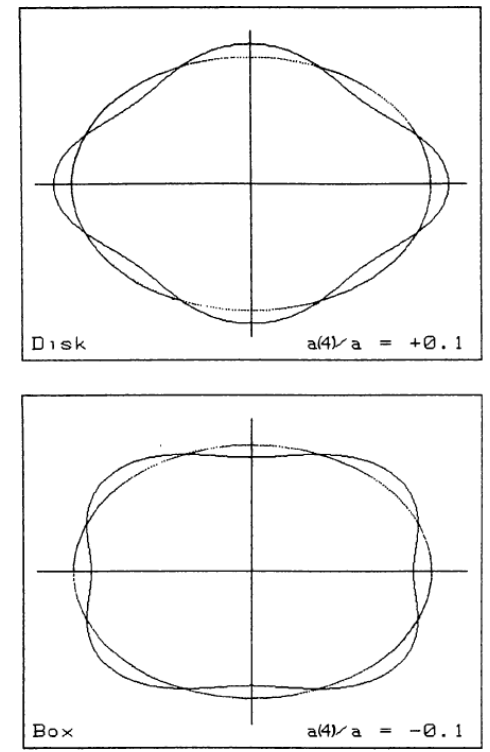

(a) Diagrama esquemático de isofotas tipo disky (arriba) y tipo boxy (abajo).

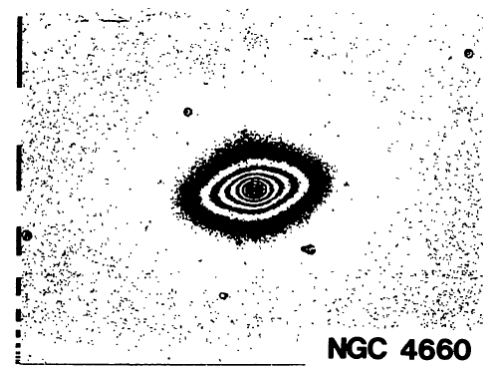

(b) Imagen de la galaxia elíptica NGC 4660 que ilustra las estructuras tipo disky con $\mathrm{B}_{4} / \mathrm{a} \sim$ +0.03 .

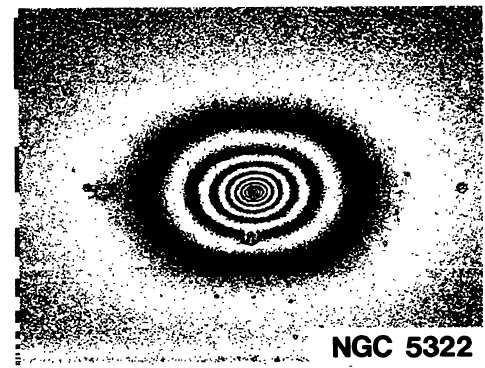

(c) Imagen de la galaxia elíptica NGC 5322 que ilustra las estructuras tipo boxy con $\mathrm{B}_{4} / \mathrm{a} \sim$ -0.01 .

Figura 4.1: Ejemplos de isofotas tipo disky y boxy, tener en cuenta que la denominación utilizada en las figuras intercambia los coeficientes del desarrollo de Fourier B por A. Figuras tomadas de Bender et al. (1988).

La forma de las isofotas correlaciona con varias propiedades de las galaxias elípticas (Kormendy \& Djorgovski, 1989), como ser propiedades cinemáticas, intensidad de emisión en rayos-X, etc. Esto motivó a Kormendy \& Bender (1996) a proponer una modificación del esquema de clasificación de Hubble para las galaxias elípticas. Sugirieron que se pueden dividir en dos sub-clases de acuerdo a la forma de sus isofotas:

- E(b) Galaxias elípticas con isofotas tipo boxy: Generalmente son muy luminosas $\left(M_{V} \lesssim-22\right.$ mag.) y están soportadas por la 
dispersión anisótropa de velocidades. Estos objetos casi isotérmicos muestran una lenta o casi nula velocidad de rotación $\left(\nu_{\text {rot }} / \sigma\right)<1$ a lo largo del eje mayor o menor. Es posible detectar emisión en rayos-X debido al gas caliente $\left(9.8 \mathrm{~L}_{\odot} \geq \log \left(\mathrm{L}_{\mathrm{B}}\right) \geq\right.$ $\left.11.2 \mathrm{~L}_{\odot}\right)$ o emisión en radio $(\sim 1020-1025 \mathrm{~W} / \mathrm{Hz})$. Se encuentran peculiaridades en los centros, lo que indicaría núcleos cinemáticamente desacoplados, que podría ser un subproducto de fusiones estelares masivas. A través de imágenes profundas del HST se han detectado perfiles tipo core en estas galaxias (Faber et al., 1997).

- E(d) Galaxias elípticas con isofotas tipo disky: Usualmente son galaxias más débiles $\left(M_{V} \gtrsim-20.5 \mathrm{mag}\right)$ soportadas por una rotación ordenada alrededor del eje menor $\left(v_{\text {rot }} / \sigma\right) \sim 0.2-1.5$. Con la resolución del HST, se encontró que los perfiles suelen ser tipo power-law en el centro. No se registran peculiaridades cinemáticas en sus centros ni emisión en rayos- $X\left(\log \left(L_{B}\right) \lesssim 9.2 L_{\odot}\right)$.

Retomando ahora al procedimiento para obtener los perfiles de brillo, la última etapa mencionada es repetida (a partir de la Ecuación 4.2) para el siguiente semieje mayor, definido por un "paso" preestablecido, que puede ser positivo o negativo, i. e. permite continuar hacia radios menores o mayores. El proceso sigue hasta alcanzar el límite fijado, que está determinado generalmente por el tamaño de la galaxia o por el nivel de ruido de la imagen (típicamente un porcentaje del nivel del cielo).

La elipticidad y el ángulo de posición no son muy representativos ("realistas") cerca del centro, por problemas de definición matemática y debido al efecto del seeing en la imagen, que distribuye la luz cercana al centro del objeto hacia radios mayores. Se presentó un análisis al respecto en la Sección § 2.3. En la práctica, además, las imágenes pueden presentar problemas técnicos que degradan la calidad del ajuste de las isofotas, por ejemplo, la presencia de objetos puntuales muy brillantes localizados cerca de la isofota calculada, pueden variar el resultado del ajuste. Para corregir este efecto, previamente a utilizar la tarea ELLIPSE en cada imagen, se enmascaran las regiones con defectos o los objetos puntuales muy brillantes.

\subsection{PROCEDIMIENTO ADOPTADO}

Considerando que el número de galaxias cuyos perfiles se pretende determinar supera los 150, y que el proceso de obtención de los perfiles consta de varias etapas que pueden automatizarse a fin de homogeneizar los resultados, para esta Tesis se desarrollaron una serie de programas informáticos. Los mismos se unificaron en un código global que utiliza principalmente tareas de IRAF, por lo que ha sido 
escrito en su propio lenguaje. Una vez calculados los perfiles, este código realiza una serie de gráficos para cada galaxia, que se muestran en el Apéndice $\S B$. Se detallará a continuación el procedimiento adoptado para la obtención de los perfiles, incluyendo el uso del código.

Las imágenes MOSAIC tienen un tamaño de aproximadamente $9.000 \times 9.000$ píxeles, por lo que son demasiado grandes para trabajar con cada galaxia de la muestra seleccionada, la mayoría de las cuales abarcan regiones de pocos píxeles. Se optó entonces por identificar cada galaxia (catalogada en la literatura o no) y determinar sus coordenadas sobre el sistema de referencia de cada imagen (recordar que trabajamos con 4 campos MOSAIC, ver Figura - 3.I). Se procedió a recortar, para cada galaxia, una sección centrada en la misma de $500 \times 500$ píxeles, aunque esta dimensión depende del tamaño del objeto y su ubicación sobre la imagen: (i) el tamaño de la imagen recortada tiene que ser lo suficientemente grande como para permitir estimar un valor del cielo local, lo más cercano posible al objeto; (ii) en el caso de objetos cercanos al borde de la imagen MOSAIC, se tomaron las dimensiones adecuadas para la imagen recortada.

Una vez recortada la galaxia de la imagen MOSAIC, se obtiene un valor de cielo que se restará a la imagen recortada. Este valor se calcula utilizando la tarea IMEXAMINE, considerando zonas alrededor del objeto de interés, que no posean ninguna fuente apreciable; el promedio de estos valores representa una buena medida del cielo local alrededor del objeto. Este procedimiento equivale a restar un plano de intensidad constante a la imagen recortada, lo cual podría mejorarse si se utilizara la ecuación general de un plano con cualquier inclinación para tener en cuenta pequeños gradientes que pudieran existir. Las pruebas que hemos realizado indican, que al ser mayormente objetos pequeños, resulta innecesario contemplar esta posibilidad. Por otro lado, se realiza una segunda corrección residual del cielo al perfil calculado, como se explica más adelante.

Contamos con imágenes en los filtros $T_{1}$ y $C$ de Washington ya registradas, por lo que tenemos, para cada objeto, dos imágenes recortadas (una en cada filtro) a las que se le ha sustraído el valor del cielo. El último paso antes de calcular el perfil de brillo, es realizar una máscara con los objetos o artefactos que pueden afectar la distribución de brillo y que no aportan a la luz del objeto de interés, por ejemplo estrellas de la Vía Láctea, defectos de la imagen (píxeles calientes, zonas saturadas, etc). Dichas máscaras se realizaron sobre cada imagen recortada (para cada galaxia) en cada filtro mediante la tarea BADPIXIMAGE, y se confeccionó una lista de los píxeles a en- 
mascarar utilizando la funcionalidad de "regiones" del DS9 ${ }^{1}$. De este modo, se cubrieron objetos y defectos de la imagen de distintas formas y tamaños, adecuándose a la necesidad. Además, se tuvieron en cuenta objetos ocultos dentro de la luz de la galaxia, utilizando diferentes niveles de despliegue ( $z 1$ y $z 2$ en la tarea DISPLAY). A pesar de que implica una tarea cuidadosa extra para cada galaxia, la máscara final resulta ser más precisa que la que se puede generar directamente en el entorno de la tarea ELLIPSE.

El siguiente paso fue ejecutar la tarea ELLIPSE sobre las imágenes recortadas en cada filtro, lo que se hizo en forma iterativa para obtener los parámetros geométricos iniciales. Estos parámetros son:

1. xо, yo: coordenadas centrales del objeto.

2. PAO: ángulo de posición de la isofota inicial.

3. ELLIPO: elipticidad de la isofota inicial.

4. SMAO: semieje mayor de la isofota inicial.

5. MINSMA: semieje mayor de la isofota más interna.

6. MAXsMA: semieje mayor de la isofota mas externa.

Para cada galaxia, se han determinado estos parámetros iniciales de forma que el ajuste de isofotas fuera lo más estable posible. El valor MINSMA se tomó lo más pequeño posible para poder mapear la zona central (dentro de las limitaciones de la resolución de las imágenes). Como las imágenes recortadas tienen el cielo restado, después de una inspección visual se tomó el valor de MAxsma para el cual el brillo de la galaxia se aproximaba al nivel del cielo, esto se puede notar en los perfiles que se presentan en el Apéndice $\S B$. Existe un último parámetro geométrico a definir, relacionado con el ajuste de isofotas, que es la cantidad de píxeles que se deja entre dos isofotas consecutivas ("paSo" o STEP); se adoptó un valor pequeño para los objetos de MAXSMA menores para tener un perfil bien definido, y se tomó un STEP mayor para los objetos más grandes. Este procedimiento se realizó para la imagen recortada en el filtro $R$ de cada objeto, dado que las imágenes en este filtro poseen mejor resolución que las C. El producto de ELLIPSE consiste en una tabla (ASCII), que se utiliza posteriormente como entrada para obtener el perfil de brillo de la galaxia en el filtro C. Tanto en el filtro $R$ como en el $C$, se realizó un primer ajuste con ELLIPSE permitiendo que los parámetros geométricos variaran libremente a lo largo del ajuste de isofotas. Esto posibilita determinar la existencia de regiones del perfil donde la evolución de los parámetros geométricos respecto al radio, presente alguna particularidad que puede relacionarse con una rotación de isofotas y que podría indicar la presencia

1 SAOImage DS9 es un conjunto de programas orientados a la visualización y procesamiento de imágenes astronómicas. Se encuentra disponible en http://ds9.si. edu/site/Home.html 
de más de una componente en el perfil de brillo. En algunos casos, en que la imagen recortada presenta defectos que pueden afectar el ajuste, se decidió (analizando cada caso en particular) fijar alguno de los parámetros geométricos. Esta última forma de operar también se empleó en aquellos casos en que la galaxia fuese tan débil que el perfil de brillo resultaba fuertemente dependiente de la elección de los parámetros iniciales. Las galaxias que caen dentro de este grupo son las dEs más débiles o las dSphs de radios un poco mayores que $\sim 10^{\prime \prime}$. Notar que fijar los parámetros geométricos para el ajuste del perfil, impide la evolución de los mismos en función del radio equivalente, pero no modifica las magnitudes integradas totales obtenidas para cada filtro.

Como se mencionó anteriormente, una vez obtenido el perfil de brillo, se procedió a evaluar la calidad del nivel de cielo adoptado originalmente. Esto se realizó considerando la curva de crecimiento del perfil a medida que se aleja del centro de la galaxia. El criterio adoptado para mejorar la estimación del cielo fue que para $\mu \sim 27.5 \mathrm{mag} \operatorname{arcsec}^{-2}$ el perfil tuviera un brillo lo más constante posible, lo que indicaría que el objeto en cuestión ya no aporta más luz que la que aporta el cielo. Este proceso de "enderezar" el cielo se realizó iterativamente para cada galaxia de la muestra y en todos los casos, el valor necesario para esta corrección fue menor a 10 ADUs.

\subsubsection{Ajuste numérico del perfil}

Para parametrizar el perfil de brillo de cada galaxia de la muestra considerada, se utilizó el ajuste unidimensional de un modelo de Sérsic (Sérsic, 1968), que en unidades de intensidad, adopta la siguiente forma,

$$
\mathrm{I}(\mathrm{r})=\mathrm{I}_{e} \cdot e^{-\mathrm{b}_{\mathrm{n}}\left[\left(\frac{\mathrm{r}}{\mathrm{r}_{\mathrm{e}}}\right)^{1 / \mathrm{n}}-1\right],}
$$

mientras que en unidades de magnitudes por segundo de arco cuadrado,

$$
\mu(r)=\mu_{e}+1.0857 \cdot b_{n}\left[\left(\frac{r}{r_{e}}\right)^{1 / n}-1\right]
$$

donde $r_{e}$ es el radio efectivo, $\mu_{e}$ es el brillo superficial efectivo y $n$ es el índice de forma de Sérsic que es una medida de la concentración de luz del perfil. La función $b_{n}$ depende del parámetro de forma $n$ y se obtiene numéricamente resolviendo la ecuación (Ciotti, 1991),

$$
\frac{\Gamma(2 n)}{2}=\gamma\left(2 n, b_{n}\right)
$$


donde $\Gamma(x)$ es la función gamma completa y $\gamma(a, x)$ la función gamma incompleta. Una forma alternativa del modelo de Sérsic, en términos de intensidad, es la siguiente

$$
I(r)=I_{0} e^{-\left(\frac{r}{r_{0}}\right)^{N}}
$$

donde $I_{0}$ es el brillo superficial central, $r_{0}$ es un parámetro de escala y $N=1 / n$. Si transformamos la ecuación anterior a unidades de magnitud por segundo de arco cuadrado,

$$
\mu(r)=\mu_{0}+1.0857\left(\frac{r}{r_{0}}\right)^{N}
$$

que es la forma que se utilizó para el ajuste de los perfiles observados Se puede obtener una transformación entre los parámetros de escala y efectivos utilizando las ecuaciones 4.4 y 4.8 :

$$
I_{0} e^{-\left(\frac{r}{r_{0}}\right)^{N}}=I_{e} e^{-b_{n}\left[\left(\frac{r}{r_{e}}\right)^{1 / n}-1\right]}=e^{b_{n}} I_{e} e^{-b_{n}\left(\frac{r}{r_{e}}\right)^{1 / n}}
$$

Considerando $r=0$, se obtiene,

$$
\begin{aligned}
I_{0} & =e^{b_{n}} I_{e} \\
\text { y luego, } r_{0} & =b_{n}^{-n} r_{e}
\end{aligned}
$$

El flujo integrado total del modelo se obtiene a partir de la integración del perfil entre $r=0$ e infinito:

$$
\mathrm{F}_{\mathrm{T}}=\int_{0}^{\infty} 2 \pi \mathrm{I}(\mathrm{r}) \mathrm{rdr}=2 \pi \int_{0}^{\infty} e^{-\mathrm{b}_{\mathrm{n}}\left[\left(\frac{\mathrm{r}}{\mathrm{re}_{\mathrm{e}}}\right)^{1 / n}-1\right]} \mathrm{rdr}
$$

Con el cambio de variables,

$$
\begin{aligned}
& x=b_{n}\left(\frac{r}{r_{e}}\right)^{1 / n} \\
& r=r_{e} b_{n}\left(\frac{x}{b_{n}}\right)^{n},
\end{aligned}
$$

se obtiene el diferencial: $d r=n r_{e} b_{n}^{-1}\left(\frac{x}{b_{n}}\right)^{n-1} d x$. Entonces, la ecuación 4.12 se puede re-escribir como,

$$
\mathrm{F}_{\mathrm{T}}=2 \pi r_{e}^{2} b_{n}^{-2 n} I_{e} n e^{b_{n}} \int_{0}^{\infty} e^{-x} x^{2 n-1} d x
$$

Utilizando la función Gamma, $\Gamma(\mathrm{m})$, se puede resolver la integral anterior (Abramowitz \& Stegun, 1972), obteniendo:

$$
F_{T}=2 \pi r_{e}^{2} b_{n}^{-2 n} I_{e} n e^{b_{n}} n \Gamma(2 n) .
$$


La magnitud integrada resulta de transformar la ecuación anterior,

$$
\begin{aligned}
m= & C_{0}-2.5 \log \left(2 \pi r_{e}^{2} b_{n}^{-2 n} I_{e} n e^{b_{n}} n \Gamma(2 n)\right) \\
m= & \mu_{0}-1.99-5 \log \left(r_{e}\right)+5 n \log \left(b_{n}\right)- \\
& -2.5 \log (n \Gamma(2 n)),
\end{aligned}
$$

donde $\mu_{0}$ es el brillo superficial central.

Los ajustes se realizaron mediante la tarea NFIT1D de IRAF, que implementa el test estadístico de $\chi^{2}$ a través del algoritmo de LevenbergMarquardt. El segundo de arco central del perfil no fue incluido en los ajustes para evitar efectos del seeing. De todas formas, mostraremos a continuación que los ajustes no se ven sensiblemente afectados para galaxias con $n \lesssim 4$ (ver Sección § 4.3). En la mayoría de los casos, se pudo realizar el ajuste del perfil con un solo modelo de Sérsic con residuos menores a $0.5 \mathrm{mag}$. Es necesario aclarar que los parámetros que se utilizarán para estudiar las relaciones de escala, han sido derivados sin intentar descomposiciones del perfil en bulbo-disco. Esto podría parecer un inconveniente en las galaxias $\mathrm{S} 0$ s, e incluso cEs, gEs y una fracción de dEs (brillantes) que muestran perfiles de dos componentes, aun cuando no se puede hacer una clara distinción entre bulbo y disco. El presente estudio traza la morfología global de las galaxias de tipo temprano, incluyendo los casos de dos componentes cuando están presentes.

\subsection{EL EFECTO DEL seeing SOBRE LOS PARÁMETROS MODELA- DOS}

Las imágenes tomadas desde tierra sufren, además de los problemas debidos a imperfecciones ópticas del telescopio, borroneos o distorsiones debidos a turbulencia en la atmósfera. Este efecto conocido como seeing afecta en mayor medida a los objetos puntuales, o muy concentrados, que a los objetos extendidos. Se suele caracterizar al seeing con una función matemática, PSF o point spread function que describe la probabilidad de que un fotón estimule un punto distinto sobre el CCD del que debería haber estimulado en ausencia de seeing. La PSF puede ser obtenida a partir de fotometría de las estrellas que se encuentren en la imagen, y puede ser descripta por una Gaussiana,

$$
\operatorname{PSF}(r)=\frac{1}{\sqrt{2 \pi} \sigma} e^{-\frac{1}{2}\left(\frac{r}{\sigma}\right)^{2}}
$$

En lugar de modelar el efecto que produce el seeing sobre los parámetros obtenidos para construir el perfil de brillo de una galaxia, como se puede ver en Trujillo et al. $(2001 \mathrm{a}, \mathrm{b})$, realizamos una serie de simulaciones simples a partir de galaxias sintéticas, siguiendo el 
planteo propuesto por Gavazzi et al. (2005). Utilizando la tarea мковJECTS del paquete ARTDATA de IRAF, se construyeron una serie de imágenes FITS de galaxias artificiales descriptas por modelos de Sérsic teóricos y elipticidad nula. Esta última condición fue necesaria para poder estimar el efecto puro del seeing sobre una galaxia con simetría axial respecto a la dirección de la visual. Además, se fijó el $\mu_{0}$ en $10 \mathrm{mag} \operatorname{arcsec}^{-2}$ y se hizo variar el índice $n$ de Sérsic entre 0.5 y 4. Por otro lado, se definió para cada imagen un nivel de cielo y un ruido similar a las imágenes MOSAIC.

Para simular el efecto del seeing se convolucionaron las imágenes utilizando la tarea GAUss, con perfiles Gaussianos de FWHM $(\sigma)$ variando entre 0.5 y 10 segundos de arco. Se obtuvieron luego los perfiles de brillo superficial de las galaxias ficticias de la misma forma y con el mismo procedimiento que para las galaxias reales. Posteriormente, se les ajustó un modelo de Sérsic excluyendo el segundo de arco central del perfil, como se mencionó en la sección anterior.

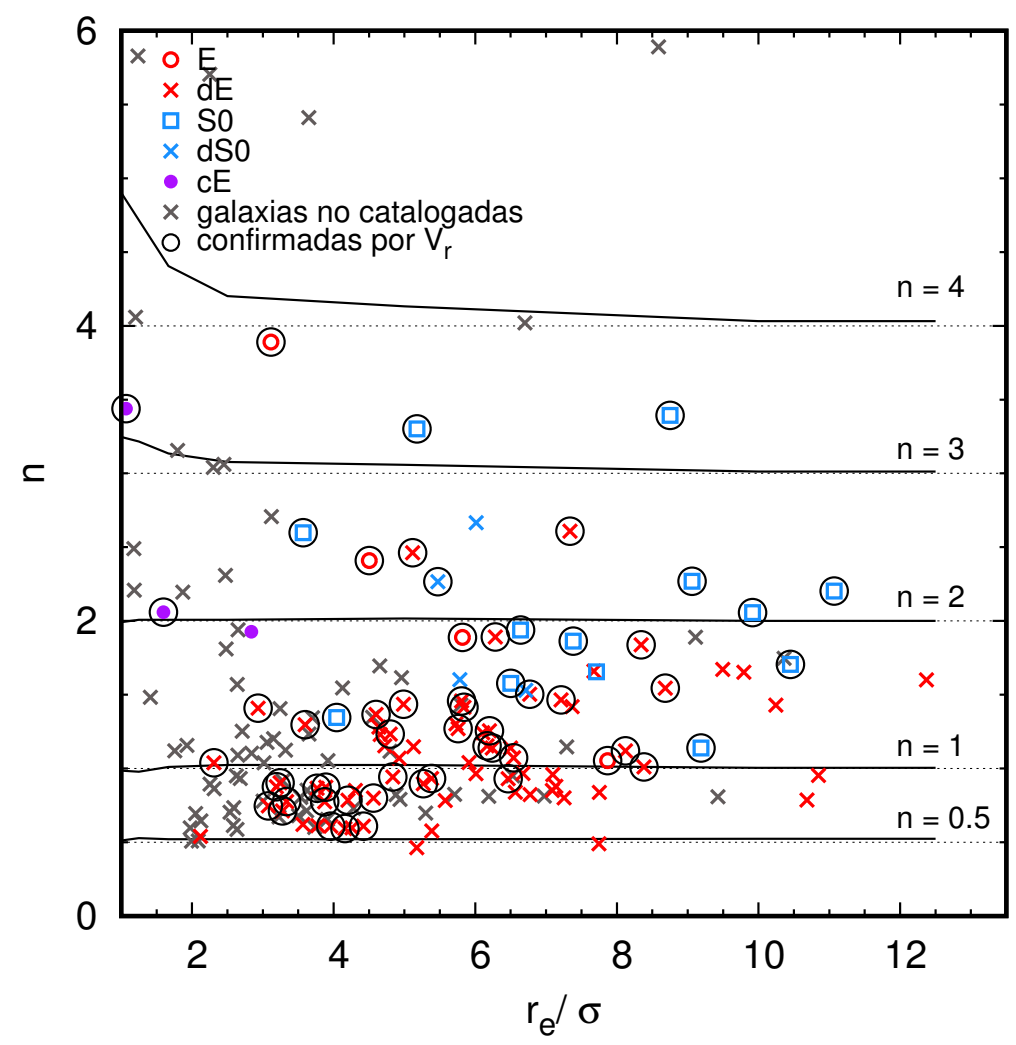

Figura 4.2: Análisis del efecto del seeing. Se grafica el índice $n$ contra $r_{e}$ (en unidades de la dispersión de la PSF adoptada para el seeing). Las líneas continuas muestran los resultados para galaxias ficticias y los diferentes símbolos corresponden las galaxias reales, descriptas arriba a la izquierda. Ver texto.

La Figura 4.2 muestra los resultados obtenidos para el índice $n$ medido en función del radio efectivo $r_{e}$ (en unidades de la dispersión 
$\sigma$ de la Gaussiana que representa el disco de seeing). Los distintos símbolos identifican los distintos tipos de galaxias reales (detallados arriba a la izquierda), y las líneas continuas representan a las galaxias ficticias, donde cada línea corresponde a un dado $n$ teórico. Se observa que para valores pequeños de $n$, en las galaxias ficticias se recupera el índice asignado teóricamente, mientras que solamente para $n>3$ hay diferencias para radios equivalentes pequeños, en los que el $n$ resulta sobre-estimado. Este resultado coincide con el obtenido por Gavazzi et al. (2005) y es acorde con que el flujo de la zona central es distribuido en los píxeles aledaños, produciendo perfiles más empinados.

Dado que son muy pocas las galaxias reales (en esta muestra) en los rangos de $n$ y $r_{e}$ en que el efecto del seeing es notable, se decidió no realizar una corrección general por seeing sino limitar el ajuste de los perfiles, excluyendo el segundo de arco central.

\subsection{RELACIÓN SEÑAL-RUIDO}

Con el objetivo de estimar la calidad de las determinaciones de perfiles y los parámetros derivados de éstos, calculamos cómo varía la relación señal-ruido $(\mathrm{S} / \mathrm{N})$ de un perfil de brillo superficial en función del radio utilizando la siguiente expresión (McDonald et al., 2011),

$$
\frac{S}{N}(r)=\frac{I_{t}(r)\left[\text { pixel }^{-2}\right] \cdot \sqrt{A_{\text {iso }}}[\text { pixel }]}{\sqrt{I_{c}}\left[\text { pixel }^{-1}\right]},
$$

donde $A_{i s o}$ es el área en píxeles que ocupa cada isofota considerada,

$$
A_{\text {iso }}=2 \pi \sqrt{0.5\left(a^{2}+b^{2}\right)},
$$

siendo $a$ y $b$ los semiejes mayor y menor de la isofota elíptica, $I_{t}(r)$ el brillo superficial total de la galaxia e $I_{c}$ el brillo superficial del cielo. La relación $S / \mathrm{N}$ para las galaxias más débiles de la muestra $\left(T_{1}>14 \mathrm{mag}\right)$ cubre un rango que va desde $1.6 \pm 0.3$ a $3.0 \pm 1.0$ para la isofota $27.5 \mathrm{mag} \operatorname{arcsec}^{-2}$.

En la Sección § 6.1.4 se incluirá un análisis de la completitud de la muestra seleccionada. 

Se describe a continuación cómo se constituyó la muestra de galaxias de tipo temprano que se estudia en esta Tesis. La fuente original ha sigo el catálogo de Antlia FS9o, del cual se tomaron las coordenadas para identificar todas las galaxias listadas en el mismo que se ubican en los cuatro campos del MOSAIC II. Además, se agregan las nuevas galaxias descubiertas en nuestro estudio previo del campo central (Smith Castelli et al., 2012), así como las nuevas candidatas, que no han sido catalogadas con anterioridad, localizadas en dichos cuatro campos.

\subsection{MUESTRA ORIGINAL: CATÁLOGO FS9O}

Como se mencionó previamente, el primer estudio de gran escala de la población de galaxias del cúmulo de Antlia ha sido el catálogo fotográfico FS9o, cuya magnitud límite es $B_{T}=18$ mag $\left(M_{B}=\right.$ $-14.7 \mathrm{mag}$ ). Las 375 galaxias (de todos los tipos) que incluye en toda el área correspondiente a Antlia, están clasificadas en base a criterios morfológicos, con índices de membresía: 1, 2, o 3, i. e. miembro definitivo, probable o posible, respectivamente. En este conjunto el 36.5\% tienen membresía 1, o sea la mayor probabilidad de ser miembros, $26.5 \%$ membresía 2, y las restantes (37\%), membresía 3. Al momento de su publicación, solo el $6 \%$ de estas galaxias de FS9o tenían velocidades radiales medidas. En trabajos sucesivos, el grupo que estudia el cúmulo de Antlia en esta Facultad y que integro actualmente, ha obtenido espectros con los instrumentos IMACS (telescopios Magallanes), GMOS, y VIMOS que, incluyendo las velocidades publicadas en $\mathrm{NED}^{1}$ permiten confirmar el $\sim 30 \%$ de las galaxias de tipo temprano como miembros del cúmulo. Recordemos que la velocidad radial de una galaxia debe estar dentro del rango $1200-4200 \mathrm{~km} \mathrm{~s}^{-1}$ para ser considerada miembro de Antlia (Smith Castelli et al., 2008a).

En particular, si consideramos las galaxias con índice de membresía I según FS9o (miembros "definitivos") y que poseen velocidades radiales medidas a partir de espectros de VIMOS, es posible confirmar que el $\approx 96 \%$ de ellas son miembros del cúmulo. Esto permite afirmar nuevamente que la clasificación de membresía que se presenta en FS9o, a pesar de ser un catálogo fotográfico, es altamente

1 This research has made use of the NASA/IPAC Extragalactic Database (NED) which is operated by the Jet Propulsion Laboratory, California Institute of Technology, under contract with the National Aeronautics and Space Administration. 
confiable. Tal conclusión ya ha sido señalada en trabajos previos (e.g. Smith Castelli et al., 2012, y referencias allí citadas). En consecuencia, se considerará a las galaxias de tipo temprano de FS9o con membresía 1 como miembros verdaderos. De este modo, todas las galaxias de tipo temprano con membresía confirmada con velocidades radiales sumadas a aquellas de FSgo con membresía 1, se consideran en el resto de esta Tesis como "miembros" de Antlia.

En base a esta selección realizada, se han obtenido los perfiles de brillo superficial en los filtros $\mathrm{C}_{\mathrm{y}} \mathrm{T}_{1}$ de 100 galaxias de tipo temprano. Entre ellas, 53 galaxias son miembros confirmados espectroscópicamente. Cabe aclarar que existen varios casos, entre las galaxias FS9o, para los cuales no fue posible obtener los perfiles de brillo porque son objetos muy débiles, o están superpuestos sobre defectos de la imagen o "gaps" (separaciones) entre los distintos CCDs. Además, también han sido excluidos de la muestra los objetos que presentan una morfología evidente que los ubica en la población de fondo ("background") y/o barras centrales o las galaxias con formación estelar, como por ejemplo las enanas compactas azules (BCDs, Vaduvescu et al., 2014). En la Figura • 5.1 se muestran ejemplos de galaxias que han sido excluidas de la muestra en consideración.

\subsection{MUESTRA FINAL}

A través de una cuidadosa búsqueda visual en las imágenes $\mathrm{C}$ y $\mathrm{T}_{1}$ de los cuatro campos MOSAIC II, se han descubierto 77 nuevas candidatas a galaxias de tipo temprano que no han sido catalogadas anteriormente. La selección preliminar se ha realizado teniendo en cuenta los siguientes criterios:

a. La galaxia no se encuentra afectada por bleeding o difracción debido a alguna estrella saturada cercana o defecto cosmético en la imagen.

b. En ambos filtros, la galaxia mantiene la forma de sus isofotas y las salidas de la tarea ELLIPSE son compatibles.

c. La tabla que se obtiene como salida de la tarea ELLIPSE alcanza al menos un brillo superficial de $27.5 \mathrm{mag} \mathrm{arcsec}^{-2}$ (filtro R) en las isofotas exteriores. Además, no se observan objetos que sea necesario enmascarar en el centro de la galaxia en estudio.

d. Los residuos del mejor ajuste del modelo de Sérsic no muestran indicios de estructura espiral subyacente.

e. El ajuste se mantiene estable aún cuando se realicen pequeños cambios en los parámetros geométricos iniciales o en el nivel del cielo. 


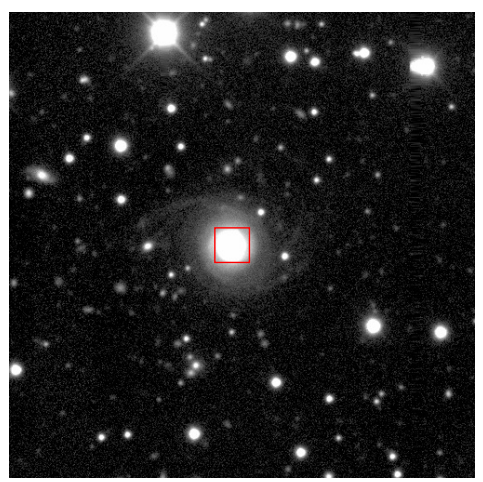

(a) FS9o 273: Estructura espiral.

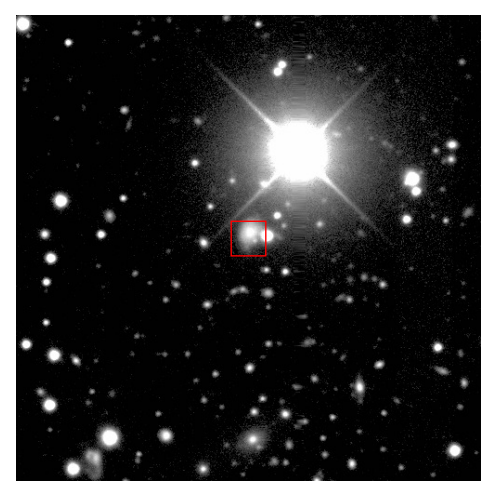

(c) FS9o 283: Estrella brillante cercana.

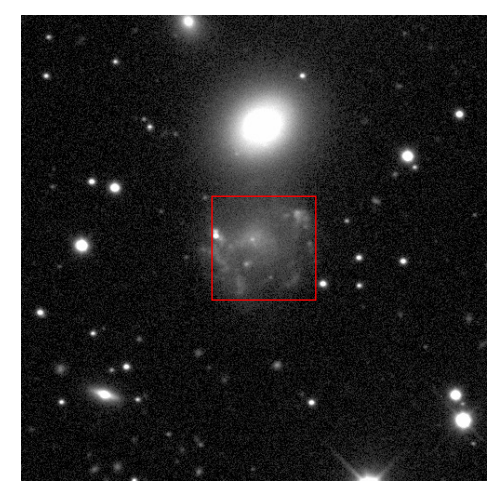

(b) FS9o 297: Morfología irregular.

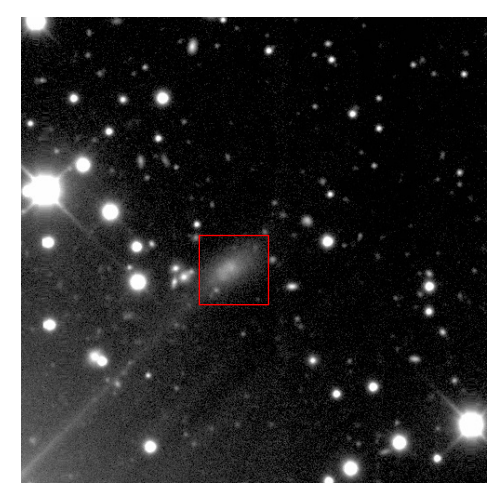

(d) FS9o 288: Galaxia débil afectada por un defecto de la imagen.

Figura 5.1: Ejemplos de galaxias excluidas de la muestra. Cada imagen cubre un campo de $23 \times 23 \mathrm{kpc}^{2}$ a la distancia de Antlia, y las galaxias están ubicadas en el centro de cada una de ellas.

f. Se incluyó en la muestra de galaxias solamente aquellos objetos con $r \geq 10$ arcsec.

Las nuevas candidatas a galaxias de tipo temprano identificadas se ubican dentro del régimen de magnitudes débiles y corresponden principalmente a morfologías similares a las dEs (nucleadas y no-nucleadas) así como dSphs. En estos casos de galaxias débiles, la probabilidad que pertenezcan al "background" es obviamente mayor que para las más brillantes, de modo que solamente una fracción de ellas pueden ser verdaderos miembros del cúmulo. Dado que no se cuenta con espectros de ellas, no podemos identificar cuáles deberían ser clasificadas como tipo tardíos en vez de tempranos. En consecuencia, agregar todas estas nuevas candidatas llevaría a borronear las relaciones de escala que son el objetivo de esta Tesis. Por tal motivo, es necesario imponer alguna restricción para seleccionar solo aquellas que poseen mayor probabilidad de ser galaxias miembro de tipo temprano. Utilizaremos como base para realizar esta distinción, 
la relación color-magnitud (RCM) seguida por las galaxias de tipo temprano que son "miembros".

La RCM de las galaxias de tipo temprano en cúmulos de galaxias es una correlación muy definida, como ya es ampliamente conocido, e.g. Penny \& Conselice (2008), Jaffé et al. (2011), Mei et al. (2012), etc. Más aun, esta RCM (también llamada "secuencia roja") es una relación universal con muy baja dispersión, que conlleva información sobre los cúmulos mismos. Se interpreta la pendiente de la RCM como una relación masa-metalicidad, puesto que el efecto de las (levemente) diferentes edades, para cada masa estelar, es muy probablemente provocar la pequeña dispersión respecto a la RCM. Esta pequeña dispersión puede ser utilizada, además de la morfología, como un criterio adicional para identificar los miembros probables del cúmulo en aquellos casos en que se carece de espectros. En trabajos previos se ha mostrado que tal dispersión no aumenta al considerar galaxias de magnitudes más débiles, sino que es prácticamente constante a lo largo de toda la RCM (Smith Castelli et al., 2008a, 2012).

La Figura $>5.2$ muestra la RCM seguida por las galaxias de tipo temprano "miembros" de Antlia. Las nuevas galaxias aún no catalogadas, graficadas con cruces grises, no poseen velocidades radiales y cubren la mitad más débil del diagrama, tomando colores más azules y más rojos con respecto a la RCM. De este modo, estas candidatas incluyen galaxias de tipo tardío que originalmente parecían galaxias de tipo temprano, así como objetos del "background". A fin de conformar la muestra final de galaxias de tipo temprano, se decidió agregar a las "miembros" ya seleccionadas, solamente aquellas nuevas galaxias ubicadas entre $\pm 3 \sigma$ de la RCM, o sea la zona que está indicada en la figura con una banda sombreada. La dispersión $\sigma$ está calculada con respecto a ambas variables, color y magnitud.

Entre estas nuevas galaxias, se encuentran siete que poseen espectros tomados con VIMOS (Caso et al., en preparación) y cuyas velocidades radiales caen dentro del rango considerado para identificar los miembros confirmados, como se explicó previamente. Por tal motivo, las incluiremos en la muestra de galaxias 'miembros'. Sus datos básicos se presentan en la Tabla 5.I, i. e. sus coordenadas y la correspondiente fotometría en el sistema de Washington. Se las denomina en forma similar a los nuevos miembros descubiertos por Smith Castelli et al. (2012), utilizando el acrónimo ANTL seguido por las coordenadas $\mathrm{J}_{2000^{2}}$.

Desde aquí en adelante, se identificará como muestra final al conjunto constituido por: 107 galaxias "miembros" de tipo temprano sumadas a 31 galaxias de la muestra de nuevas galaxias de tipo temprano que se ubican dentro de $\pm 3 \sigma$ de la RCM. Esto es, la "muestra final" contiene 138 galaxias.

2 http://cdsweb.u-strasbg.fr/vizier/Dic/iau-spec.htx 


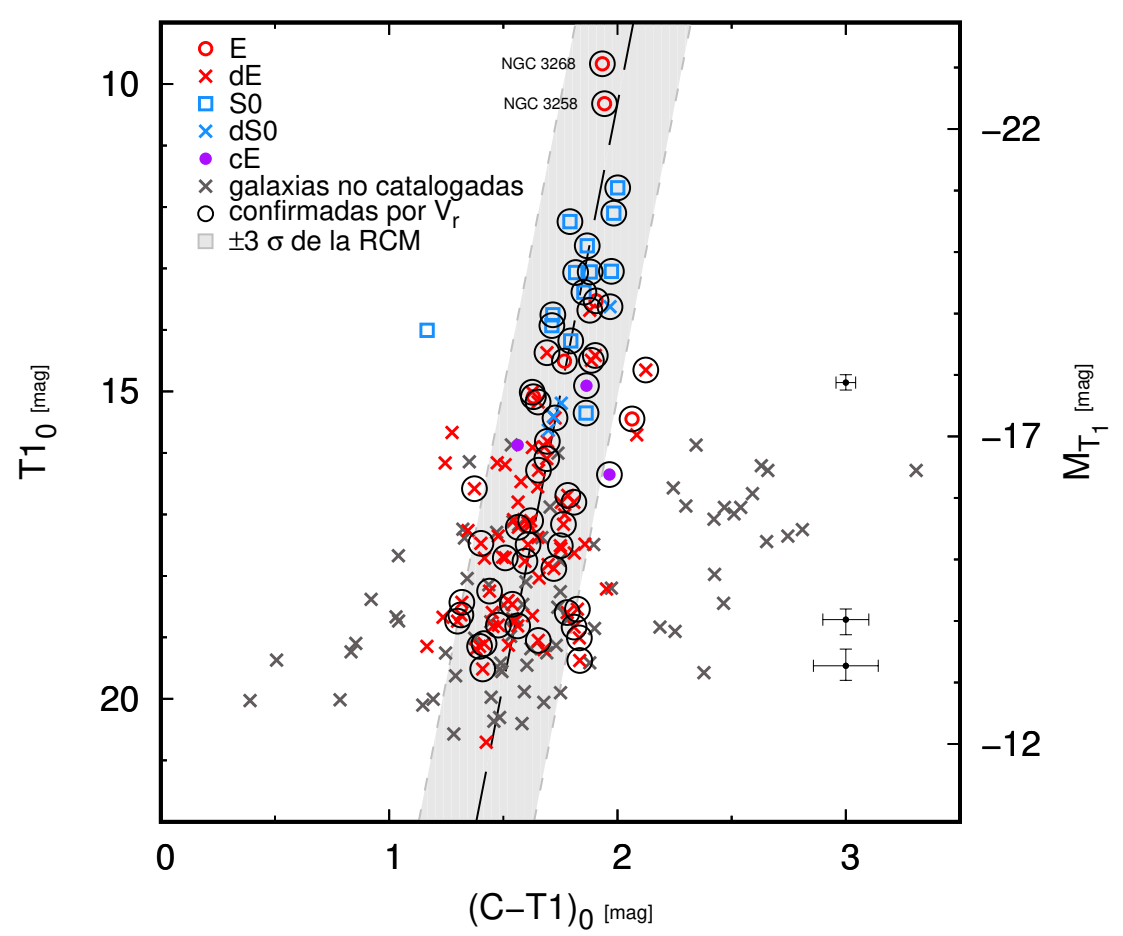

Figura 5.2: Diagrama color-magnitud de galaxias de tipo temprano y nuevas galaxias del cúmulo de Antlia (se identifican los símbolos en el gráfico). La línea de trazos muestra la RCM seguida por las galaxias "miembros" de tipo temprano (i.e. galaxias de tipo temprano de FS9o confirmadas espectroscópicamente o con membresía 1) mientras que la zona sombreada corresponde a la región del gráfico dentro de $\pm 3 \sigma$ con respecto a dicha relación. Las dos gEs están identificadas en el extremo de magnitudes más brillantes. Los errores típicos para distintos órdenes de magnitud están graficados sobre la derecha del diagrama.

\begin{tabular}{ccccc}
\hline ID & $\alpha_{2000}$ & $\delta_{2000}$ & $\left(\mathrm{~T}_{1}\right)_{0}$ & $\left(\mathrm{C}-\mathrm{T}_{1}\right)_{0}$ \\
\hline ANTL J103046.7-353918.0 & $10: 30: 46.7$ & $-35: 39: 18.0$ & 18.24 & 1.43 \\
ANTL J103036.4-353047.2 & $10: 30: 36.4$ & $-35: 30: 47.2$ & 17.87 & 1.72 \\
ANTL J103033.1-352638.4 & $10: 30: 33.1$ & $-35: 26: 38.4$ & 18.73 & 1.29 \\
ANTL J103037.4-352708.3 & $10: 30: 37.4$ & $-35: 27: 08.3$ & 19.10 & 1.41 \\
ANTL J103021.4-353105.2 & $10: 30: 21.4$ & $-35: 31: 05.2$ & 15.01 & 1.62 \\
ANTL J103022.0-353805.3 & $10: 30: 22.0$ & $-35: 38: 05.3$ & 17.46 & 1.40 \\
ANTL J103013.7-352458.6 & $10: 30: 13.7$ & $-35: 24: 58.6$ & 19.37 & 1.83 \\
\hline
\end{tabular}

Tabla 5.1: Nuevas galaxias enanas, miembros de Antlia, confirmados mediante espectros de VIMOS. 

Parte III

RELACIONES DE ESCALA 



\subsection{RESULTADOS}

Se describirán las relaciones de escala obtenidas para la muestra final de galaxias de tipo temprano del cúmulo de Antlia. En la Sección $\S 5.2$ se ha realizado una descripción introductoria de la RCM de galaxias de tipo temprano y cómo fue utilizada para seleccionar las que más probablemente sean miembros del cúmulo entre las nuevas encontradas. Se realiza a continuación un análisis más detallado de la RCM, y posteriormente se estudiarán relaciones de escala que involucran parámetros estructurales globales de la muestra final.

\subsubsection{La relación color-magnitud}

En la Figura 5.2 se presentó la RCM de las galaxias de tipo temprano de la muestra final, las referencias morfológicas se encuentran indicadas en la figura. La línea negra a trazos representa un ajuste lineal por mínimos cuadrados de las galaxias de tipo temprano "miembros" teniendo en cuenta errores en ambos ejes,

$$
\left(T_{1}\right)_{0}=(-18.9 \pm 0.1)\left(C-T_{1}\right)_{0}+(48.1 \pm 2.6),
$$

donde la desviación estándar es $\sigma=1.59$ mag. El 9o \% de las galaxias confirmadas espectroscópicamente como miembros del cúmulo, identificadas en la Figura $\$ 5.2$ con círculos negros abiertos, caen dentro de $\pm 3 \sigma$ del ajuste lineal, zona que se encuentra representada por la banda sombreada. Esto avala la selección de nuevas galaxias dentro de tales límites de color.

En trabajos previos del cúmulo (Smith Castelli et al., 2008a, 2012), no había sido posible detectar la existencia de un apartamiento del extremo brillante de la RCM con respecto al ajuste lineal realizado con todas las galaxias de tipo temprano. Pequeñas diferencias en los colores $\left(C-T_{1}\right)$ en las galaxias más brillantes son probablemente los responsables de este "quiebre" en $M_{T_{1}} \approx-20$ mag. De hecho, los colores de estas galaxias brillantes son más azules en esta Tesis $(\Delta(\mathrm{C}-\mathrm{T} 1)=0.5 \mathrm{mag})$, en la cual las magnitudes no son sólo isofotales, sino totales. Parecería que, como consecuencia de la integración del modelo de Sérsic hasta infinito, se puede percibir por primera vez un quiebre suave en el extremo de magnitudes brillantes de la RCM 
(Figura - 5.2). Dado que en Antlia se encuentran principalmente galaxias lenticulares brillantes y pocas elípticas brillantes, el quiebre es definido por sólo un pequeño número de galaxias.

La Figura $>$ 6.I muestra una imagen alternativa de la RCM seguida por todas las galaxias de la muestra final, i. e. los "miembros" y las galaxias nuevas identificadas en esta Tesis que quedan dentro de $\pm 3 \sigma$ del ajuste de la RCM. La línea a trazos es el mismo ajuste que en la Figura 5.2 para los miembros confirmados del cúmulo, sobre todo el rango de magnitudes. La línea horizontal punteada representa el color medio para las galaxias del extremo brillante $\left(M_{T_{1}} \leq-20 \mathrm{mag}\right)$. Los puntos conectados por líneas (rojas, azules y verdes) representan los colores medios para cada intervalo de magnitud. Se puede observar que para la región de magnitudes más brillantes, el color se mantiene aproximadamente constante alrededor de $\left(\mathrm{C}-\mathrm{T}_{1}\right)_{0} \sim 1.9 \mathrm{mag}$. En la parte de abajo del mismo gráfico, se muestra el histograma con el número de galaxias en cada intervalo de magnitud.

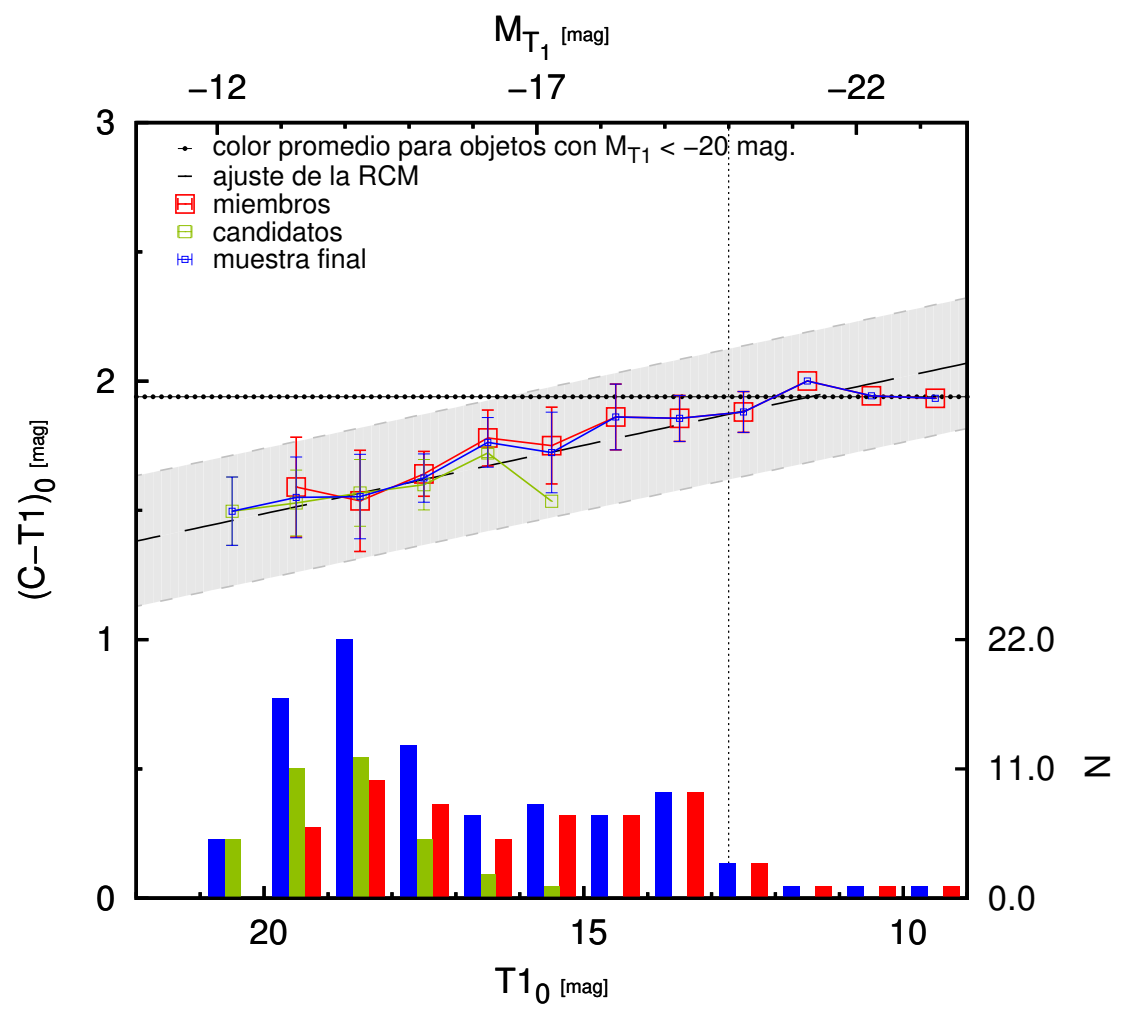

Figura 6.1: Apartamiento respecto al comportamiento lineal en la zona brillante de la RCM. La línea vertical punteada indica la magnitud donde se detecta el apartamiento $M_{T_{1}} \sim-20$ mag. Arriba: Relación color-magnitud, la banda sombreada es la misma que en la Figura - 5.2. Abajo: Histograma del número de galaxias en función de la magnitud (ordenadas sobre el lado derecho). 


\subsubsection{Relaciones de escala de parámetros estructurales}

La Figura $>6.2$ muestra cinco relaciones de escala para la muestra final de galaxias de tipo temprano del cúmulo de Antlia: panel (a) $\mu_{0}$ contra magnitud absoluta $M_{V}$, panel (b) $M_{V}$ contra índice de Sérsic $n$, y panel (c) $\mu_{0}$ contra $n$; panel (d) $\mu_{e}$ contra $M_{V}$, y panel (e) $r_{e}$ contra $M_{V}$. Los diferentes símbolos se encuentran explicados en cada gráfico, e identifican los tipos morfológicos, las nuevas galaxias no catalogadas previamente que quedan dentro de $\pm 3 \sigma$ de la RCM, y miembros confirmados por velocidad radial. Para facilitar la comparación de los resultados obtenidos para Antlia con los de otros cúmulos de galaxias, se transformaron los parámetros en el filtro $T_{1}$ al filtro $V$ mediante las ecuaciones dadas por Fukugita et al. (1995) y la relación $\mathrm{R}_{\mathrm{C}}-\mathrm{T}_{1} \approx-0.02$ (Geisler, 1996). Se siguió el procedimiento descripto por Graham (2013) utilizando los datos obtenidos en esta Tesis, con el objetivo de obtener las expresiones para cada una de las relaciones entre los parámetros estructurales. Los gráficos Figura $\bullet 6.2 \mathrm{a}$ y Figura $\bullet 6.2 b$ muestran relaciones aproximadamente lineales definidas por todas las galaxias de tipo temprano, excepto las dos cEs confirmadas. Estas relaciones se extienden desde las $\mathrm{gEs}$ en el extremo brillante, hasta las candidatas a dSphs en el extremo más débil, cubriendo más 10 mag en $M_{V}$. Los ajustes lineales presentados en estas figuras fueron realizados tomando en cuenta errores en ambos ejes y excluyendo las galaxias cEs. Las siguientes expresiones son el resultado de aplicar el método de mínimos cuadrados a los datos, los ajustes se muestran en línea punteada.

$$
\begin{gathered}
\mu_{0}=(1.2 \pm 0.08) M_{V}+(40.1 \pm 1.2) \\
M_{V}=(-10.1 \pm 1.3) \log (n)-(14.5 \pm 0.2)
\end{gathered}
$$

Se han presentado expresiones equivalentes por Graham (2013, y referencias allí citadas) para la muestra de galaxias compilada por Graham \& Guzmán (2003), en el filtro B: $\mu_{0}=1.49 \mathrm{M}_{\mathrm{B}}+44.03$ y $\mathrm{M}_{\mathrm{B}}=$ $-9.4 \log (n)-14.3(B-V=0.96$ para galaxias Es, Fukugita et al. 1995).

Se puede obtener fácilmente una relación lineal entre $\mu_{0}$ y $n$ al combinar las dos expresiones anteriores,

$$
\mu_{0}=-14.57 \log (n)+22.47,
$$

que está representada en la Figura $\triangle 6.2 \mathrm{c}$ y provee un buen ajuste a lo largo de todo el rango de magnitudes que cubre la muestra de Antlia. Este comportamiento es esperable, debido a que $\mu_{0}$ y $n$ son variables que se encuentran acopladas de acuerdo al modelo de Sérsic. Los coeficientes de correlación lineal calculados para los gráficos Figura $\bullet 6.2 \mathrm{a}$ y Figura $\bullet 6.2 \mathrm{~b}$ resultan 0.9 y -0.7 , respectivamente, lo 


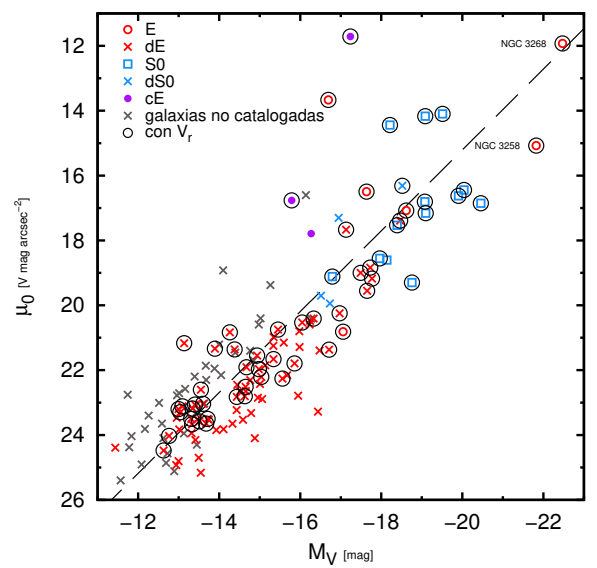

(a) Brillo superficial central contra magnitud absoluta (filtro V).

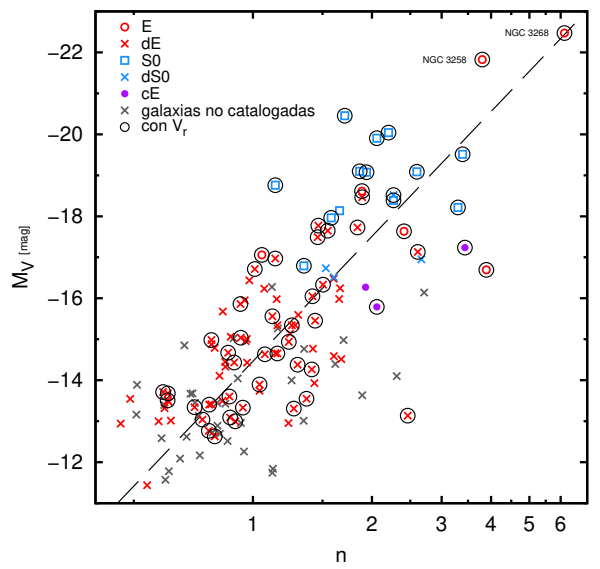

(b) Magnitud absoluta contra índice de Sérsic (filtro V).

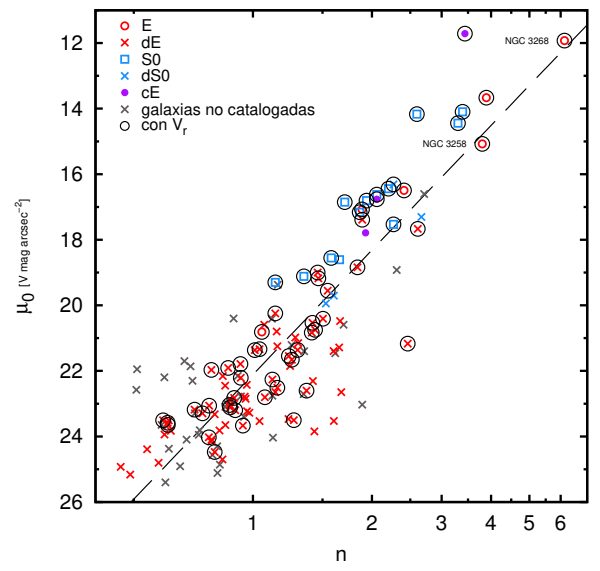

(c) Brillo superficial central contra índice de Sérsic (filtro V).

Figura 6.2: Relaciones de escala para la muestra final de galaxias del cúmulo de Antlia. Las referencias se encuentran descriptas en cada gráfico. Las líneas a trazos muestran los respectivos ajustes por mínimos cuadrados. 


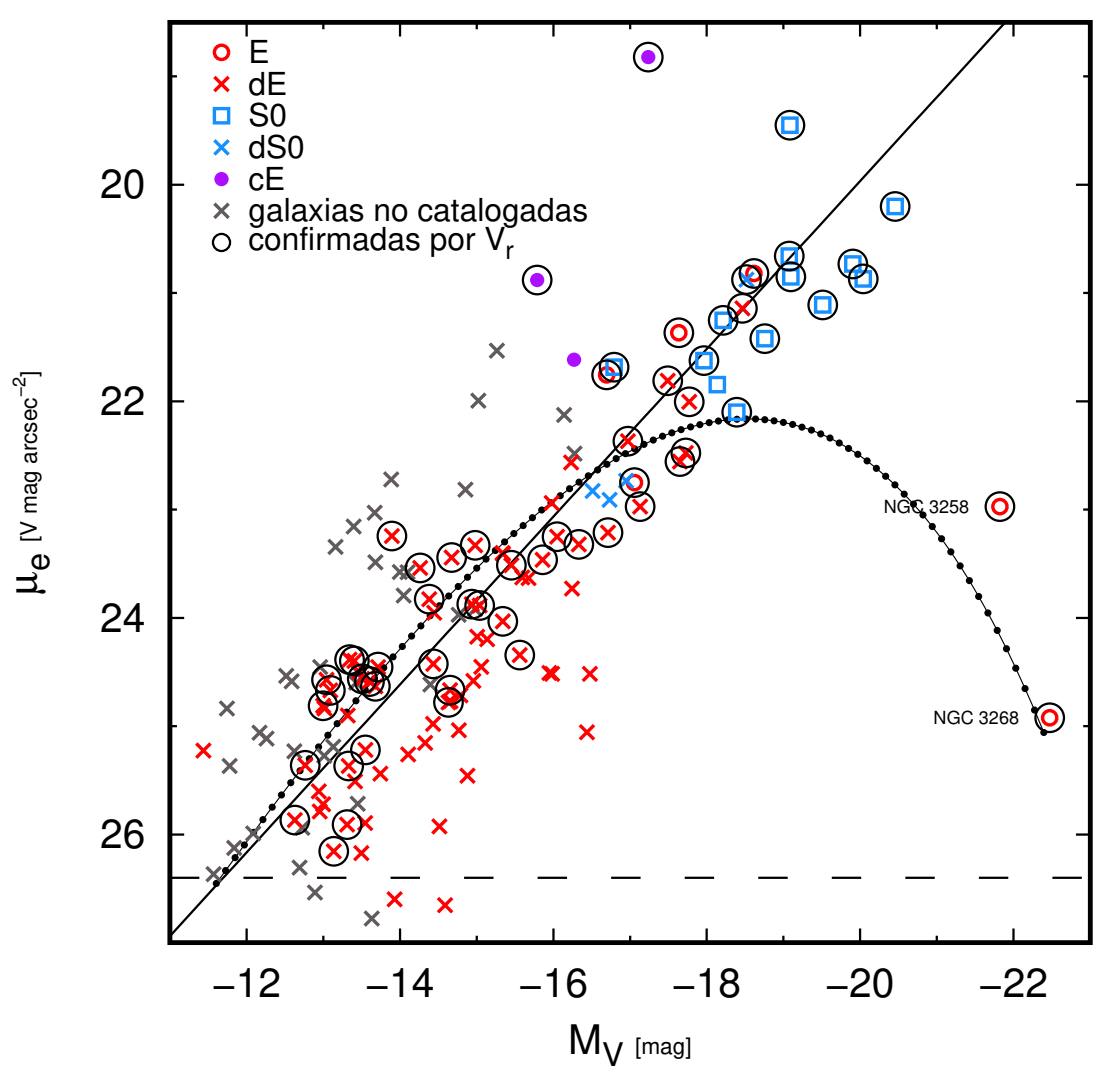

(d) Brillo superficial efectivo contra magnitud absoluta (filtro V).

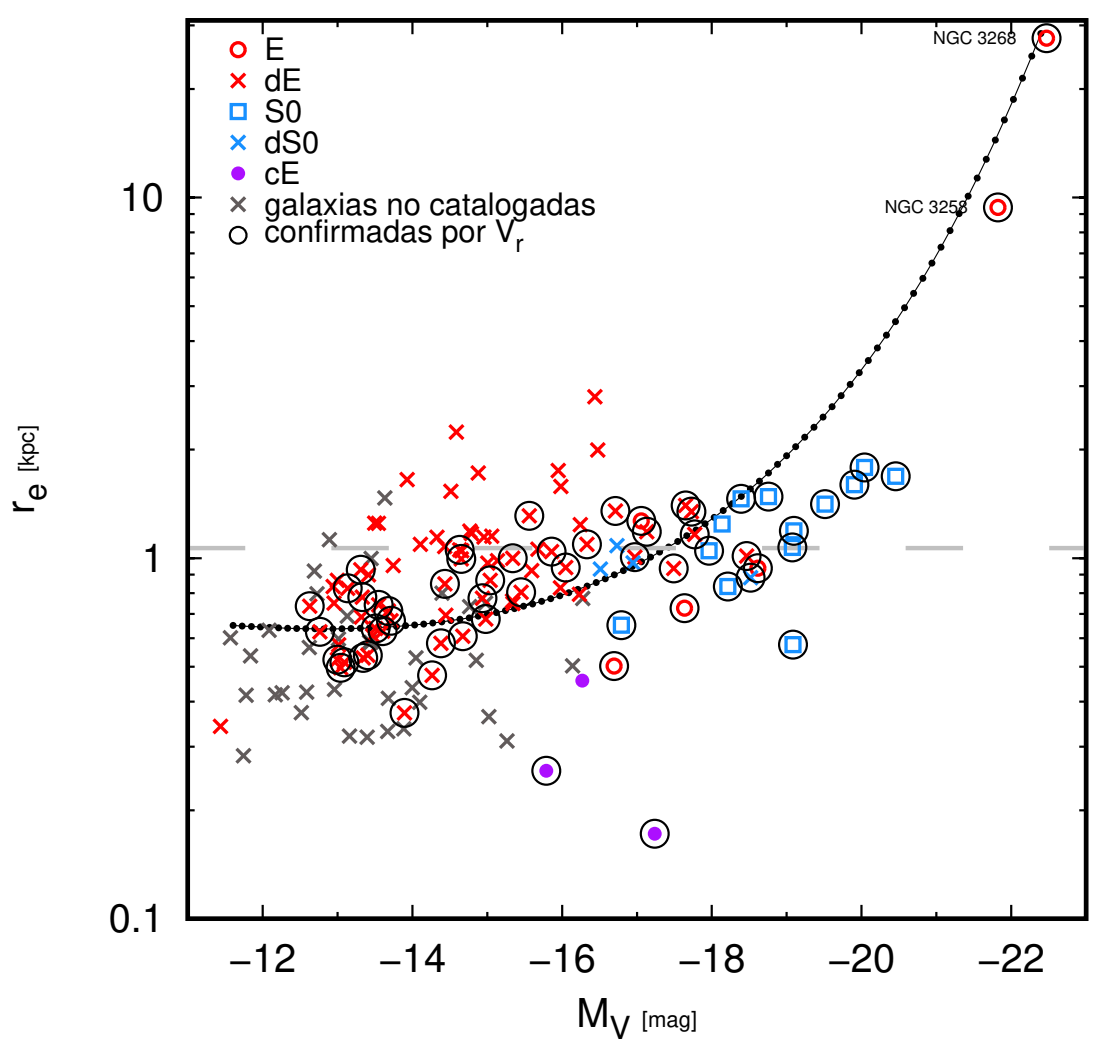

(e) Radio efectivo contra magnitud absoluta (filtro $V$ ). Las líneas de puntos representan las respectivas relaciones curvas obtenidas siguiendo Graham (2013), la línea horizontal a trazos indica el radio efectivo promedio para las dEs $\left\langle\mathrm{r}_{\mathrm{e}}\right\rangle=1.07 \mathrm{kpc}$.

Figura 6.2: (cont.). 
que indica que la correlación lineal provee un buen ajuste para ambos.

La correlaciones lineales $\mu_{e}-M_{V}$ y $r_{e}-M_{V}$ se pueden ver claramente en las Figura $\bullet$ 6.2d y Figura $\bullet$ 6.2e, seguidas por todas las galaxias de tipo temprano de la muestra con excepción de cuatro miembros confirmados: las dos gEs (NGC 3258 y NGC 3268) y las dos cEs o galaxias tipo M 32 (FS9o 110 y FS90 192, Smith Castelli et al., 2012).

Por último, una manera diferente de ajustar las dos últimas relaciones es mediante las funciones curvas que se muestran Figuras 6.2d y 6.2e con líneas punteadas. Debemos aclarar que tales funciones curvas se calculan a partir de las relaciones lineales empíricas obtenidas previamente. Hemos comprobado, además, que pequeñas variaciones en los coeficientes de las relaciones lineales pueden generar cambios grandes en la curva de Figura $\bullet 6.2 \mathrm{~d}$ y pequeños en la de Figura $\bullet 6.2 \mathrm{e}$.

En el siguiente capítulo se desarrollará una discusión relacionando los diferentes ajustes que se pueden realizar a las relaciones de escala y cómo pueden ser interpretados.

\subsubsection{La relación de Kormendy}

La relación de Kormendy (Kormendy, 1985, RK) es una correlación entre el brillo superficial efectivo promedio y el radio efectivo, $\left\langle\mu_{e}\right\rangle$ contra $\log \left(r_{e}\right)$, que ha resultado una herramienta útil para estudiar la formación de galaxias de tipo temprano.

La Figura $\bullet 6.3$ presenta la RK de las galaxias de Antlia. Una vez más, las galaxias brillantes y enanas, de tipo temprano, muestran diferentes comportamientos en este plano. Las E más brillantes siguen una relación lineal en la que gEs y cEs se ubican en extremos opuestos, mientras que las enanas presentan una distribución más dispersa y confusa. Por un lado, se ha propuesto que la distribución de enanas está de acuerdo con la dirección de las rectas de magnitud absoluta constante, que están incluidas en el gráfico. Por otro lado, ya hemos señalado que la mayoría de las enanas tienen $r_{e}$ cercanos a $1 \mathrm{kpc}$. Esto último se ve reflejado en la relación curva $\left\langle\mu_{e}\right\rangle$ contra $r_{e}$ obtenida por Graham (2011). En nuestro caso, esta relación curva, mostrada en la Figura $\bullet 6.3$, fue calculada usando los datos de Antlia, es decir, a través de las relaciones lineales que se muestran en las Figura $\bullet 6.2 a$ $\mathrm{y}$ Figura $\bullet 6.2 \mathrm{C}$ excluyendo las galaxias $\mathrm{cE}$. 


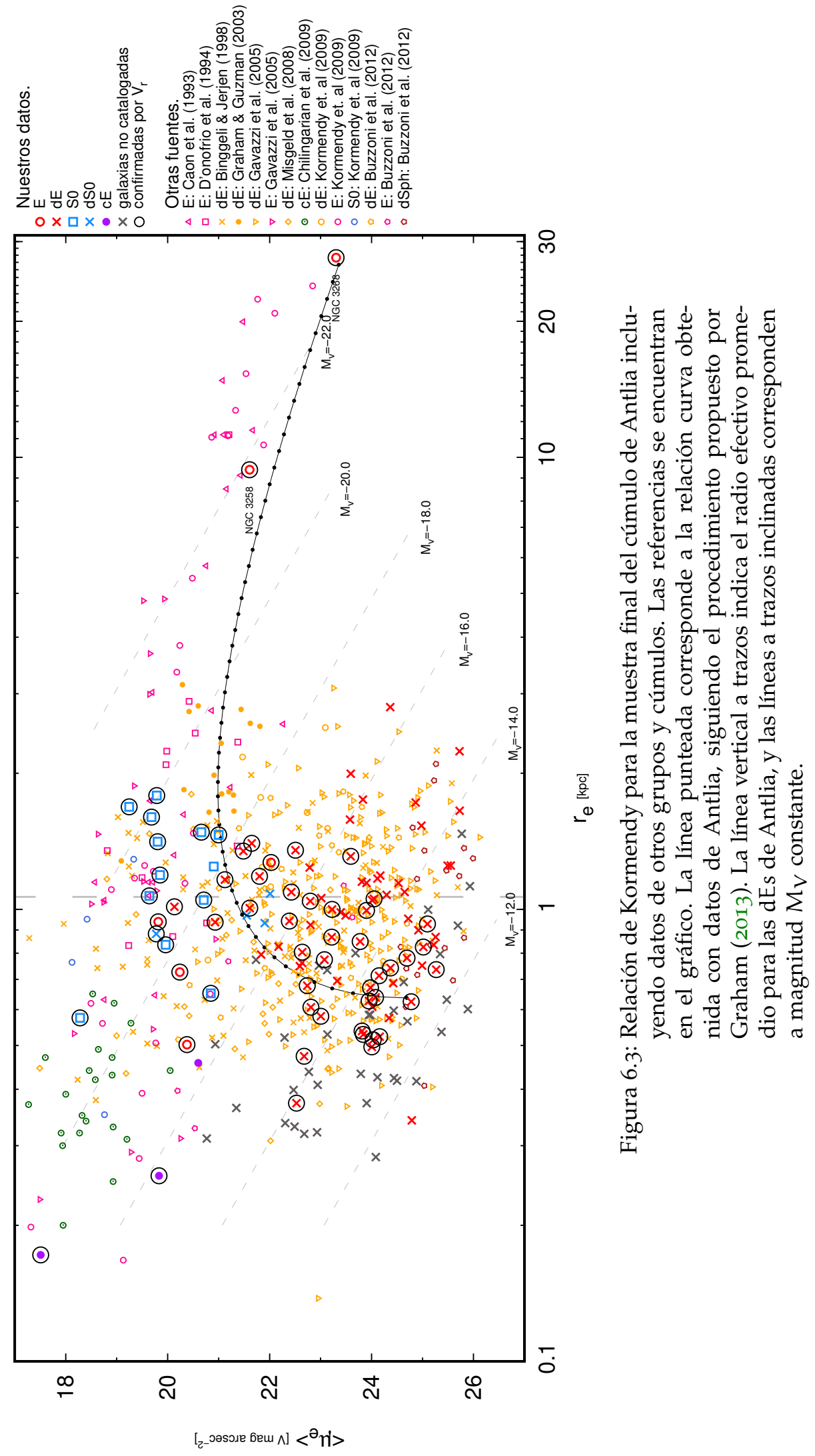




\subsubsection{Cálculo de la completitud de la muestra}

El cálculo de la completitud de la muestra resulta de gran importancia para observaciones de objetos débiles. Dado que los resultados que se muestran en esta Tesis corresponden principalmente a ajustes numéricos sobre una muestra de objetos de bajo brillo superficial, la completitud de la misma repercute directamente en los ajustes y dispersiones calculadas.

Dado que la detección de los objetos fue realizada en forma visual, es decir, se inspeccionó cada imagen por sectores y se identificaron todos los objetos extendidos con morfología elíptica, no es aplicable ningún método automático para determinar la completitud de la muestra. Aplicando el procedimiento descripto por Lieder et al. (2012, y referencias allí citadas), se utilizó la relación entre la magnitud absoluta y el brillo superficial efectivo (Figura $\bullet 6.2 \mathrm{~d}$ ) obtenida para las galaxias de la muestra final para estimar el límite de completitud. En particular, se realizó un ajuste lineal en el rango de magnitudes $-16<M_{V}<-18$ mag para no entrar en el rango de incompletitud. El ajuste es el siguiente

$$
\mu_{e}=(0.57 \pm 0.2) M_{V}+(32.21 \pm 3.4),
$$

donde la desviación estándar es $\sigma=0.92 \mathrm{mag}$. Por otro lado, teniendo en cuenta los criterios de selección para la muestra (Sección $\S 5.2$ ), se calculó el brillo superficial efectivo de un objeto con $n=1$ y $r_{e}=1 \mathrm{kpc}$ (típico para dEs), que presentara un radio isofotal $r=10$ arcsec para la isofota $\mu=27.5 \mathrm{mag} \operatorname{arcsec}^{-2}$; el valor obtenido es de $\mu_{e, l i m}=$ 26.4 mag $\operatorname{arcsec}^{-2}$. El ajuste dado por la Ecuación 6.5, junto con $\mu_{e, l i m}$ se grafican en la Figura $\bullet 6.4$.

Se utilizó la dispersión de la relación lineal para la zona de objetos que no estarían afectados por incompletitud. La recta gris a trazos representa $\mu_{e}+2 \sigma$. En particular, usamos un intervalo de $2 \sigma$ (banda sombreada) de la relación magnitud absoluta-brillo superficial efectivo para determinar la intersección con el límite isofotal $\mu_{e, \text { lim }}=26.4 \mathrm{mag} \operatorname{arcsec}^{-2}$, en $M_{V} \approx-13 \mathrm{mag}$. El intervalo define una certeza estadística del $96 \%$. Por lo tanto, esperamos perder el $2 \%$ de los objetos para magnitudes $M_{V}>-13$ mag, suponiendo una dispersión constante en el rango completo de variación de la muestra de la relación entre el brillo superficial efectivo y la luminosidad.

\subsection{DISCUSIÓN}

En este capítulo se presenta la discusión sobre las relaciones fotométricas y estructurales que fueron construidas para la "muestra 


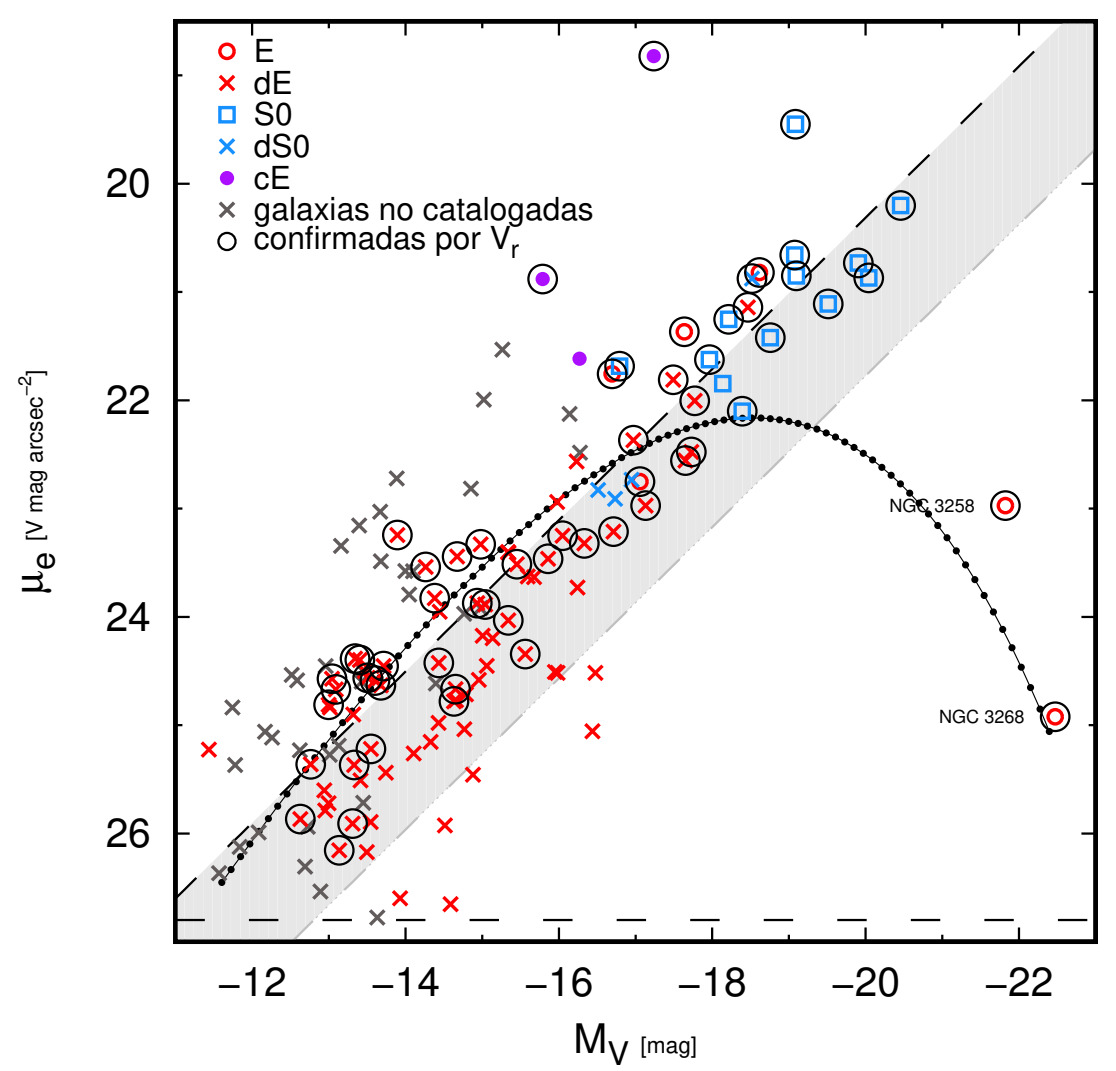

Figura 6.4: Se reproduce la Figura $\bullet$ 6.2d, brillo superficial efectivo contra magnitud absoluta (filtro $\mathrm{V}$ ) y se agregan el ajuste de la ecuación 6.5 y la recta horizontal $\mu_{\mathrm{e}, \mathrm{lim}}=26.4 \mathrm{mag} \operatorname{arcsec}^{-2}$.

final" del cúmulo de Antlia, así como la comparación con resultados para otros cúmulos.

\subsubsection{Las relaciones fotométricas}

La RCM que se ha obtenido para las galaxias de tipo temprano de Antlia es una correlación estrecha, con baja dispersión, que es común en cúmulos o grupos. Es atribuida principalmente a una relación masa-metalicidad (Terlevich et al., 1999; Smith Castelli et al., 2012, y referencias allí citadas). El estudio de la RCM resulta de interés tanto desde el punto de vista observacional como mediante simulaciones numéricas. Desde una perspectiva observacional ha sido estudiada en diferentes grupos y cúmulos (Binggeli et al., 1988; Secker et al., 1997; Khosroshahi et al., 2004). La "universalidad" de esta relación para galaxias tempranas ha sido sugerida desde los primeros estudios, y muchos autores han reportado un comportamiento lineal similar en distintos cúmulos (Mieske et al., 2007; Lisker et al., 2008; Misgeld et al., 2008; Smith Castelli et al., 2008a; Misgeld et al., 2009), aunque en los últimos años también se ha comenzado a tener en cuenta la 
posibilidad de la existencia de relaciones no-lineales (Ferrarese et al., 2006; Janz \& Lisker, 2009).

Por ejemplo, desde hace aproximadamente una década se viene discutiendo la existencia de un apartamiento del extremo brillante de la RCM, con respecto al ajuste lineal realizado sobre todas las galaxias de tipo temprano (e.g. Bernardi et al., 2007, 2011; Graham, 2008, 2011). Jiménez et al. (2011) estudiaron el extremo brillante de la RCM de cúmulos de galaxias mediante una combinación de simulaciones cosmológicas de $\mathrm{N}$-cuerpos de cúmulos de galaxias y un modelo semi-analítico de formación de galaxias (Lagos et al., 2008). En estas simulaciones, el apartamiento de la parte brillante de la RCM aparece como una clara consecuencia de la evolución de las galaxias. El mismo efecto puede detectarse en la RCM observada para galaxias de tipo temprano, por ejemplo en el cúmulo de Hydra I (Misgeld et al., 2008), el cúmulo de Virgo (Ferrarese et al., 2006; Janz \& Lisker, 2009), o una recopilación obtenida del Sloan Digital Sky Survey (SDSS) (Skelton et al., 2009). Como hace notar Graham (2011), ya había sido detectado en el estudio del cúmulo de galaxias Shapley 8 por Metcalfe et al. (1994). En todos estos casos, se encuentra un "quiebre" en la relación para las magnitudes más brillantes: las galaxias de tipo temprano de mayor masa muestran un color casi constante, aunque ha sido interpretado en modos diferentes por diferentes autores. Jiménez et al. (2011) explican este comportamiento como una consecuencia de que la evolución de estas galaxias brillantes desde $z \sim 2$ está dominada por fusiones secas, tanto mayores como menores. En ese caso, las galaxias deberían moverse hacia magnitudes más brillantes a medida que ganan masa, mientras que sin gas, la formación estelar (y el enriquecimiento) se detiene, de forma que sus colores permanecen prácticamente invariantes.

La magnitud absoluta de este quiebre para Antlia es $M_{T_{1}} \approx-20$ mag y está en muy buen acuerdo con el valor obtenido por Jiménez et al. (2011) para la RCM simulada en el mismo sistema fotométrico (ver su Figura 1). En la misma figura también se observa que la RCM está compuesta por galaxias con metalicidades crecientes desde las más débiles hasta las más brillantes de la relación. Este último resultado también apoya la idea que la metalicidad es la principal responsable de la pendiente de la RCM.

Respecto a la pequeña dispersión observada en la RCM (Bower et al., 1992; Terlevich et al., 2001; Smith Castelli et al., 2008a), es una consecuencia de la dispersión en ambas variables: edad y metalicidad, siendo la edad de la población estelar el más influyente (e.g. Gallazzi et al., 2006). Por un lado, esto sugiere que la población estelar de las galaxias de tipo temprano ha evolucionado pasivamente desde los primeros tiempos. Y por otro lado, otra posible explicación es que la dispersión medida puede entenderse con modelos que predicen una 
migración continua de galaxias de tipo tardío hacia la RCM, debido a diferentes procesos que detienen la formación estelar en ellas (Ruhland et al., 2009).

\subsubsection{Las relaciones estructurales}

Si analizamos ahora las relaciones que involucran parámetros estructurales (Figura $>$ 6.2, paneles (a) a (e)), es necesaria una explicación para comprender por qué las galaxias gE se ubican en tales posiciones en estos gráficos. Las dos gE (NGC 3258 y NGC 3268 ) fueron clasificadas como galaxias con perfil tipo core (e.g. ver Capetti \& Balmaverde, 2005; Kharb et al., 2012, y referencias allí citadas). Sus perfiles están caracterizados por un déficit de luminosidad central con respecto a la extrapolación hacia el centro del mejor ajuste global del modelo de Sérsic. No podemos detectar estos cores en los perfiles porque tienen tamaños típicos menores al 1 arcsec central, y los ajustes que se realizaron en esta Tesis excluyen esa zona del perfil de brillo. De todas formas, se tuvo en cuenta que las dos galaxias gE tienen perfiles tipo core. Este tipo de galaxias comparten además otras propiedades, como rotación lenta e isofotas tipo boxy, en contrario de las Es más débiles con perfiles tipo power law. Así, si el brillo superficial central $\mu_{0}$ de una galaxia tipo core es medido de la parte más interna de su perfil, presentará un valor menor (más débil) respecto a la relación que se muestra en el panel (c), cayendo por debajo del ajuste lineal. Sin embargo, Jerjen \& Binggeli (1997) y Graham \& Guzmán (2003) notaron que si $\mu_{0}$ se toma de la extrapolación hacia el centro del modelo global de Sérsic, seguirá la misma relación lineal junto con las otras galaxias de tipo temprano. De acuerdo a esto, como los $\mu_{0}$ de las dos $g E s$ de Antlia fueron calculados de esta última forma, no deberían caer por fuera de estas relaciones lineales previas, dentro de la dispersión presente en los datos.

Como fue mencionado anteriormente, los datos representados en la Figura $\bullet 6.2 \mathrm{~d}$ y Figura $\bullet 6.2 \mathrm{e}$ siguen correlaciones lineales, excepto por cuatro miembros: las dos gEs centrales y las dos cEs. Respecto a estas cuatro galaxias que se apartan de las relaciones, varios autores han argumentado la existencia de una dicotomía entre las galaxias de tipo temprano "normales" y enanas, en el sentido que los datos se ubican a lo largo de dos secuencias diferentes (o relaciones lineales) separadas por un vacío (o gap) en $M_{V} \approx-18$ mag (e.g. Kormendy et al., 2009; Kormendy \& Bender, 2012, y referencias allí citadas). Según este escenario, las galaxias $\mathrm{gE}$ y $\mathrm{cE}$ se encuentran ubicadas en los extremos opuestos de la secuencia definida por las galaxias elípticas "normales", en la que las cEs se ubican en la zona de mayor $\mu_{e} y$ menor $r_{e}$, mientras que la otra secuencia es trazada principalmente por las $\mathrm{dEs}$. Como se mencionó en Capítulo $\S 1$, la existencia de estas 
dos secuencias (o "ramas") se interpreta como una evidencia de que son dos poblaciones de galaxias de origen distinto.

A partir de analizar la fila inferior de la Figura $\bullet$ 6.2, es difícil establecer la existencia de dos secuencias separadas para las galaxias de tipo temprano que no son enanas, principalmente porque en este rango de magnitudes Antlia posee galaxias So, y muy pocas E "normales" o brillantes. Las gEs se apartan claramente del resto de las galaxias de tipo temprano, pero Graham (2013, y referencias allí citadas) sugieren un escenario alternativo. Graham et al. muestran que se pueden deducir las relaciones curvas para $\mu_{e}$ contra $M_{V}$ y $\log \left(r_{e}\right)$ contra $M_{V}$, que se extienden desde las enanas hasta las gigantes (e.g., fig. 12 en Graham \& Guzmán 2003, y fig. 2.8 en Graham 2013) sin considerar las cEs, utilizando relaciones matemáticas entre los parámetros de Sérsic así como las relaciones lineales empíricas de las Figura $\bullet 6.2 \mathrm{a}$ y Figura $\bullet 6.2 \mathrm{~b}$. Estas relaciones curvas se muestran en las Figura $\bullet 6.2 \mathrm{~d}$ y Figura $\bullet$ 6.2e con líneas punteadas. En ambos gráficos, la ubicación de las dos gEs de Antlia está en muy buen acuerdo con su respectiva relación curva, mientras que en el lado opuesto, en magnitudes más débiles, las relaciones curvas coinciden con las dEs. Ambas relaciones de escala parecen conectar las galaxias elípticas enanas y gigantes $y$, de acuerdo con esta última idea, las enanas parecen ser el extremo de baja masa de estas secuencias que unifican las galaxias E. De este modo, las Es tienen un rango continuo de concentración, medida por el índice de forma de Sérsic n (Caon et al., 1993). Por otro lado, estas relaciones curvas no parecen ajustar correctamente a las galaxias lenticulares (particularmente en el panel (d)) ni a las cEs Las galaxias de estos dos tipos morfológicos no fueron incluidas en el análisis de las relaciones de escala realizado por Graham (2013). Sin embargo, las galaxias S0s de Antlia parecen ajustar bien cuando se incluyen datos de otros sistemas (ver más adelante).

Debe ser tenido en cuenta que los ajustes de los perfiles de brillo para las $\mathrm{SO}$ s y cEs se realizaron con un solo modelo de Sérsic. Además, debido a las pocas cEs y Es brillantes presentes en el cúmulo de Antlia, resulta difícil testear el escenario propuesto por Kormendy et al. (2009) con nuestros datos actuales.

Es interesante notar que las galaxias mas débiles de Antlia, que parecen similares a las dSph en el Grupo Local, parecen extender casi todas las relaciones de escala que se muestran en la Figura $\bullet 6.2$, hacia menores luminosidades y siguiendo la misma tendencia que las dEs. La única excepción es el tamaño, como se observa en la Figura • 6.2e, donde las candidatas a $\mathrm{dSph}$ presentan radios efectivos menores que el promedio $\left\langle\mathrm{r}_{\mathrm{e}}\right\rangle=1.07 \mathrm{kpc}(\sigma=0.13 \mathrm{kpc})$. Este promedio fue calculado para las galaxias dEs $\left(-18<M_{V}<-14 \mathrm{mag}\right)$ de la muestra final. El hecho que las dShps tengan radios más pequeños que las dEs ya ha sido indicado por Smith Castelli et al. (2012) para un número me- 
nor galaxias débiles en Antlia y fue explicado como una consecuencia de las limitaciones de la fotometría isofotal. En esta Tesis se calculan magnitudes integradas "totales" y brillo superficial para cada galaxia. Se ha encontrado un efecto similar en galaxias de otros cúmulos. Por ejemplo, usando una compilación de datos de diversos sistemas estelares, Graham (2013) presentaron un análisis global de tamaños contra masas estelares. Se puede ver en su fig. 3.c que las $d E s$ tienen radio efectivos de alrededor de $1 \mathrm{kpc}$, mientras que las $\mathrm{dSphs}$ muestran una suave pendiente, tal que sus tamaños disminuyen a medida que disminuye la masa estelar. Un gráfico muy similar fue publicado recientemente por Norris et al. (2014, sus figs. 11 y 16). Otro ejemplo de tales tendencias diferentes entre los tamaños de las dEs y dSphs lo presenta Forbes et al. (2008), en su fig. 7 que muestra radios mitad de luz contra la magnitud absoluta en el filtro $\mathrm{K}$ para un conjunto diferente de datos.

El hecho que las galaxias dEs presentan radios efectivos aproximadamente constantes, ya ha sido reportado en diferentes cúmulos y grupos (e.g. Smith Castelli et al., 2008a, y referencias allí citadas). El promedio del radio efectivo calculado en esta Tesis $\left(\left\langle r_{e}\right\rangle=1.07 \mathrm{kpc}\right)$, se encuentra en acuerdo, entre otros, con los obtenidas por Misgeld et al. (2008) para el cúmulo de Hydra, considerando las galaxias más débiles que $M_{V}=-18 \mathrm{mag}$. Esta tendencia es seguida por la relación curva en la Figura $>$ 6.2e, puesto que el radio efectivo tiende a un valor constante cercano a $1 \mathrm{kpc}$ para el extremo de magnitudes más débiles.

\subsubsection{Comparación con otros cúmulos de galaxias}

Se consideraron datos de otros cúmulos de galaxias para tratar de comprender mejor las dos relaciones de escala que se ven en las Figuras 6.2d y 6.2e, i.e. aquellas que de acuerdo con Graham (2013) pueden ser descriptas por funciones curvas, y de acuerdo con Kormendy et al. (2009) por dos secuencias lineales de distinta pendiente. A fin de obtener mayor claridad, se reproducen ambos gráficos con mayor tamaño en la Figura $\bullet 6.5$, agregando los parámetros de galaxias de tipo temprano de distintos grupos y cúmulos: Fornax, Virgo, Coma, Hydra y el grupo de NGC 5044. En cada panel se identifican los símbolos y fuentes correspondientes. Las relaciones curvas que se muestran aquí son las mismas que se obtuvieron previamente usando solamente los datos de Antlia (Figura $\bullet 6.2 \mathrm{~d}$ y Figura $\bullet 6.2 \mathrm{e}$ ).

La Figura $>$ 6.5a muestra que las galaxias de tipo temprano de Antlia siguen la misma tendencia que las de otros sistemas, preservando una dispersión similar y en buen acuerdo con la zona de magnitudes débiles de la relación curva. Las cEs en Antlia se ubican sobre los diagramas junto con otras cEs $y$, como se espera, tienen valores 
más altos de $\mu_{e}$ que otras galaxias de tipo temprano de similar luminosidad. Las dos gEs de Antlia se ubican cerca de la relación curva, en la zona de magnitudes más brillantes, ya que fue calculada para Antlia, pero muchas Es brillantes $\left(M_{V}<-18 \mathrm{mag}\right)$ de otros sistemas presentan $\mu_{e}$ más brillante y forman una aparente secuencia paralela por arriba de la función curva. Por un lado, las galaxias de tipo temprano parecen estar distribuidas en este gráfico a lo largo de una única secuencia que une las galaxias enanas, S0s, y E normales/brillantes, siendo las cEs las únicas que se apartan. Por otro lado, la dispersión es muy distinta para las galaxias de tipo temprano más brillantes y más débiles que $M_{V} \sim-18$ mag y la existencia de dos secuencias lineales distintas no puede descartarse, particularmente debido a la ubicación que ocupan las galaxias cE.

Debido a las relaciones que existen entre los distintos parámetros derivados del modelo de Sérsic, se puede aplicar un análisis similar a la relación tamaño-luminosidad presentada en la Figura $\bullet 6.5 \mathrm{~b}$. La ubicación de las galaxias de tipo temprano de Antlia en este gráfico está en buen acuerdo con las de otros cúmulos. La relación curva obtenida para Antlia, es aplicable para una parte de las galaxias de tipo temprano, dejando de lado las cEs que poseen radios más pequeños que galaxias de similar luminosidad. Las Es más brillantes, en el extremo de radios mayores, y las dSphs en el extremo opuesto, también caen por debajo de la relación curva. Una vez más, no se aprecian vacíos en la relación tamaño-luminosidad, pero no puede descartarse ahora la existencia de dos secuencias lineales de pendiente distinta . En comparación con el gráfico del panel (a), se ha incluido mayor cantidad de galaxias $\mathrm{cE}$ con datos disponibles en la literatura (Chilingarian et al., 2009), por lo que parece más probable que las E gigantes y cEs puedan caer sobre la misma secuencia, mientras que la otra secuencia corresponde principalmente a las dEs.

Janz \& Lisker (2008) desarrollaron un estudio sobre las galaxias de tipo temprano de Virgo con una muestra de datos homogénea del Sloan Digital Sky Survey (SDSS) y concluyeron que las gigantes y las enanas no forman parte de una misma secuencia en la relación tamaño-luminosidad. Por otro lado, Ferrarese et al. (2006) realizaron un análisis de galaxias de tipo temprano de Virgo con datos homogéneos obtenidos con la Advanced Camera for Surveys of the Hubble Space Telescope (ACS-HST) y sus resultados apoyan el esquema alternativo, aunque sugieren que las dEs constituirían una población diversa con diferente origen y evolución.

A fin de comparar los resultados y completar regiones vacías en el diagrama de la RK, se agregan datos de otros cúmulos y grupos en la Figura $\bullet 6.3$, en forma análoga a lo hecho en la Figura $\bullet 6.5 \mathrm{~b}$. La RK puede ser entendida físicamente como una proyección, en el plano de fotometría superficial, del plano fundamental (PF) de las 


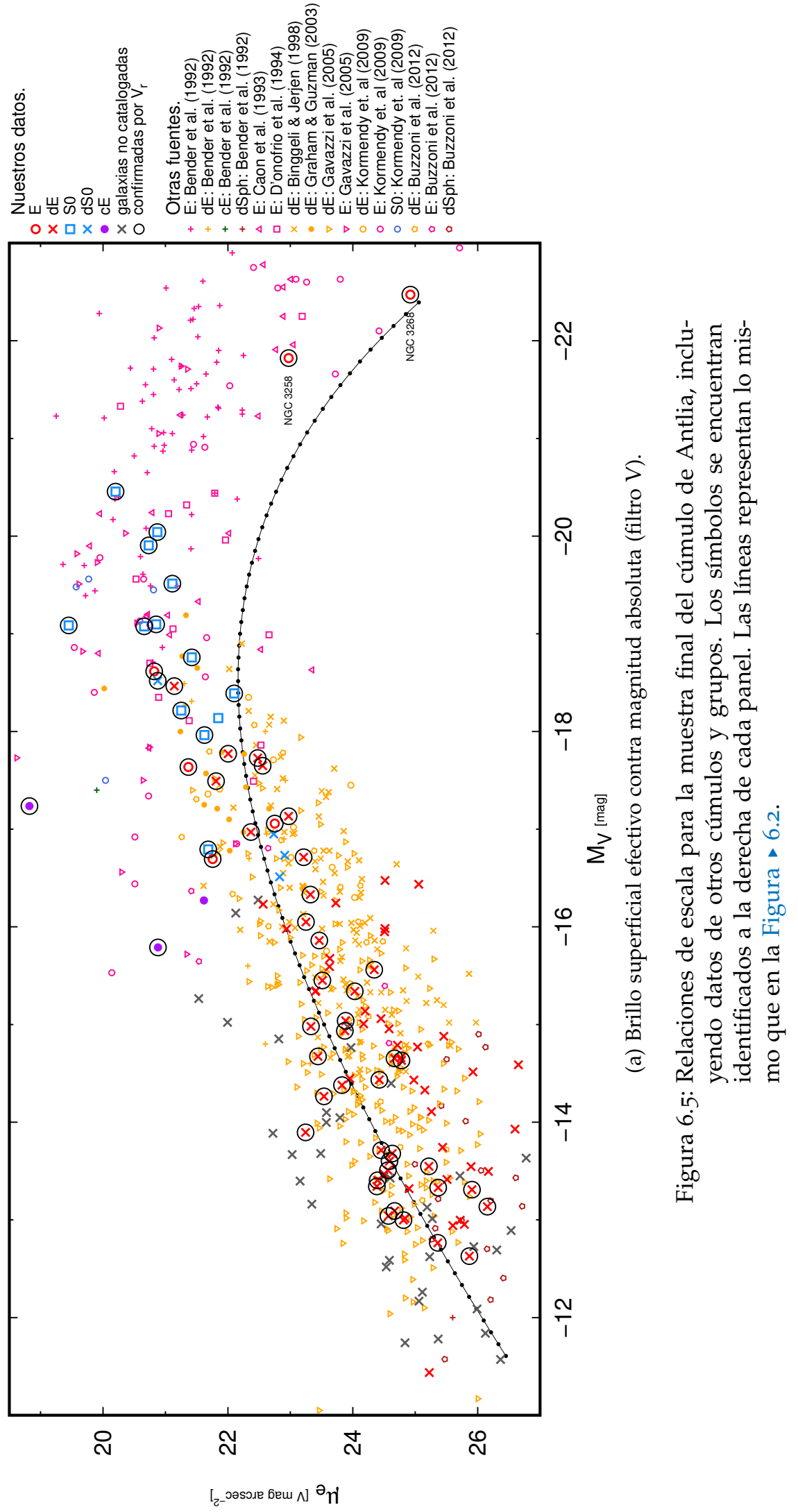




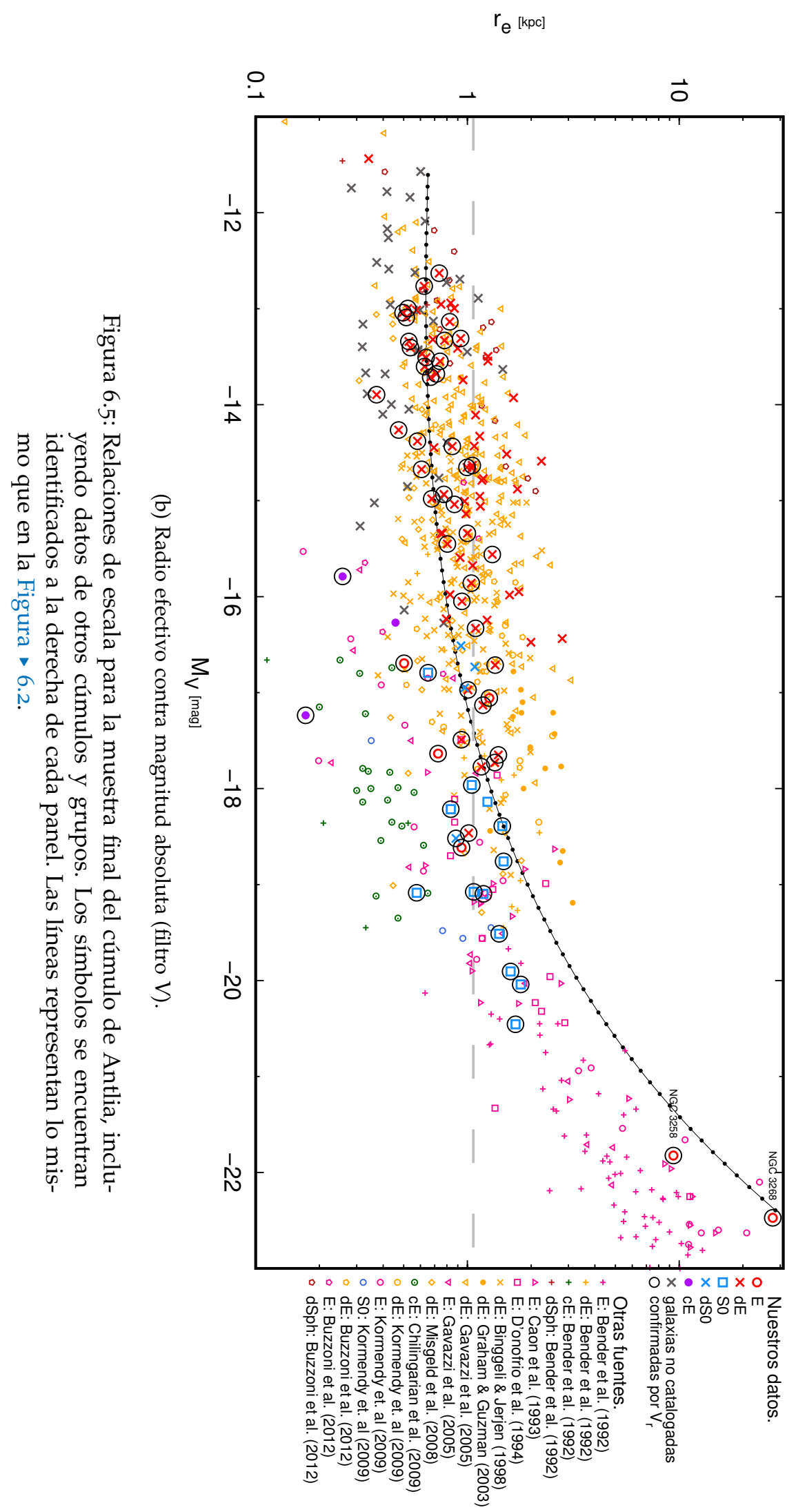


galaxias de tipo temprano (Djorgovski \& Davis, 1987). El PF vincula $\left\langle\mu_{e}\right\rangle, \log \left(r_{e}\right), y \log \left(\sigma_{0}\right)$, siendo $\sigma_{0}$ la dispersión central de velocidades. Fue originalmente obtenido para galaxias brillantes de tipo temprano $\left(M_{\mathrm{B}} \lesssim-18 \mathrm{mag}\right.$ ), pero parece no haber una única RK para las galaxias de tipo temprano brillantes y enanas. Por ejemplo, D'Onofrio et al. (2008) estudiaron el PF de una muestra de más de 1500 galaxias de tipo temprano y concluyeron que los coeficientes del PF, y análogamente los de la RK, dependen del rango de magnitud absoluta de la muestra de galaxias. Basándose en galaxias de tipo temprano de 16 grupos cercanos, Khosroshahi et al. (2004) mostraron que las RKs seguidas por las galaxias de tipo temprano brillantes y las enanas están desplazadas y presentan diferentes pendientes. Se puede ver en su figura 6. que la RK seguida por las enanas está alineada con las líneas de magnitud absoluta constante.

Graham (2013) explica la RK original solo para galaxias de tipo temprano brillantes como "una tangente a la rama brillante de lo que de hecho es una relación curva"1. También sostiene que la tendencia diferente de las enanas en esta relación, que mantienen un radio efectivo casi constante, no implica que existan diferentes mecanismos físicos involucrados en las galaxias de tipo temprano brillantes y enanas, sino que siguen una variación estructural continua, que depende de la forma de los perfiles de brillo con la luminosidad.

De este modo, nuevamente nos enfrentamos a esta dualidad. Los resultados deducidos a partir de la muestra de Antlia parecen ser más coincidentes con la propuesta de Graham (2013, y referencias allí citadas), i.e. la existencia de una única relación con una variación continua desde las galaxias de tipo temprano brillantes hasta las enanas, excluyendo las cEs. Si se incluyen datos de otros sistemas, la situación ya no es clara. Si se consideran las galaxias cE conjuntamente con las brillantes de tipo temprano, la evidencia de la existencia de dos familias distintas como en el escenario propuesto por Kormendy et al. (2009, y referencias allí citadas) parece ser el más apropiado.

1 "... a tangent to the bright arm of what is actually a curved distribution..." 

Parte IV

CONCLUSIONES 



\section{CONCLUSIONES}

Esta Tesis presenta el primer análisis global, sobre un área de aproximadamente 1.5 grados cuadrados, de las relaciones de escala fotométricas y estructurales seguidas por las galaxias de tipo temprano del cúmulo de Antlia. Estas relaciones han sido construidas en base a la fotometría superficial realizada sobre imágenes MOSAIC II-CTIO de 177 galaxias, siendo el $44 \%$ de ellas nuevos objetos descubiertos, no catalogados en la bibliografía. Del total de esta muestra de galaxias de tipo temprano, 53 galaxias son miembros confirmados a partir de velocidades radiales, medidas en espectros GEMINI-GMOS, VIMOSVLT, y de la literatura. Se ha utilizado como base para la identificación de galaxias el catálogo FSgo Ferguson \& Sandage (1990), el cual brinda un criterio morfológico de membresía. Se seleccionaron las galaxias de tipo temprano con membresía 1 según FSgo (miembros definite), confirmadas por velocidad radial y/o cuya fotometría las ubica a $\pm 3 \sigma$ de la relación color-magnitud (Figura $>$ 5.2).

Se obtuvieron magnitudes y colores integrados totales además de los parámetros estructurales, para cada galaxia, mediante el ajuste de un modelo de Sérsic a los perfiles de brillo observados, que fueron luego integrados numéricamente hasta infinito. A partir de los distintos parámetros obtenidos por estos ajustes, se han construido las relaciones de escala para la población de galaxias tempranas del cúmulo de Antlia.

El diagrama color-magnitud en el sistema fotométrico de Washington muestra que todas las galaxias de tipo temprano siguen una estrecha relación lineal (RCM), a lo largo de más de 1o mag. Prácticamente todas las galaxias confirmadas espectroscópicamente como miembros del cúmulo se encuentran dentro de $\pm 3 \sigma$ de la RCM, lo que sustenta la existencia del cúmulo como una única estructura global. Se ha detectado un leve apartamiento en el extremo brillante de la RCM, que puede interpretarse como una consecuencia de que las fusiones secas sean el proceso dominante en la formación de galaxias elípticas gigantes, a partir de $z \sim 2$ (e.g. Jiménez et al., 2011).

Las galaxias de tipo temprano de Antlia pueden ajustarse mediante relaciones lineales en los planos $\mu_{0}-M_{V}$ y $M_{V}-\log (n)$. Siguiendo los pasos del procedimiento aplicado por Graham (2013, y referencias allí citadas), estas relaciones lineales junto con las relaciones matemáticas que vinculan los parámetros del modelo de Sérsic, hemos obtenido dos funciones curvas que ajustan a la mayoría de las galaxias de tipo temprano en los planos $\mu_{e}-M_{V}$ y $\log (r e)-M_{V}$. Las dos 
galaxias cE confirmadas como miembros del cúmulo no siguen estas relaciones curvas, y la mayoría de las galaxias $S 0$ quedan además por fuera de la relación curva $\mu_{e}-M_{V}$. Debido a las pocas galaxias Es brillantes y cEs presentes en Antlia, no es posible afirmar cuál de las dos opciones es la más apropiada para ajustar los datos en estos últimos planos: una única función curva o dos relaciones lineales con pendientes diferentes (Kormendy et al., 2009, y referencias allí citadas). Es necesario recordar que los perfiles de brillo para las galaxias $c E$ y So han sido ajustados con modelos de Sérsic de una sola componente.

Si incluimos datos de otros grupos y cúmulos en los planos $\mu_{e}-$ $M_{V}$ y $\log \left(r_{e}\right)-M_{V}$, las galaxias Es brillantes y las cEs llenan los espacios que habían quedado prácticamente vacíos en los gráficos. En estos casos, como en la relación de Kormendy, el ajuste de dos relaciones lineales de distinta pendiente para las galaxias de tipo temprano brillantes y enanas resulta ser una opción válida. Las relaciones curvas obtenidas previamente, utilizando solo datos de Antlia, proveen un ajuste razonable si no se tienen en cuenta las cEs, pero aún en ese caso el ajuste para las galaxias brillantes resulta desplazado.

Finalmente, los resultados de las relaciones de escala de Antlia, sumados a los de otros grupos y cúmulos, parecen estar en un mejor acuerdo con el escenario sugerido por Kormendy y colaboradores, quienes proponen que las elípticas brillantes se formarían por fusiones ("mergers"), y la enanas a partir de galaxias de tipo tardío por efectos del entorno y "feedback" de supernovas (Kormendy et al., 2009, y referencias allí citadas). 
Parte V

APÉNDICE 

CATÁlOGOS DEL CÚMULO DE ANTLIA

\section{A.1 CATÁlogos}

En este Apéndice se listan las propiedades de las galaxias estudiadas: identificación (FSgo y ANTL para las galaxias nuevas); coordenadas, morfología (según FSgo y nueva clasificación para las galaxias ANTL), índice de color $(B-V)$, índice de Sérsic, brillo superficial central, longitud de escala, brillo superficial efectivo, radio efectivo (estos últimos parámetros correspondientes al filtro $T_{1}$ ), fotometría de Washington, y velocidad radial heliocéntrica. Una descripción de la selección de la muestra se puede consultar en el Capítulo §5. 


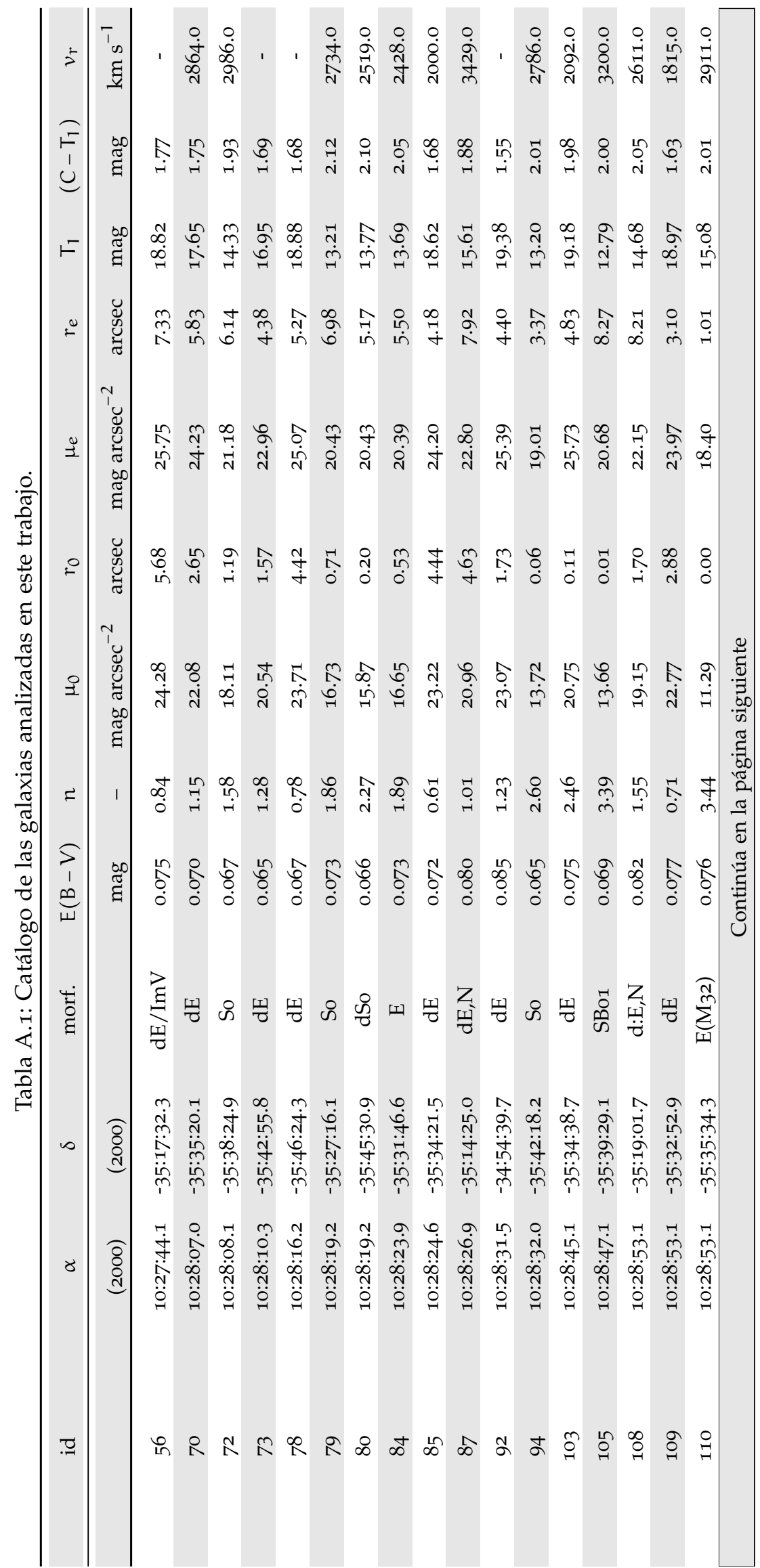




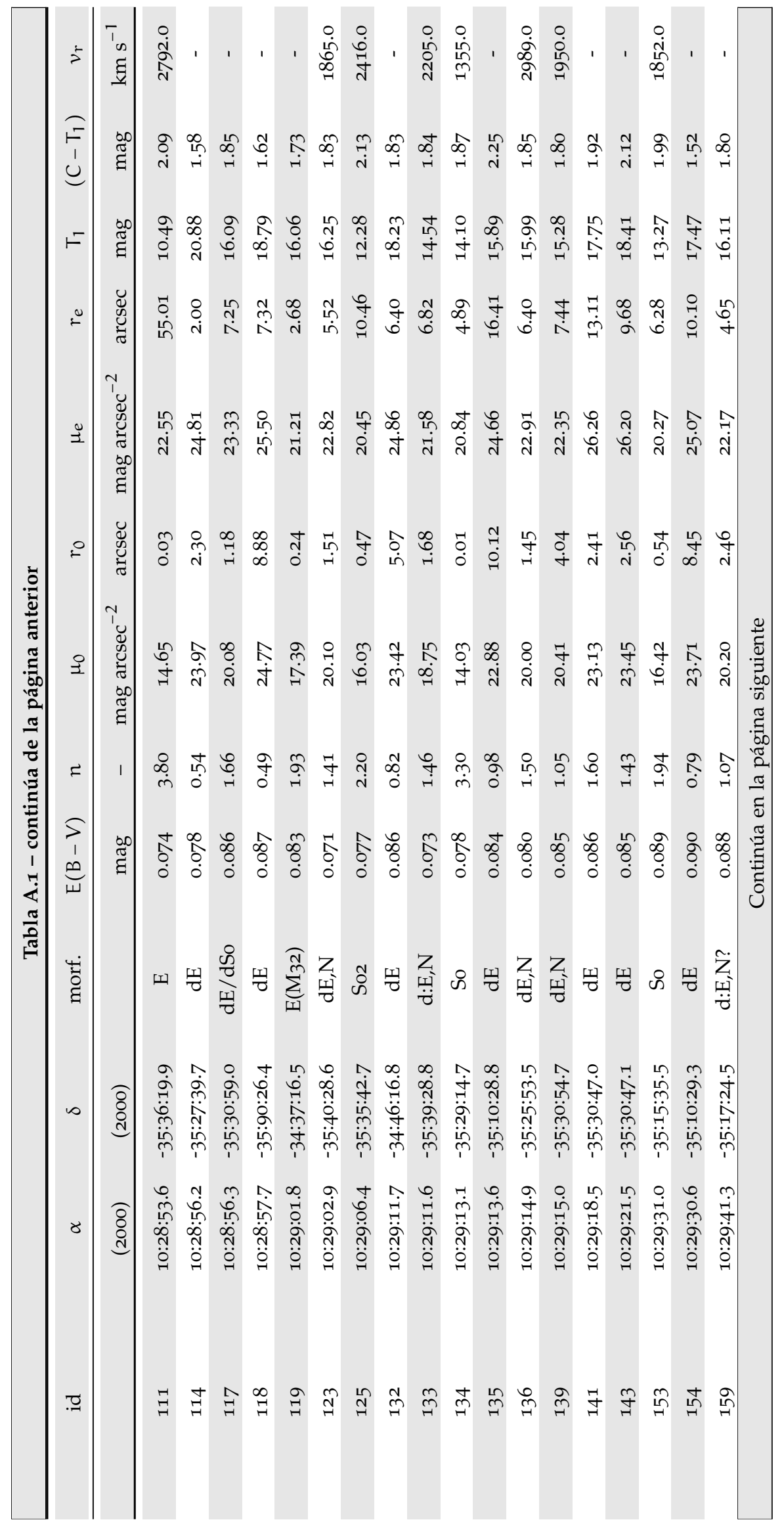




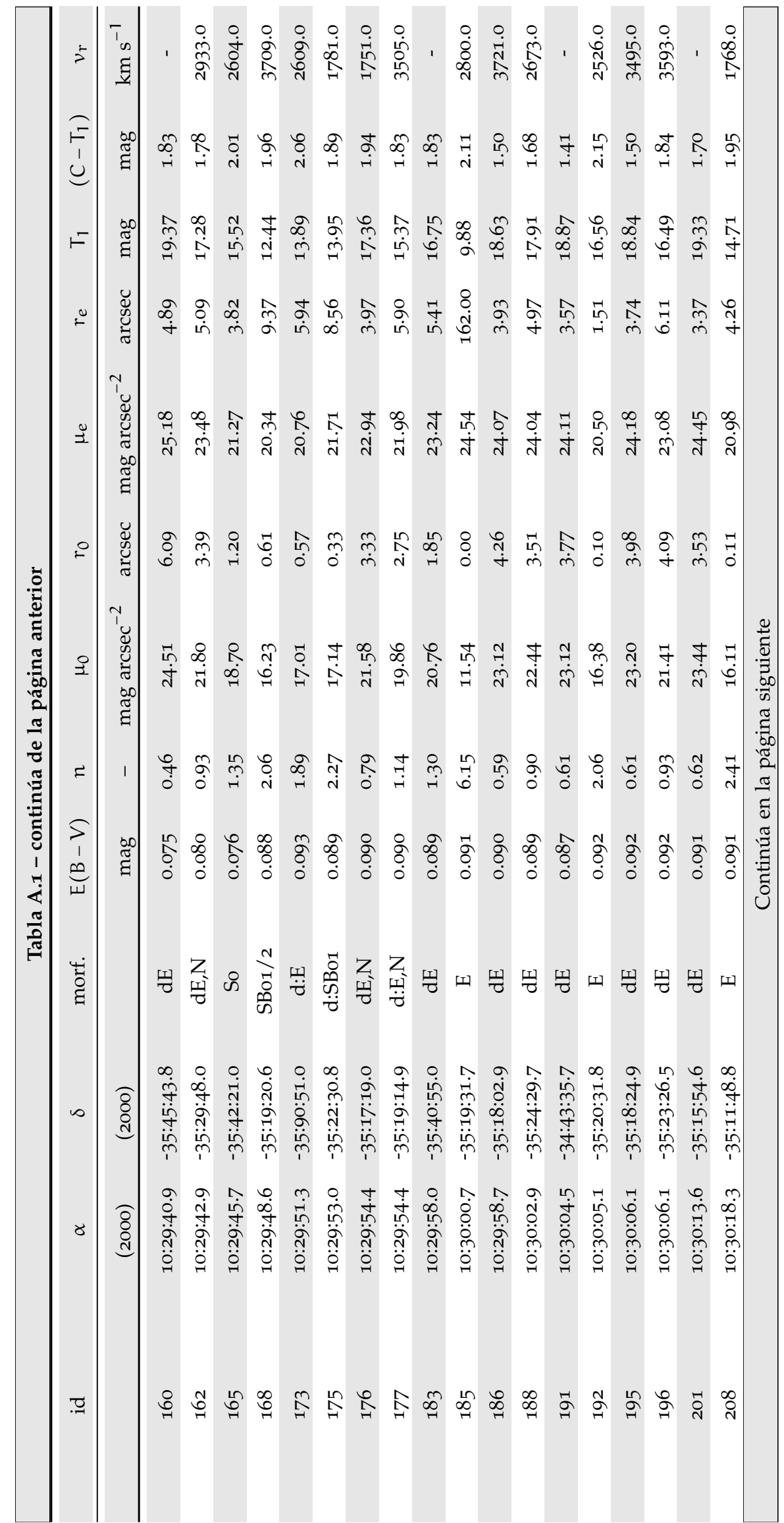




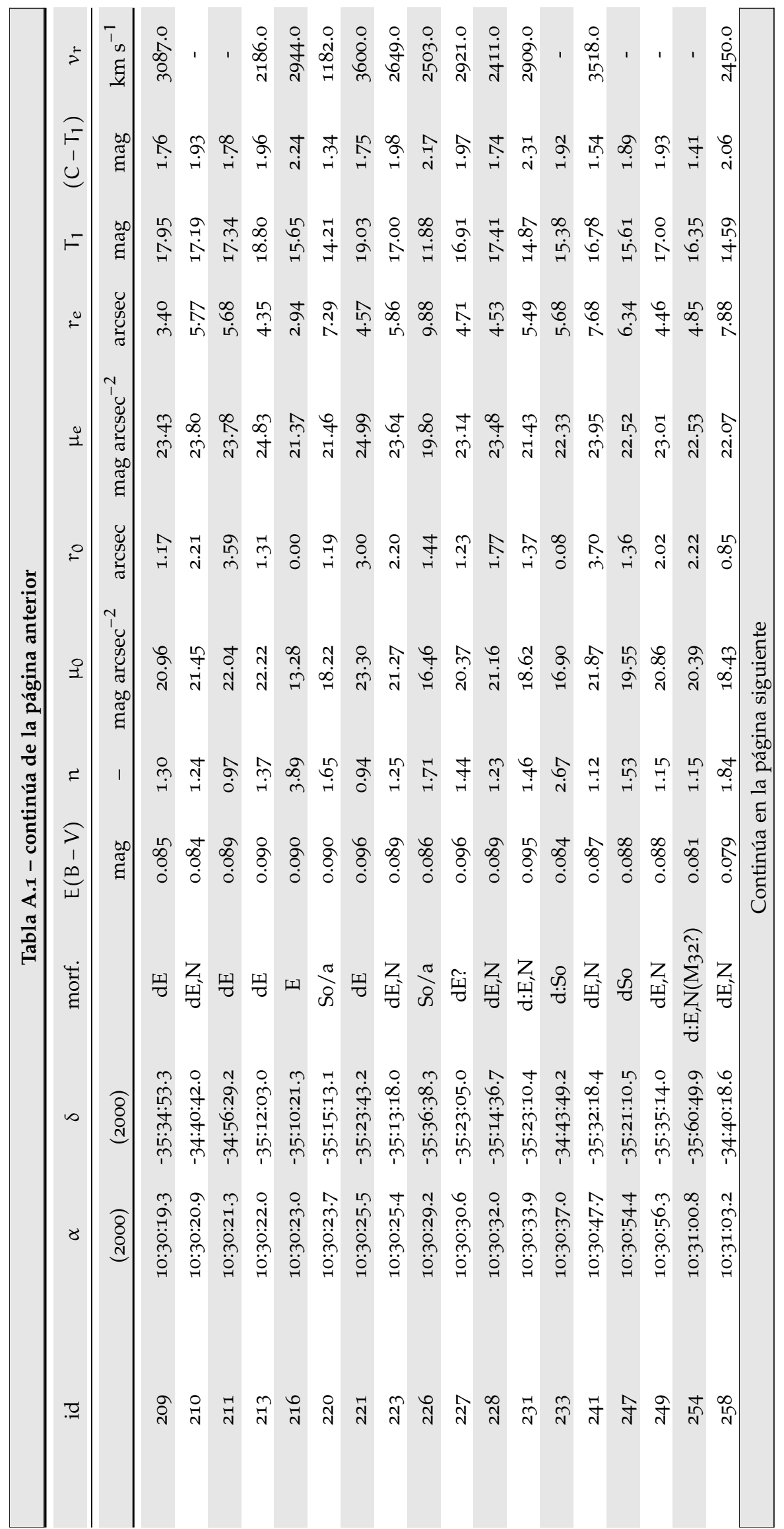




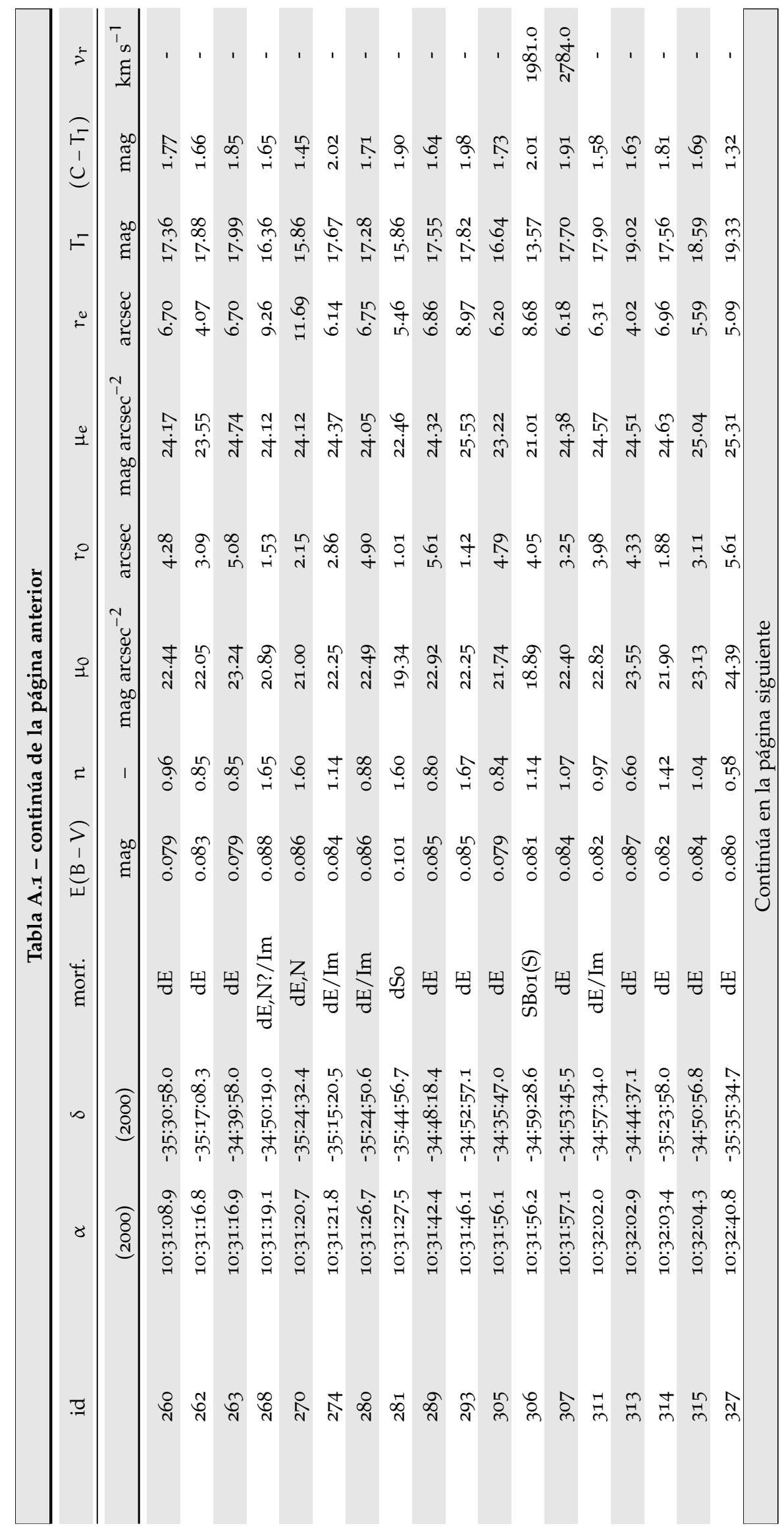




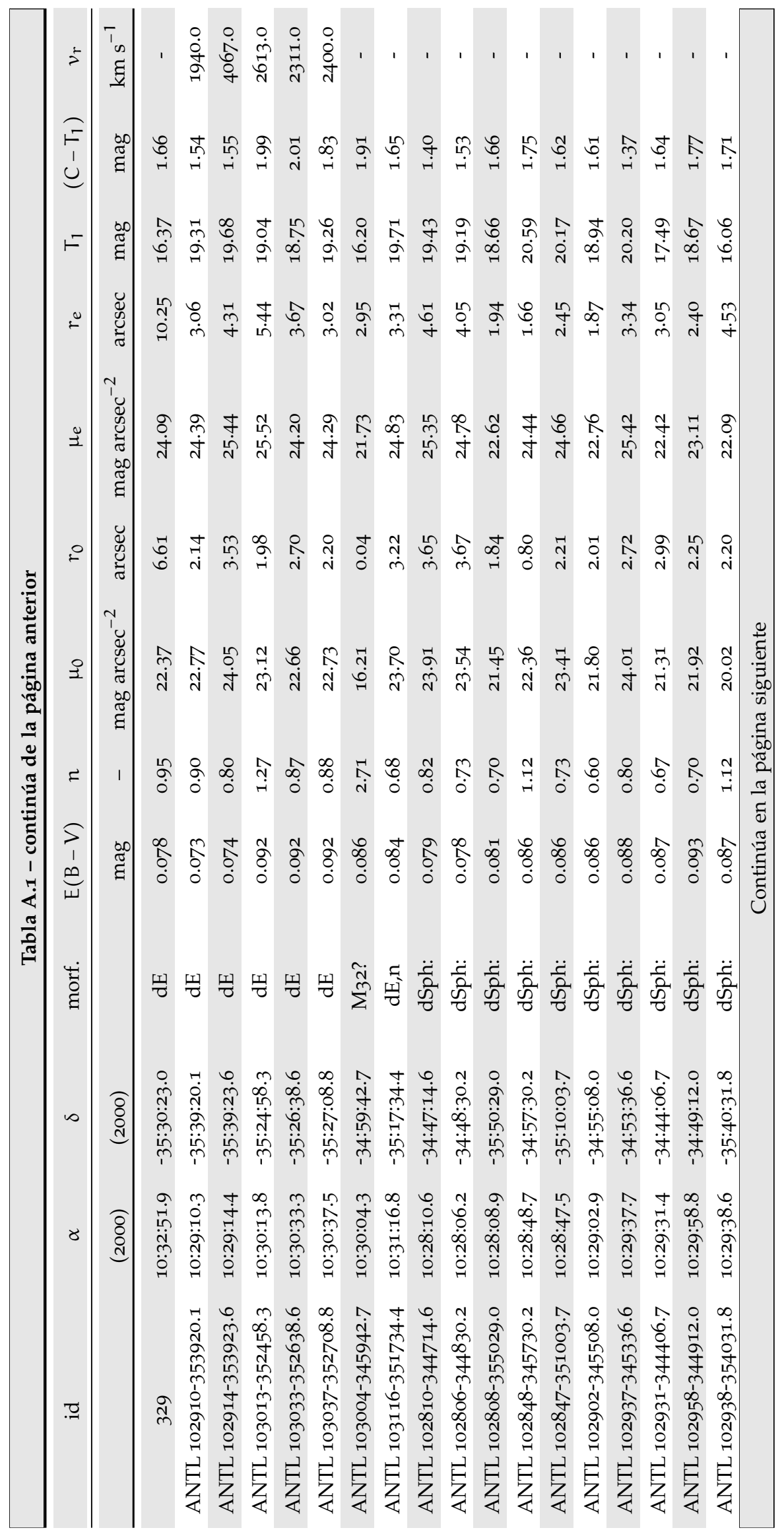




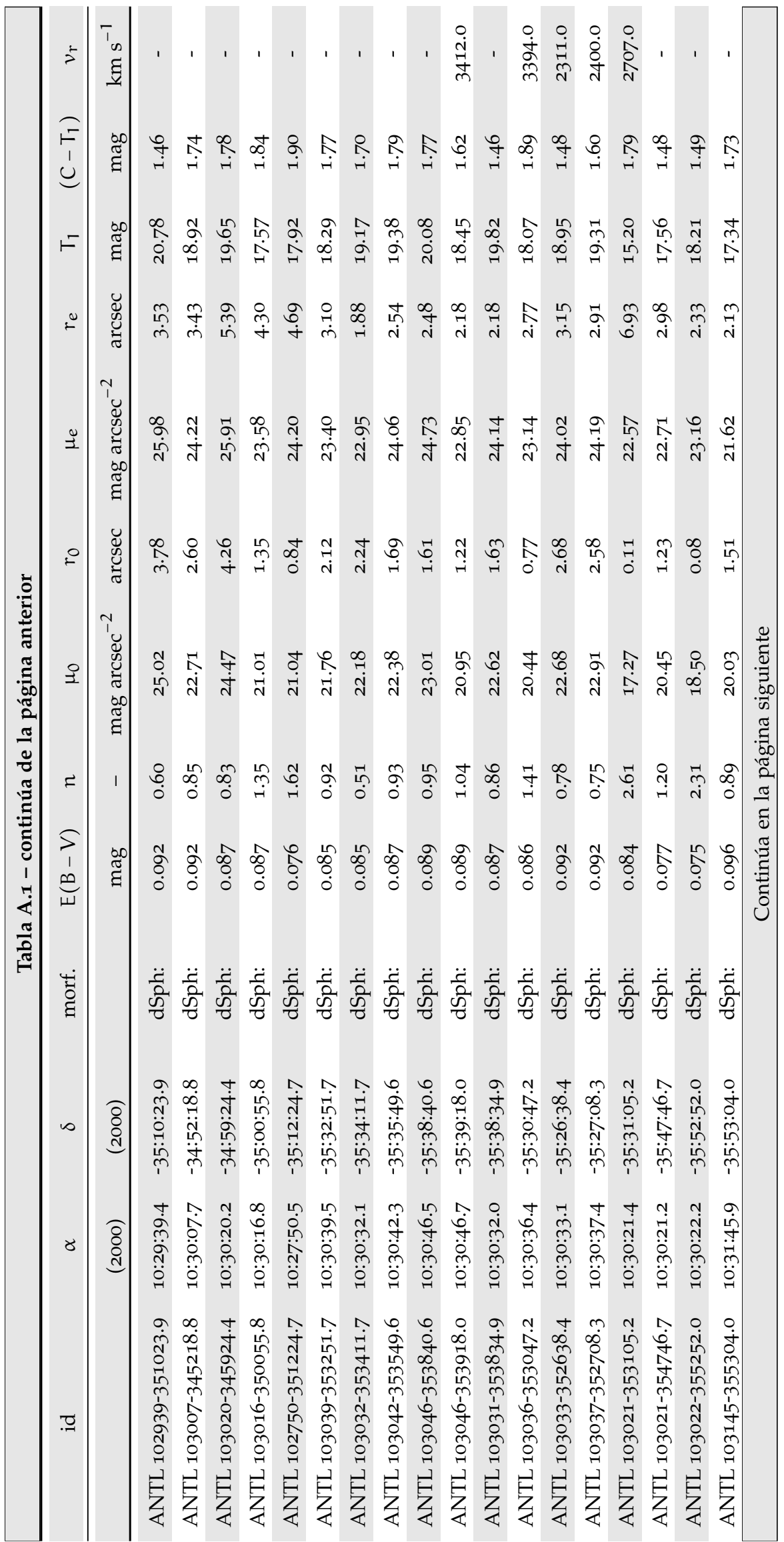




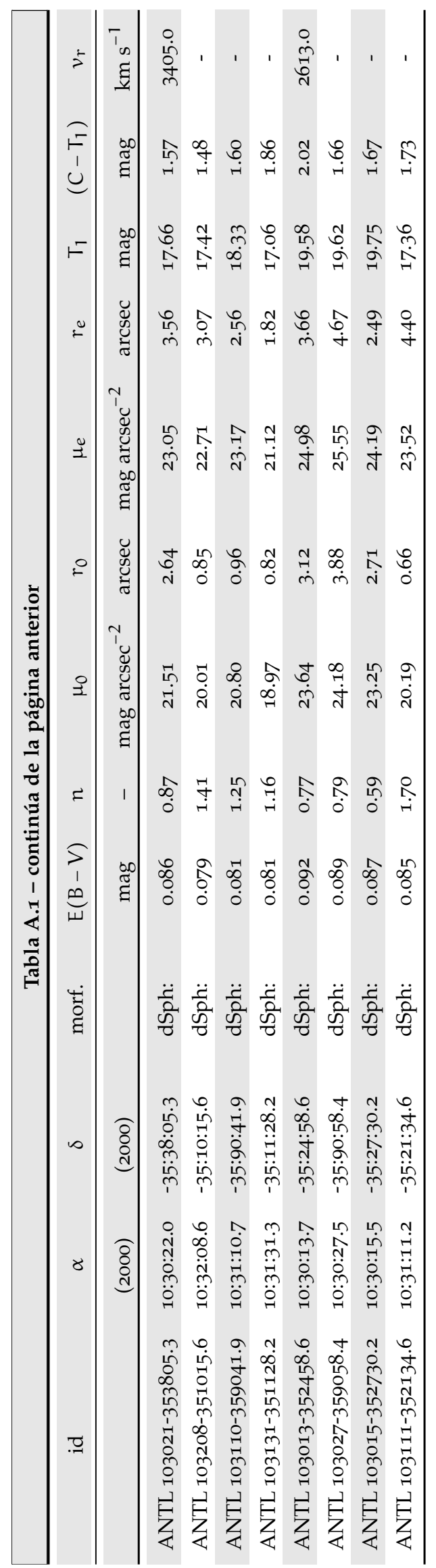



B.I PERFILES

En este Apéndice se muestran los perfiles de brillo superficial de las galaxias de la muestra. Se adjutan sólo 4 ejemplos y los restantes se puede descargar en: http://pinque. fcaglp. unlp. edu . ar/ juanpablo/ tesis/
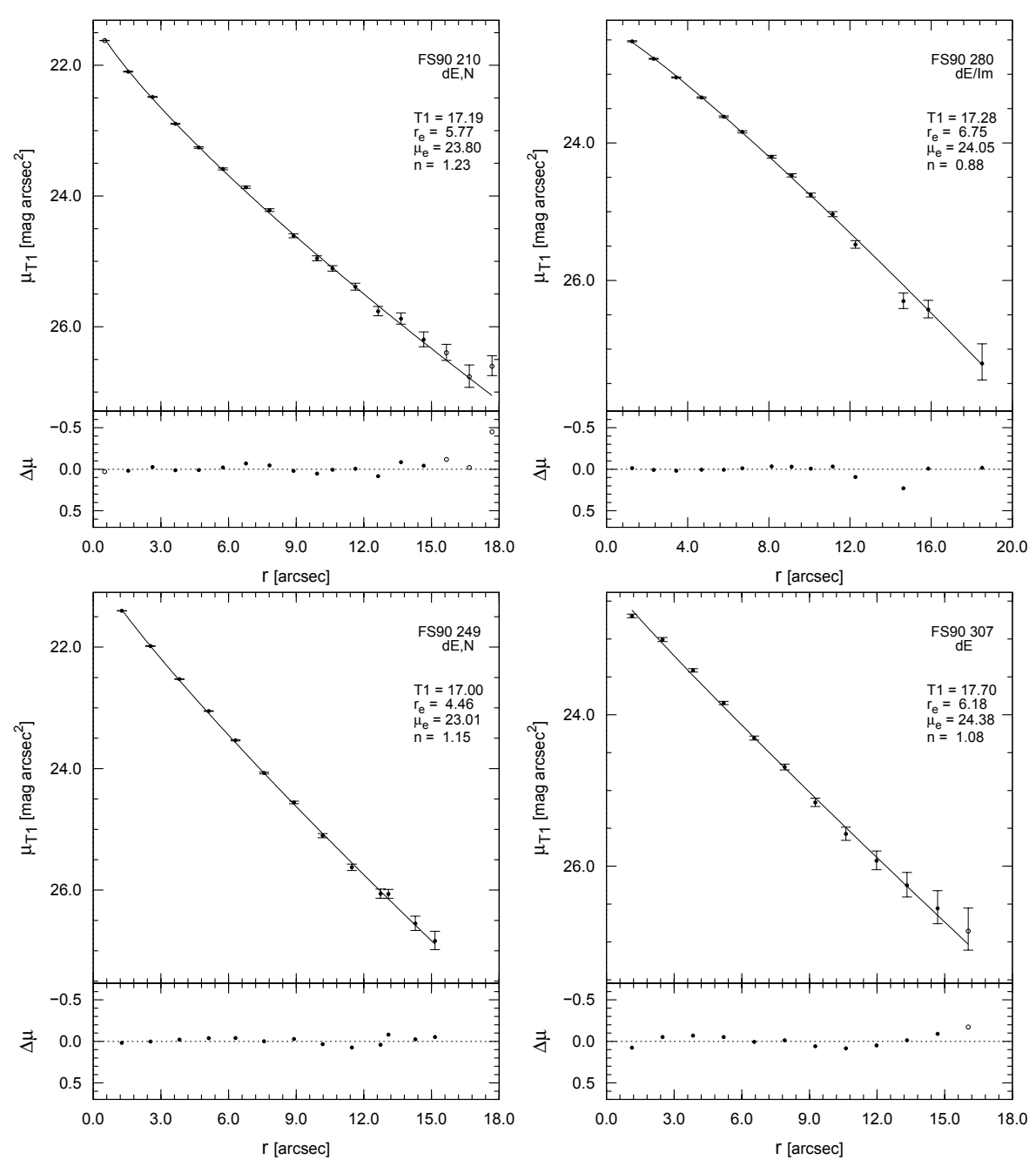



\section{BIBLIOGRAFÍA}

Abramowitz, M. y Stegun, I. A.: 1972, Handbook of Mathematical Functions, With Formulas, Graphs, and Mathematical Tables,, Dover Publications, Incorporated (citado en página 42)

Allanson, S. P., Hudson, M. J., Smith, R. J., y Lucey, J. R.: 2009, ApJ 702, 1275 (citado en página 8)

Arimoto, N. y Yoshii, Y.: 1987, A\&A 173, 23 (citado en página 9)

Baade, W.: 1944, ApJ 100, 147 (citado en página 24)

Baldry, I. K.: 2008, Astronomy and Geophysics 49(5), 25 (citado en página 4)

Barnes, J. E.: 2004, MNRAS 350, 798 (citado en página 12)

Barnes, J. E. y Hernquist, L.: 1992a, ARA\&A 30, 705 (citado en página 7)

Barnes, J. E. y Hernquist, L.: 1992b, Nature 360, 715 (citado en página 11)

Bassino, L. P., Richtler, T., y Dirsch, B.: 2008, MNRAS 386, 1145 (citado en página 22)

Bautz, L. P. y Morgan, W. W.: 1970, ApJ 162, L149 (citado en página 17)

Bekki, K. y Shioya, Y.: 1997, ApJ 478, L17 (citado en página 7)

Bell, E. F., McIntosh, D. H., Katz, N., y Weinberg, M. D.: 2003, ApJS 149, 289 (citado en página 9)

Bender, R., Burstein, D., y Faber, S. M.: 1992, ApJ 399, 462 . (citado en páginas ix, 8 y 25)

Bender, R., Burstein, D., y Faber, S. M.: 1993, ApJ 411, 153 (citado en página 8)

Bender, R., Doebereiner, S., y Moellenhoff, C.: 1988, A\&AS 74, 385 (citado en página 37)

Bender, R. y Saglia, R. P.: 1999, in D. R. Merritt, M. Valluri, \& J. A. Sellwood (eds.), Galaxy Dynamics - A Rutgers Symposium, Vol. 182 of Astronomical Society of the Pacific Conference Series, p. 113 (citado en página 12)

Bender, R., Surma, P., Doebereiner, S., Moellenhoff, C., y Madejsky, R.: 1989, A\&A 217, 35 (citado en página 7)

Bernardi, M., Hyde, J. B., Sheth, R. K., Miller, C. J., y Nichol, R. C.: 2007, AJ 133, 1741 (citado en página 64)

Bernardi, M., Roche, N., Shankar, F., y Sheth, R. K.: 2011, MNRAS 412, 684 (citado en página 64) 
Bernardi, M., Sheth, R. K., Annis, J., Burles, S., Eisenstein, D. J., Finkbeiner, D. P., Hogg, D. W., Lupton, R. H., Schlegel, D. J., SubbaRao, M., Bahcall, N. A., Blakeslee, J. P., Brinkmann, J., Castander, F. J., Connolly, A. J., Csabai, I., Doi, M., Fukugita, M., Frieman, J., Heckman, T., Hennessy, G. S., Ivezić, Ž., Knapp, G. R., Lamb, D. Q., McKay, T., Munn, J. A., Nichol, R., Okamura, S., Schneider, D. P., Thakar, A. R., y York, D. G.: 2003, AJ 125, 1866 (citado en página 8)

Binggeli, B. y Cameron, L. M.: 1991, A\&A 252, 27 (citado en página 24)

Binggeli, B. y Jerjen, H.: 1998, A\&A 333, 17 (citado en página 26)

Binggeli, B., Sandage, A., y Tammann, G. A.: 1985, AJ 90, 1681 (citado en página 20)

Binggeli, B., Sandage, A., y Tammann, G. A.: 1988, ARA\&A 26, 509 (citado en página 63)

Binggeli, B., Sandage, A., y Tarenghi, M.: 1984, AJ 89, 64 (citado en página 13)

Blumenthal, G. R., Faber, S. M., Primack, J. R., y Rees, M. J.: 1984, Nature 311, 517 (citado en página 11)

Boselli, A., Boissier, S., Cortese, L., y Gavazzi, G.: 2008, A\&A 489, 1015 (citado en página 14)

Boselli, A. y Gavazzi, G.: 2006, PASP 118, 517 (citado en página 13)

Bower, R. G., Lucey, J. R., y Ellis, R. S.: 1992, MNRAS 254, 601 . (citado en páginas 8 y 64)

Bower, R. G., Terlevich, A., Kodama, T., y Caldwell, N.: 1999, in P. Carral \& J. Cepa (eds.), Star Formation in Early Type Galaxies, Vol. 163 of Astronomical Society of the Pacific Conference Series, p. 211. (citado en páginas ix y 10)

Boylan-Kolchin, M., Ma, C.-P., y Quataert, E.: 2005, in American Astronomical Society Meeting Abstracts, Vol. 37 of Bulletin of the American Astronomical Society, p. \#105.04 (citado en página 11)

Boylan-Kolchin, M., Ma, C.-P., y Quataert, E.: 2006, MNRAS 369, 1081 (citado en página 11)

Bressan, A., Chiosi, C., y Fagotto, F.: 1994, ApJS 94, 63 (citado en página 9)

Busarello, G., Capaccioli, M., Capozziello, S., Longo, G., y Puddu, E.: 1997, A\&A 320, 415 (citado en página 8)

Buta, R. J.: 2013, Galaxy Morphology, p. 1 (citado en página 3)

Buzzoni, A., Cellone, S. A., Saracco, P., y Zucca, E.: 2012, MNRAS 420, 3427

Calderón, J. P.: 2010, Master's thesis, Facultad de Ciencias Astronómicas y Geofísicas - Universidad Nacional de La Plata, Ciudad de La Plata, Buenos Aires, Argentina . (citado en páginas 29 y 30)

Caldwell, N.: 1999, AJ 118, 1230 (citado en página 26) 
Canterna, R.: 1976, AJ 81, 228 (citado en página 29)

Caon, N., Capaccioli, M., y DÓnofrio, M.: 1993, MNRAS 265, 1013 (citado en página 66)

Capelato, H. V., de Carvalho, R. R., y Carlberg, R. G.: 1995, ApJ 451, 525 (citado en página 11 )

Capetti, A. y Balmaverde, B.: 2005, A\&A 440, 73 (citado en página 65)

Caso, J. P., Bassino, L. P., Richtler, T., Calderón, J. P., y Smith Castelli, A. V.: 2014, MNRAS 442, 891 . (citado en páginas 23 y 31)

Caso, J. P., Bassino, L. P., Richtler, T., Smith Castelli, A. V., y Faifer, F. R.: 2013, MNRAS 430, 1088 (citado en página 23)

Chilingarian, I., Cayatte, V., Revaz, Y., Dodonov, S., Durand, D., Durret, F., Micol, A., y Slezak, E.: 2009, Science 326, 1379 (citado en página 68)

Chiosi, C. y Carraro, G.: 2002, MNRAS 335, 335 (citado en página 9)

Cimatti, A., Daddi, E., Renzini, A., Cassata, P., Vanzella, E., Pozzetti, L., Cristiani, S., Fontana, A., Rodighiero, G., Mignoli, M., y Zamorani, G.: 2004, Nature 430, 184 (citado en página 9)

Ciotti, L.: 1991, A\&A 249, 99 (citado en página 41)

Ciotti, L., Lanzoni, B., y Renzini, A.: 1996, MNRAS 282, 1 (citado en página 8)

Ciotti, L. y van Albada, T. S.: 2001, ApJ 552, L13 (citado en página 11)

Clemens, M. S., Bressan, A., Nikolic, B., Alexander, P., Annibali, F., y Rampazzo, R.: 2006, MNRAS 370, 702 (citado en página 5)

Clemens, M. S., Bressan, A., Nikolic, B., y Rampazzo, R.: 2009, MNRAS 392, L35 (citado en página 5)

Collobert, M., Sarzi, M., Davies, R. L., Kuntschner, H., y Colless, M.: 2006, MNRAS 370, 1213 (citado en página 12)

Cowie, L. L., Songaila, A., Hu, E. M., y Cohen, J. G.: 1996, AJ 112, 839 (citado en página 12)

Croton, D. J., Springel, V., White, S. D. M., De Lucia, G., Frenk, C. S., Gao, L., Jenkins, A., Kauffmann, G., Navarro, J. F., y Yoshida, N.: 2006, MNRAS 365, 11 (citado en página 12)

Dantas, C. C., Capelato, H. V., Ribeiro, A. L. B., y de Carvalho, R. R.: 2003, MNRAS 340, 398 (citado en página 11)

Davies, J. I. y Phillipps, S.: 1988, MNRAS 233, 553 (citado en página 13)

De Lucia, G., Kauffmann, G., y White, S. D. M.: 2004, MNRAS 349, 1101 (citado en página 12)

de Vaucouleurs, G.: 1948, Annales dÁstrophysique 11, 247 (citado en página 5)

Dirsch, B., Richtler, T., y Bassino, L. P.: 2003, A\&A 408, 929 . (citado en páginas $17,22,29$ y 30) 
Djorgovski, S. y Davis, M.: 1987, ApJ 313, 59 . (citado en páginas 8, 24 y 71)

DÓnofrio, M., Capaccioli, M., y Caon, N.: 1994, MNRAS 271, 523

Dressler, A.: 1980, ApJ 236, 351 (citado en página 5)

Dressler, A., Lynden-Bell, D., Burstein, D., Davies, R. L., Faber, S. M., Terlevich, R., y Wegner, G.: 1987, ApJ 313, 42 (citado en página 8)

D'Onofrio, M., Fasano, G., Varela, J., Bettoni, D., Moles, M., Kjærgaard, P., Pignatelli, E., Poggianti, B., Dressler, A., Cava, A., Fritz, J., Couch, W. J., y Omizzolo, A.: 2008, ApJ 685, 875 (citado en página 71)

D'Onofrio, M., Valentinuzzi, T., Secco, L., Caimmi, R., y Bindoni, D.: 2006, New A Rev. 50, 447 (citado en página 9)

Ebneter, K., Davis, M., y Djorgovski, S.: 1988, AJ 95, 422 (citado en página 7)

Eggen, O. J., Lynden-Bell, D., y Sandage, A. R.: 1962, ApJ 136, 748 (citado en página 9)

Erwin, P., Graham, A. W., y Caon, N.: 2004, Coevolution of Black Holes and Galaxies p. 12 (citado en página 6)

Evstigneeva, E. A., de Carvalho, R. R., Ribeiro, A. L., y Capelato, H. V.: 2004, MNRAS 349, 1052 (citado en página 11)

Faber, S. M.: 1987, Science 238, 1155 (citado en página 8)

Faber, S. M. y Jackson, R. E.: 1976, ApJ 204, 668 . (citado en páginas 8 y 24$)$

Faber, S. M., Tremaine, S., Ajhar, E. A., Byun, Y.-I., Dressler, A., Gebhardt, K., Grillmair, C., Kormendy, J., Lauer, T. R., y Richstone, D.: 1997, AJ 114, 1771 (citado en página 38)

Fabricant, D., Lecar, M., y Gorenstein, P.: 1980, ApJ 241, 552 (citado en página 18 )

Fall, S. M. y Efstathiou, G.: 1980, MNRAS 193, 189 (citado en página 11)

Ferguson, H. C. y Binggeli, B.: 1994, A\&A Rev. 6, 67 (citado en página 13)

Ferguson, H. C. y Sandage, A.: 1990, AJ 100, 1 . (citado en páginas ix, $14,17,18,19,20$ y 75)

Ferguson, H. C. y Sandage, A.: 1991, AJ 101, 765 . (citado en páginas x y 20)

Ferrarese, L., Côté, P., Jordán, A., Peng, E. W., Blakeslee, J. P., Piatek, S., Mei, S., Merritt, D., Milosavljević, M., Tonry, J. L., y West, M. J.: 2006, ApJS 164, 334 . (citado en páginas 13, 26, 64 y 68)

Ferrarese, L. y Merritt, D.: 2000, ApJ 539, L9 (citado en página 8)

Finoguenov, A., Jones, C., Böhringer, H., y Ponman, T. J.: 2002, ApJ 578, 74 (citado en página 19) 
Finoguenov, A., Reiprich, T. H., y Böhringer, H.: 2001, A\&A 368, 749 (citado en página 19)

Fisher, D. B. y Drory, N.: 2008, AJ 136, 773

Forbes, D. A.: 1991, MNRAS 249, 779 (citado en página 8)

Forbes, D. A., Lasky, P., Graham, A. W., y Spitler, L.: 2008, MNRAS 389, 1924 (citado en página 67)

Fukugita, M., Shimasaku, K., y Ichikawa, T.: 1995, PASP 107, 945 (citado en página 57)

Gallazzi, A., Brinchmann, J., Charlot, S., y White, S. D. M.: 2008, MNRAS 383, 1439 (citado en página 9)

Gallazzi, A., Charlot, S., Brinchmann, J., y White, S. D. M.: 2006, MNRAS 370, 1106 (citado en página 64)

Gavazzi, G., Donati, A., Cucciati, O., Sabatini, S., Boselli, A., Davies, J., y Zibetti, S.: 2005, A\&A 430, 411 . (citado en páginas 26, 44 y 45)

Gebhardt, K., Bender, R., Bower, G., Dressler, A., Faber, S. M., Filippenko, A. V., Green, R., Grillmair, C., Ho, L. C., Kormendy, J., Lauer, T. R., Magorrian, J., Pinkney, J., Richstone, D., y Tremaine, S.: 2000, ApJ 539, L13 (citado en página 8)

Geisler, D.: 1996, AJ 111, 480 . (citado en páginas 30 y 57)

Gibbons, R. A., Fruchter, A. S., y Bothun, G. D.: 2001, AJ 121, 649 (citado en página 8)

González-García, A. C. y van Albada, T. S.: 2003, MNRAS 342, L36 (citado en página 11)

Goudfrooij, P. y de Jong, T.: 1995, A\&A 298, 784 (citado en página 8)

Graham, A. W.: 2004, ApJ 613, L33 . (citado en páginas 6 y 7)

Graham, A. W.: 2008, ApJ 680, 143 (citado en página 64)

Graham, A. W.: 2011, in M. Koleva, P. Prugniel, \& I. Vauglin (eds.), EAS Publications Series, Vol. 48 of EAS Publications Series, pp 231-236 . (citado en páginas 6o y 64)

Graham, A. W.: 2013, Elliptical and Disk Galaxy Structure and Modern Scaling Laws, p. 91, Planets, Stars and Stellar Systems. Volume 6: Extragalactic Astronomy and Cosmology . (citado en páginas 57, 59, 61, 66, 67, 71 y 75)

Graham, A. W. y Driver, S. P.: 2007, ApJ 655, 77 (citado en página 6)

Graham, A. W., Erwin, P., Caon, N., y Trujillo, I.: 2003a, in V. AvilaReese, C. Firmani, C. S. Frenk, \& C. Allen (eds.), Revista Mexicana de Astronomia y Astrofisica Conference Series, Vol. 17 of Revista Mexicana de Astronomia y Astrofisica Conference Series, pp 196-197 (citado en página 6)

Graham, A. W., Erwin, P., Trujillo, I., y Asensio Ramos, A.: 2003b, AJ 125, 2951 (citado en página 6)

Graham, A. W. y Guzmán, R.: 2003, AJ 125, 2936 . (citado en páginas 57,65 y 66) 
Graves, G. J., Faber, S. M., y Schiavon, R. P.: 2009, ApJ 698, 1590 (citado en página 8)

Grillo, C. y Gobat, R.: 2010, MNRAS 402, L67 (citado en página 8)

Gültekin, K., Richstone, D. O., Gebhardt, K., Lauer, T. R., Tremaine, S., Aller, M. C., Bender, R., Dressler, A., Faber, S. M., Filippenko, A. V., Green, R., Ho, L. C., Kormendy, J., Magorrian, J., Pinkney, J., y Siopis, C.: 2009, ApJ 698, 198 (citado en página 8)

Guzman, R., Lucey, J. R., Carter, D., y Terlevich, R. J.: 1992, MNRAS 257, 187 (citado en página 8)

Haehnelt, M. G. y Kauffmann, G.: 2002, MNRAS 336, L61 (citado en página 7)

Harris, H. C. y Canterna, R.: 1977, AJ 82, 798 (citado en página 31)

Hopp, U. y Materne, J.: 1985, A\&AS 61, 93 (citado en página 17)

Hubble, E. P.: 1936, Realm of the Nebulae, Realm of the Nebulae, by E.P. Hubble. New Haven: Yale University Press, 1936. ISBN 9780300025002 . (citado en páginas ix y 3)

Humphrey, P. J. y Buote, D. A.: 2010, MNRAS 403, 2143 (citado en página 8)

Jaffé, Y. L., Aragón-Salamanca, A., De Lucia, G., Jablonka, P., Rudnick, G., Saglia, R., y Zaritsky, D.: 2011, MNRAS 410, 280 (citado en página 50 )

Janz, J. y Lisker, T.: 2008, ApJ 689, L25 (citado en página 68)

Janz, J. y Lisker, T.: 2009, ApJ 696, L102 (citado en página 64)

Jedrzejewski, R. I.: 1987, MNRAS 226, 747 (citado en página 36)

Jerjen, H. y Binggeli, B.: 1997, in M. Arnaboldi, G. S. Da Costa, \& P. Saha (eds.), The Nature of Elliptical Galaxies; 2nd Stromlo Symposium, Vol. 116 of Astronomical Society of the Pacific Conference Series, p. 239 . (citado en páginas 26 y 65)

Jerjen, H., Binggeli, B., y Freeman, K. C.: 2000, AJ 119, 593 (citado en página 26)

Jiménez, N., Cora, S. A., Bassino, L. P., Tecce, T. E., y Smith Castelli, A. V.: 2011, MNRAS 417, 785 . (citado en páginas 64 y 75)

Jorgensen, I., Franx, M., y Kjaergaard, P.: 1996, MNRAS 280, 167 (citado en página 9)

Kawata, D. y Gibson, B. K.: 2003, MNRAS 340, 908 (citado en página 9)

Kharb, P., Capetti, A., Axon, D. J., Chiaberge, M., Grandi, P., Robinson, A., Giovannini, G., Balmaverde, B., Macchetto, D., y Montez, R.: 2012, AJ 143, 78 (citado en página 65)

Khosroshahi, H. G., Raychaudhury, S., Ponman, T. J., Miles, T. A., y Forbes, D. A.: 2004, MNRAS 349, 527 . (citado en páginas 63 y 71)

Klypin, A., Kravtsov, A. V., Valenzuela, O., y Prada, F.: 1999, ApJ 522, 82 (citado en página 13) 
Kodama, T., Arimoto, N., Barger, A. J., y Aragón-Salamanca, A.: 1998, A\&A 334, 99 (citado en página 10)

Kormendy, J.: 1977, ApJ 218, 333 (citado en página 24)

Kormendy, J.: 1985, ApJ 295, 73 (citado en página 60)

Kormendy, J. y Bender, R.: 1996, ApJ 464, L119 (citado en página 37)

Kormendy, J. y Bender, R.: 2012, ApJS 198, 2 . (citado en páginas 3, 4, 5 y 65)

Kormendy, J. y Djorgovski, S.: 1989, ARA\&A 27, 235 (citado en página 37)

Kormendy, J., Fisher, D. B., Cornell, M. E., y Bender, R.: 2009, ApJS 182, 216 . (citado en páginas ix, 21, 26, 65, 66, 67, 71 y 76)

Lagos, C. D. P., Cora, S. A., y Padilla, N. D.: 2008, MNRAS 388, 587 (citado en página 64 )

Larson, R. B.: 1974, MNRAS 166, 585 (citado en página 9)

Larson, R. B.: 1980, Royal Society of London Philosophical Transactions Series A 296, 299 (citado en página 14)

Larson, R. B. y Tinsley, B. M.: 1978, ApJ 219, 46 (citado en página 12)

Lavery, R. J. y Henry, J. P.: 1988, ApJ 330, 596 (citado en página 12)

Lieder, S., Lisker, T., Hilker, M., Misgeld, I., y Durrell, P.: 2012, A\&A 538, A69 (citado en página 62)

Lin, D. N. C. y Faber, S. M.: 1983, ApJ 266, L21 (citado en página 13)

Lisker, T., Grebel, E. K., y Binggeli, B.: 2008, AJ 135, 380 (citado en página 63)

Madau, P., Ferguson, H. C., Dickinson, M. E., Giavalisco, M., Steidel, C. C., y Fruchter, A.: 1996, MNRAS 283, 1388 (citado en página 12)

Malin, D. F. y Carter, D.: 1983, ApJ 274, 534 . (citado en páginas 7 y 10)

Mastropietro, C., Moore, B., Mayer, L., Debattista, V. P., Piffaretti, R., y Stadel, J.: 2005, MNRAS 364, 607 (citado en página 14)

Matteucci, F.: 2003, Ap\&SS 284, 539 (citado en página 9)

McDermid, R. M., Emsellem, E., Shapiro, K. L., Bacon, R., Bureau, M., Cappellari, M., Davies, R. L., de Zeeuw, T., Falcón-Barroso, J., Krajnović, D., Kuntschner, H., Peletier, R. F., y Sarzi, M.: 2006, MNRAS 373, 906 (citado en página 10)

McDonald, M., Courteau, S., Tully, R. B., y Roediger, J.: 2011, MNRAS 414, 2055 (citado en página 45)

Mehlert, D., Thomas, D., Saglia, R. P., Bender, R., y Wegner, G.: 2003, A\&A 407, 423 (citado en página 12)

Mei, S., Raichoor, A., Stanford, A. S., Holden, B. P., Nakata, F., Rosati, P., Shankar, F., Tanaka, M., Ford, H. C., Huertas-Company, M., Illingworth, G. D., Kodama, T., Postman, M., Rettura, A., Blakeslee, 
J. P., Demarco, R., Jee, M. J., y Rick, W.: 2012, in American Astronomical Society Meeting Abstracts 219, Vol. 219 of American Astronomical Society Meeting Abstracts, p. \#411.06 (citado en página 50)

Metcalfe, N., Godwin, J. G., y Peach, J. V.: 1994, MNRAS 267, 431 (citado en página 64)

Mieske, S., Hilker, M., Infante, L., y Mendes de Oliveira, C.: 2007, A\&A 463, 503 (citado en página 63)

Mihos, J. C. y Hernquist, L.: 1996, ApJ 464, 641 (citado en página 12) Milosavljević, M. y Merritt, D.: 2001, ApJ 563, 34 (citado en página 7) Misgeld, I., Hilker, M., y Mieske, S.: 2009, A\&A 496, 683 (citado en página 63)

Misgeld, I., Mieske, S., y Hilker, M.: 2008, A\&A 486, 697 . (citado en páginas 63,64 y 67 )

Mo, H. J., Mao, S., y White, S. D. M.: 1998, MNRAS 295, 319 (citado en página 11 )

Moore, B., Lake, G., y Katz, N.: 1998, ApJ 495, 139 (citado en página 14)

Naab, T., Khochfar, S., y Burkert, A.: 2006, ApJ 636, L81 (citado en página 11)

Nakazawa, K., Makishima, K., Fukazawa, Y., y Tamura, T.: 2000, PASJ 52, 623 - (citado en páginas 18 y 19)

Nieto, J.-L. y Bender, R.: 1989, A\&A 215, 266 (citado en página 7)

Nipoti, C., Londrillo, P., y Ciotti, L.: 2006, MNRAS 370,681 (citado en página 10)

Norris, M. A., Kannappan, S. J., Forbes, D. A., Romanowsky, A. J., Brodie, J. P., Faifer, F. R., Huxor, A., Maraston, C., Moffett, A. J., Penny, S. J., Pota, V., Smith-Castelli, A., Strader, J., Bradley, D., Eckert, K. D., Fohring, D., Stark, J. M. D. V., y Vaduvescu, O.: 2014, ArXiv: 1406.6065 (citado en página 67)

Pedersen, K., Yoshii, Y., y Sommer-Larsen, J.: 1997, ApJ 485, L17 . (citado en páginas ix, 18 y 19)

Peebles, P. J. E.: 1982, ApJ 263, L1 (citado en página 11)

Penny, S. J. y Conselice, C. J.: 2008, MNRAS 383, 247 (citado en página 50)

Prugniel, P. y Simien, F.: 1996, A\&A 309, 749 (citado en página 8)

Prugniel, P. y Simien, F.: 1997, A\&A 321, 111 (citado en página 5)

Reda, F. M., Forbes, D. A., y Hau, G. K. T.: 2005, MNRAS 360, 693 (citado en página 8 )

Rees, M. J. y Ostriker, J. P.: 1977, MNRAS 179, 541 (citado en página II)

Reid, N., Boisson, C., y Sansom, E. A.: 1994, MNRAS 269, 713 (citado en página 7) 
Renzini, A.: 2006, ARA\&A 44, 141 . (citado en páginas 5 y 15)

Rieke, G. H. y Lebofsky, M. J.: 1985, ApJ 288, 618 (citado en página 31)

Robertson, B., Cox, T. J., Hernquist, L., Franx, M., Hopkins, P. F., Martini, P., y Springel, V.: 2006, ApJ 641, 21 . (citado en páginas 8 y II)

Ruhland, C., Bell, E. F., Häußler, B., Taylor, E. N., Barden, M., y McIntosh, D. H.: 2009, ApJ 695, 1058 (citado en página 65)

Sadler, E. M. y Gerhard, O. E.: 1985, MNRAS 214, 177 (citado en página 7)

Saglia, R. P., Maraston, C., Greggio, L., Bender, R., y Ziegler, B.: 2000, A\&A 360, 911 (citado en página 9)

Sandage, A.: 1975, ApJ 202, 563 (citado en página 17)

Schlafly, E. F. y Finkbeiner, D. P.: 2011, ApJ 737, 103 (citado en página 31)

Schweizer, F.: 1980, ApJ 237, 303 (citado en página 11)

Schweizer, F. y Seitzer, P.: 1988, ApJ 328, 88 . (citado en páginas 7 y II)

Scodeggio, M., Gavazzi, G., Belsole, E., Pierini, D., y Boselli, A.: 1998, MNRAS 301, 1001 (citado en página 8)

Secco, L. y Bindoni, D.: 2009, New A 14, 567 (citado en página 8)

Secker, J., Harris, W. E., y Plummer, J. D.: 1997, PASP 109, 1377 (citado en página 63)

Seitzer, P. y Schweizer, F.: 1990, A survey for fine structure in $E+$ So galaxies., pp 270-271 (citado en página 7)

Sérsic, J. L.: 1968, Atlas de galaxias australes, Cordoba, Argentina: Observatorio Astronomico, 1968 . (citado en páginas 5, 10, 26 y 41)

Shaver, P. A., Wall, J. V., Kellermann, K. I., Jackson, C. A., y Hawkins, M. R. S.: 1996, Nature 384, 439 (citado en página 12)

Silk, J.: 1977, ApJ 214, 152 (citado en página 11)

Skelton, R. E., Bell, E. F., y Somerville, R. S.: 2009, ApJ 699, L9 (citado en página 64 )

Smith, R., Davies, J. I., y Nelson, A. H.: 2010, MNRAS 405, 1723 (citado en página 14)

Smith Castelli, A. V., Bassino, L. P., Richtler, T., Cellone, S. A., Aruta, C., y Infante, L.: 2008a, MNRAS 386, 2311 . (citado en páginas 21, $47,50,55,63,64$ y 67)

Smith Castelli, A. V., Cellone, S. A., Faifer, F. R., Bassino, L. P., Richtler, T., Romero, G. A., Calderón, J. P., y Caso, J. P.: 2012, MNRAS 419, 2472 . (citado en páginas ix, 21, 22, 23, 47, 48, 50, 55, 60, 63 y 66)

Smith Castelli, A. V., Faifer, F. R., Richtler, T., y Bassino, L. P.: 2008b, MNRAS 391, 685 (citado en página 21) 
Springel, V., Di Matteo, T., y Hernquist, L.: 2005, ApJ 620, L79 (citado en página 12)

Stanford, S. A., Eisenhardt, P. R., y Dickinson, M.: 1998, ApJ 492, 461 (citado en página 9)

Steinmetz, M. y Navarro, J. F.: 2002, New A 7, 155 (citado en página 10)

Tammann, G. A. y Sandage, A.: 1985, ApJ 294, 81 (citado en página 20)

Terlevich, A. I., Caldwell, N., y Bower, R. G.: 2001, MNRAS 326, 1547 (citado en página 64)

Terlevich, A. I. y Forbes, D. A.: 2002, MNRAS 330, 547 (citado en página 10 )

Terlevich, A. I., Kuntschner, H., Bower, R. G., Caldwell, N., y Sharples, R. M.: 1999, MNRAS 310, 445 (citado en página 63)

Terlevich, R., Davies, R. L., Faber, S. M., y Burstein, D.: 1981, MNRAS 196, 381 (citado en página 8)

Thomas, D., Maraston, C., Bender, R., y Mendes de Oliveira, C.: 2005, ApJ 621, 673 (citado en página 15)

Toomre, A.: 1977, in B. M. Tinsley \& R. B. G. Larson, D. Campbell (eds.), Evolution of Galaxies and Stellar Populations, p. 401 (citado en página 10)

Trenti, M., Bertin, G., y van Albada, T. S.: 2005, A\&A 433, 57 (citado en página 9)

Trinchieri, G. y Goudfrooij, P.: 2002, A\&A 386, 472 (citado en página 8)

Trujillo, I., Aguerri, J. A. L., Cepa, J., y Gutiérrez, C. M.: 2001a, MNRAS 321, 269 (citado en página 43)

Trujillo, I., Aguerri, J. A. L., Cepa, J., y Gutiérrez, C. M.: 2001b, MNRAS 328, 977 (citado en página 43)

Trujillo, I., Burkert, A., y Bell, E. F.: 2004a, ApJ 600, L39 (citado en página 8)

Trujillo, I., Erwin, P., Asensio Ramos, A., y Graham, A. W.: 2004b, AJ 127, 1917 (citado en página 6)

Vaduvescu, O., Kehrig, C., Bassino, L. P., Smith Castelli, A. V., y Calderón, J. P.: 2014, A\&A 563, A118 (citado en página 48)

van Albada, T. S.: 1982, MNRAS 201, 939 (citado en página 9)

van den Bergh, S.: 1976, ApJ 206, 883 • (citado en páginas ix, 4 y 5)

van Dokkum, P. G. y Stanford, S. A.: 2003, ApJ 585, 78 (citado en página 10)

Volonteri, M. y Madau, P.: 2003, in J. M. Centrella (ed.), The Astrophysics of Gravitational Wave Sources, Vol. 686 of American Institute of Physics Conference Series, pp 181-19o (citado en página 7) 
White, S. D. M. y Rees, M. J.: 1978, MNRAS 183, 341 . (citado en páginas 10 y 11 )

Yoshii, Y. y Arimoto, N.: 1987, A\&A 188, 13 (citado en página 13) 



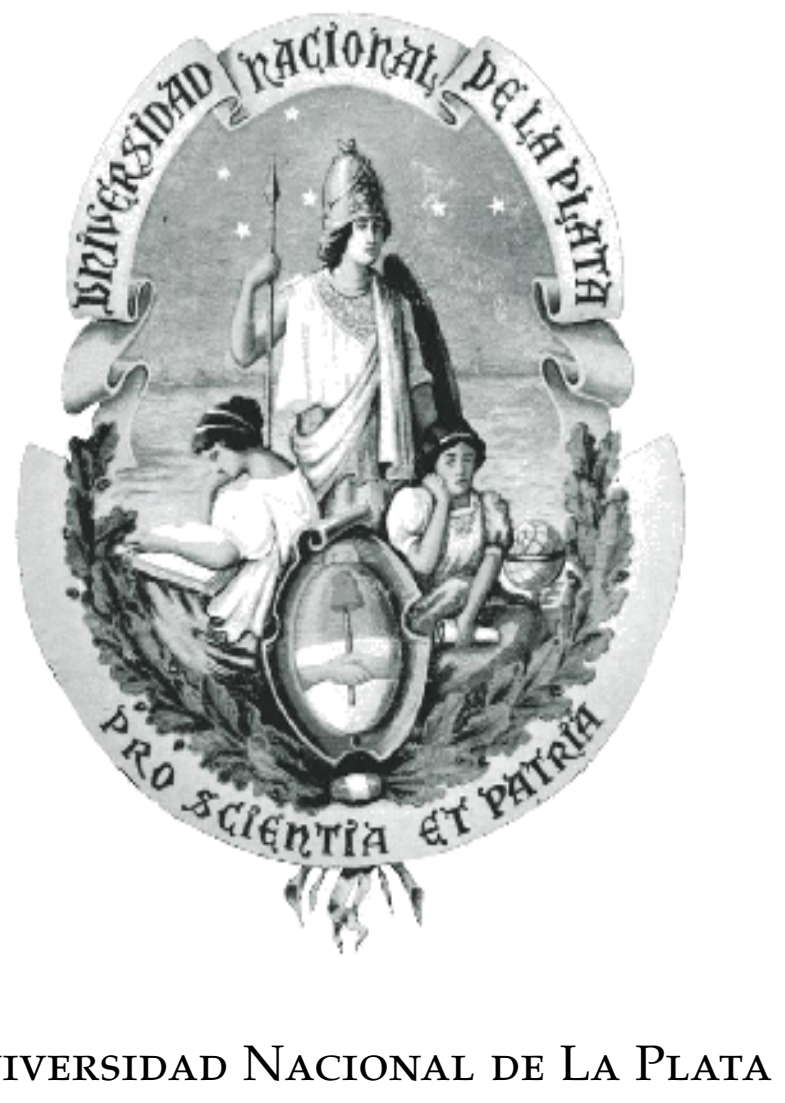

